\title{
Antioxidant and Oxidative Stress: A Mutual Interplay in Age-Related Diseases
}

\author{
Bee Ling Tan ${ }^{1}$, Mohd Esa Norhaizan ${ }^{1,2,3 *}$, Winnie-Pui-Pui Liew ${ }^{1}$ and \\ Heshu Sulaiman Rahman ${ }^{4 \dagger}$
}

${ }^{1}$ Department of Nutrition and Dietetics, Faculty of Medicine and Health Sciences, Universiti Putra Malaysia, Selangor, Malaysia, ${ }^{2}$ Laboratory of Molecular Biomedicine, Institute of Bioscience, Universiti Putra Malaysia, Selangor, Malaysia, ${ }^{3}$ Research Centre of Excellent, Nutrition and Non-Communicable Diseases (NNCD), Faculty of Medicine and Health Sciences, Universiti Putra Malaysia, Selangor, Malaysia, ${ }^{4}$ College of Veterinary Medicine, University of Sulaimani, Sulaimani, Iraq

OPEN ACCESS

Edited by:

Andres Trostchansky,

Universidad de la República, Uruguay

Reviewed by:

Suowen Xu,

University of Rochester, United States Veronica Demicheli,

Universidad de la República, Uruguay

*Correspondence:

Mohd Esa Norhaizan

nhaizan@upm.edu.my

${ }^{\dagger}$ Present Address: Heshu Sulaiman Rahman,

Faculty of Biotechnology and Biomolecular Sciences, Universiti

Putra Malaysia, Selangor, Malaysia;

College of Veterinary Medicine,

University of Sulaimani, Sulaimani, Iraq

Specialty section:

This article was submitted to

Experimental Pharmacology and Drug

Discovery,

a section of the journal

Frontiers in Pharmacology

Received: 30 May 2018 Accepted: 24 September 2018

Published: 16 October 2018

Citation:

Tan BL, Norhaizan ME, Liew W-P-P and Sulaiman Rahman H (2018) Antioxidant and Oxidative Stress: A Mutual Interplay in Age-Related Diseases. Front. Pharmacol. 9:1162. doi: 10.3389/fphar.2018.01162
Aging is the progressive loss of organ and tissue function over time. Growing older is positively linked to cognitive and biological degeneration such as physical frailty, psychological impairment, and cognitive decline. Oxidative stress is considered as an imbalance between pro- and antioxidant species, which results in molecular and cellular damage. Oxidative stress plays a crucial role in the development of age-related diseases. Emerging research evidence has suggested that antioxidant can control the autoxidation by interrupting the propagation of free radicals or by inhibiting the formation of free radicals and subsequently reduce oxidative stress, improve immune function, and increase healthy longevity. Indeed, oxidation damage is highly dependent on the inherited or acquired defects in enzymes involved in the redox-mediated signaling pathways. Therefore, the role of molecules with antioxidant activity that promote healthy aging and counteract oxidative stress is worth to discuss further. Of particular interest in this article, we highlighted the molecular mechanisms of antioxidants involved in the prevention of age-related diseases. Taken together, a better understanding of the role of antioxidants involved in redox modulation of inflammation would provide a useful approach for potential interventions, and subsequently promoting healthy longevity.

Keywords: age-related diseases, healthy longevity, inflammation, oxidative stress, oxidative damage

\section{INTRODUCTION}

The average life expectancy has increased rapidly over the past decades, with an average of around 71.4 years in 2015 worldwide (World Health Organization, 2018). In view of the demographics of the world population in between 2000 and 2050, the population over 60 years is expected to grow from 605 million to 2 billion people (World Health Organization, 2014). Although the increasing life expectancy reflects a positive human development, a new challenge is arising. In fact, growing older is positively linked to cognitive and biological degeneration such as physical frailty, psychological impairment, and cognitive decline (Jin et al., 2015).

Age-related diseases have become the greatest health threats in the twenty-first century. Aging is an intrinsic, universal, multifactorial, and progressive process characterized as degenerative in nature, accompanied by progressive loss of function and ultimately increased mortality rate 
(Dabhade and Kotwal, 2013; López-Otín et al., 2013; Shokolenko et al., 2014; Chang et al., 2017). Among the theories that explain the aging process, the free radical theory of aging is long-established (Harman, 1956). This theory speculates that aging is a consequence of the failure of several defensive mechanisms to respond to the reactive oxygen species (ROS)induced damage, particularly at the mitochondria (Islam, 2017). Age-related diseases are related to structural changes in mitochondria, accompanied by the alterations of biophysical properties of the membrane including alteration in the electron transport chain complexes activities, decreased fluidity, and subsequently resulted in energy imbalance and mitochondrial failure. These perturbations impair cellular homeostasis and mitochondrial function and enhance vulnerability to oxidative stress (Eckmann et al., 2013; Chistiakov et al., 2014). Elderly people are susceptible to oxidative stress due to a decline in the efficiency of their endogenous antioxidant systems. Organs such as brain and heart, with high rates of oxygen consumption and limited respiration levels, are particularly vulnerable to this phenomenon, hence partially explaining the high prevalence of cardiovascular diseases (CVD) and neurological disorders in elderly (Corbi et al., 2008).

Oxidative stress plays a crucial role in the development of age-related diseases including arthritis, diabetes, dementia, cancer, atherosclerosis, vascular diseases, obesity, osteoporosis, and metabolic syndromes (Tan et al., 2015a; Liu et al., 2017). ROS are generated within the biological system to modulate the cellular activities such as cell survival, stressor responses, and inflammation (He and Zuo, 2015; Zuo et al., 2015). Elevation of ROS has been associated with the onset and progression of aging. Although ROS generation may not be an essential factor for aging (López-Otín et al., 2013), they are more likely to exacerbate agerelated diseases progression via oxidative damage and interaction with mitochondria (Dias et al., 2013). Due to their reactivity, high concentrations of ROS can cause oxidative stress by disrupting

\footnotetext{
Abbreviations: ABCA1, adenosine triphosphate-binding cassette transporter A1; AMD, age-related macular degeneration; ATP, adenosine triphosphate; COX, cyclooxygenase; COX-2, cyclooxygenase-2; CRP, C-reactive protein; DDR, DNA damage response; ERK, extracellular signal-regulated kinase; GLUT1, glucose transporter type 1; GSNO, S-nitroglutathione; GST $\alpha, \alpha$-glutathione S-transferase; HDL, high-density lipoprotein; HGPS, Hutchinson-Gilford progeria syndrome; HO-1, heme oxygenase-1; $\mathrm{H} 2 \mathrm{O} 2$, hydrogen peroxide; ICAM-1, intercellular adhesion molecule 1; IKK, IкB kinase; IL-1 $\beta$, interleukin-1beta; iNOS, inducible nitric oxide synthase; IL-6, interleukin-6; JNKs, c-Jun N-terminal kinases; LPS, lipopolysaccharide; MAPKs, mitogen-activated protein kinases; MHC, major histocompatibility complex; MMP-1, matrix metalloproteinase1; NADH, nicotinamide adenine dinucleotide; NADPH, nicotinamide adenine dinucleotide phosphate; NADPH-oxidase, nicotinamide adenine dinucleotide phosphate-oxidase; NCDs, non-communicable diseases; NF- $\mathrm{kB}$, nuclear factorkappa B; NO, nitric oxide; Nrf-2, nuclear factor E2-related factor 2; O2, oxygen; O2•, superoxide; $\bullet \mathrm{OH}$, hydroxyl radical; $\mathrm{ONOO}^{-}$, peroxynitrite; oxLDL, oxidized-low density lipoprotein; PAI-1, plasminogen activator inhibitor-1; PGs, prostaglandins; PGG2, prostaglandin G2; PGH2, prostaglandin H2; PKC, protein kinase C; PPAR $\gamma$, peroxisome proliferator-activated receptor gamma; PP2A, phosphoprotein phosphatase 2A; PUFAs, polyunsaturated fatty acids; RANKL, receptor activator of nuclear factor kappa B ligand; RNS, reactive nitrogen species; ROS, reactive oxygen species; SAPS, senescence-associated secretory phenotype; TGF- $\beta$, transforming growth factor beta; TNF- $\alpha$, tumor necrosis factor- $\alpha$; TPP, triphenylphosphonium; Trx, thioredoxin; UQ, ubiquinone; VCAM-1, vascular cell adhesion molecule 1; 5-LOX, 5-lipoxygenase.
}

the balance of antioxidant and prooxidant levels (Zuo et al., 2015). Emerging research evidence has suggested that natural compounds can reduce oxidative stress and improve immune function (Ricordi et al., 2015). Indeed, oxidation damage is highly dependent on the inherited or acquired defects in enzymes involved in the redox-mediated signaling pathways. Therefore, the role of molecules with antioxidant activity that promote healthy aging and counteract oxidative stress is worth to discuss further. Of particular interest in this article, we highlighted the molecular mechanisms of antioxidants involved in the prevention of age-related diseases. An in-depth understanding of the role of antioxidants involved in redox modulation of inflammation would provide a useful approach for potential interventions, and subsequently promoting healthy longevity.

\section{REDOX IMBALANCE IN AGE-RELATED DISEASES}

In the last few decades, several models have been suggested to define the interconnection and the biological pathways of aging (Dice, 1993). The widely accepted theory is the "oxidative stress hypothesis" (Ghezzi et al., 2017) that advanced and modified the free radical theory of aging (Harman, 1956). Based on the oxidative stress hypothesis, oxidative damage is not solely triggered by the unrestricted ROS production, but it also caused by other oxidants, such as reactive lipid species and reactive nitrogen species (RNS). The hypothesis of oxidative stress highlights the crucial role of antioxidant defenses as an important component of the overall redox balance of the organism. However, several studies demonstrated that avoiding oxidative stress damage does not increase longevity (Buffenstein et al., 2008; Pérez et al., 2009a,b).

Oxidative stress is considered as an imbalance between proand antioxidant species, which results in molecular and cellular damage (Conti et al., 2016). Mitochondria are major organelles that are accountable for generation of energy through oxidative phosphorylation to generate adenosine triphosphate (ATP), a molecule which is crucial for cellular actions (Weinberg et al., 2015). The electron transport chain consumes up to $90 \%$ of total oxygen $\left(\mathrm{O}_{2}\right)$ taken up by the cells (Wallace, 2013). During this process, ROS are generated as by-products for the partial four-electron reduction of $\mathrm{O}_{2}$ to produce water molecule, which is the last electron acceptor in the ATP generation process (Ambrosio et al., 1993). Nearly $0.1-0.5 \%$ of inhaled $\mathrm{O}_{2}$ is converted to superoxide $\left(\mathrm{O}_{2}^{-}\right)$during the normal physiological states (Servais et al., 2009). In the normal healthy state, the generation and oxidation of ROS occur in a controlled manner. By contrast, the ROS production is increased under high-stress conditions or under disease states. The ROS generated from aerobic respiration caused a cumulative oxidative damage in macromolecules, including lipids, DNA, and proteins, which subsequently lead to cells death (Scheibye-Knudsen et al., 2015), and affect the healthspan of numerous principal organ systems (Dai et al., 2014).

An alteration of the redox status and the dysregulation of the immune system during aging may lead to the elevation of 
systemic inflammatory status. Both of these processes caused the activation of inflammatory mediators via oxidative stressinduced redox imbalance. The age-related redox imbalance is more likely triggered by the net effect of low antioxidative defense systems and incessantly produce of reactive species, including superoxide $\left(\mathrm{O}_{2}^{-}\right)$, hydroxyl radical $(\bullet \mathrm{OH})$, peroxynitrite $\left(\mathrm{ONOO}^{-}\right)$, hydrogen peroxide $\left(\mathrm{H}_{2} \mathrm{O}_{2}\right)$, reactive lipid aldehydes, and reactive nitric oxide (NO) (Chung et al., 2009; Lennicke et al., 2015). Unresolved chronic inflammation during aging may serve as a pathophysiologic association which converts normal functional changes to the age-related degenerative diseases (Viola and Soehnlein, 2015). Oxidative stress is reinforced by several reactive species, including $\mathrm{H}_{2} \mathrm{O}_{2}$, singlet oxygen, other radicals, and non-radicals, which are consistently produced in the body due to the aerobic metabolism, and thereby potentially altering basic structural components such as proteins, lipids, and nucleic acids (Weidinger and Kozlov, 2015).

Template biosynthesis of polypeptide chains on ribosomes usually does not produce a functional protein. The newly developed polypeptide chain must undergo certain chemical modifications outside the ribosome. Thus, these modifications are most often accompanied by enzymes and take place after all the information supplied by the template RNA (mRNA) has been read, that is after mRNA translation. These additional processes are known as posttranslational modifications. There are four primary groups of protein functions which require posttranslational modification of amino acid residue side chains. The functional activity of several proteins requires the presence of certain prosthetic groups covalently bound to the polypeptide chain. These are usually involving complex organic molecules which take part in the protein activity for instance, the transformation of inactive apoproteins into enzymes. Another important group of modifications is protein tags, which provide intracellular localization of proteins such as marking the proteins for transport to the proteasome, where they will be proteolyzed and hydrolyzed. Additionally, some of the posttranslational modifications regulate biochemical processes by varying enzymatic activity (Knorre et al., 2009).

Naturally, the organism has several antioxidant defenses to protect against hostile oxidative environments, including classical antioxidant enzymes for example catalase, glutathione peroxidase, and superoxide dismutase as well as non-enzymatic ROS scavengers, such as $\beta$-carotene, vitamin $C$, vitamin $E$, and uric acid (Espinosa-Diez et al., 2015; Harris et al., 2015). Among all the antioxidant enzymes, glutathione peroxidase is the most powerful biological antioxidative reductant (Cross et al., 1977). Collectively, maintaining a healthy redox balance status is crucial for the physiological acid-base buffer system in the body for the optimal homeostatic cellular activities. Changing in redox balance would have a great impact on the transcriptional activities and cellular signaling pathways because most of the activation and reactions is dependent on the reduction/oxidation processes. Figure 1 shows the effect of oxidative stress and the interaction of aging and age-related diseases.

\section{CHRONIC INFLAMMATION AND AGING (INFLAMMAGING)}

Inflammaging is a chronic, low-grade, and systemic inflammation in aging, which is occurred in the absence of overt infection (Franceschi and Campisi, 2014). Chronic inflammation is usually derived from the damaged cells or macromolecules due to an inadequate elimination or increased production. The ability of gut to sequester harmful microbes declines with age. Therefore, some of the harmful products that produced by the microbial constituents of the human body, such as gut microbiota, is capable to permeable into surrounding tissues (Biagi et al., 2011), and subsequently leading to chronic low-grade inflammation.

Senescence, a cellular response to stress and other damage (Franceschi and Campisi, 2014). Persistent senescent cells have been associated with aging or age-related diseases via secretion of proinflammatory cytokines that alter the tissue microenvironment or modify the function of normal cells (Baker et al., 2011). The study reported by Coppé et al. (2010) demonstrated that elimination of senescent cells in prematurely aged mice can prevent many age-related diseases. Increased inflammation may also derive from the stimulation of coagulation system. Coagulation is regarded as a part of the inflammation system. Aging promotes the hypercoagulable state and increased the risk of arterial and venous thrombosis in the elderly (Franceschi and Campisi, 2014). Additionally, aging also alters the immune system, which is subsequently leading to inflammaging. Adaptive immunity decreases with age; conversely, innate immunity demonstrated minute changes in mild hyperactivity (Santoro et al., 2018). The response of innate immunity might increase when adaptive immunosenescence progresses. These age-related changes could be due to the lifelong exposure to antigens and pathogens, as well as intrinsic changes in immune cells (Stephenson et al., 2018).

\section{MOLECULAR INFLAMMATION INVOLVED DURING AGING}

Numerous age-related diseases undergo the inflammation process, which is a risk factor in or partly of disease development (DeBalsi et al., 2017). For instance, several age-related diseases including diabetes, dementia, metabolic syndrome, osteoporosis, cancer, arthritis, and cardiovascular diseases have been recognized as inflammatory disorders (Tan et al., 2015b; Abbas et al., 2017; Liu et al., 2017). The interaction between inflammation and oxidative stress is tightly associated with the prostaglandins (PGs) biosynthetic pathway that produces reactive species (Kawahara et al., 2015). PGs are lipid metabolites of arachidonic acid which have strong proinflammatory responses with pathogenic activities. For example, certain PG metabolites act as an active mediator of inflammation. While, some of the reactive species produced from PGs metabolism may exacerbate inflammation and induce tissue damage (Blaser et al., 2016). Cyclooxygenase (COX) is a predominant enzyme in the PG synthetic pathway, which 


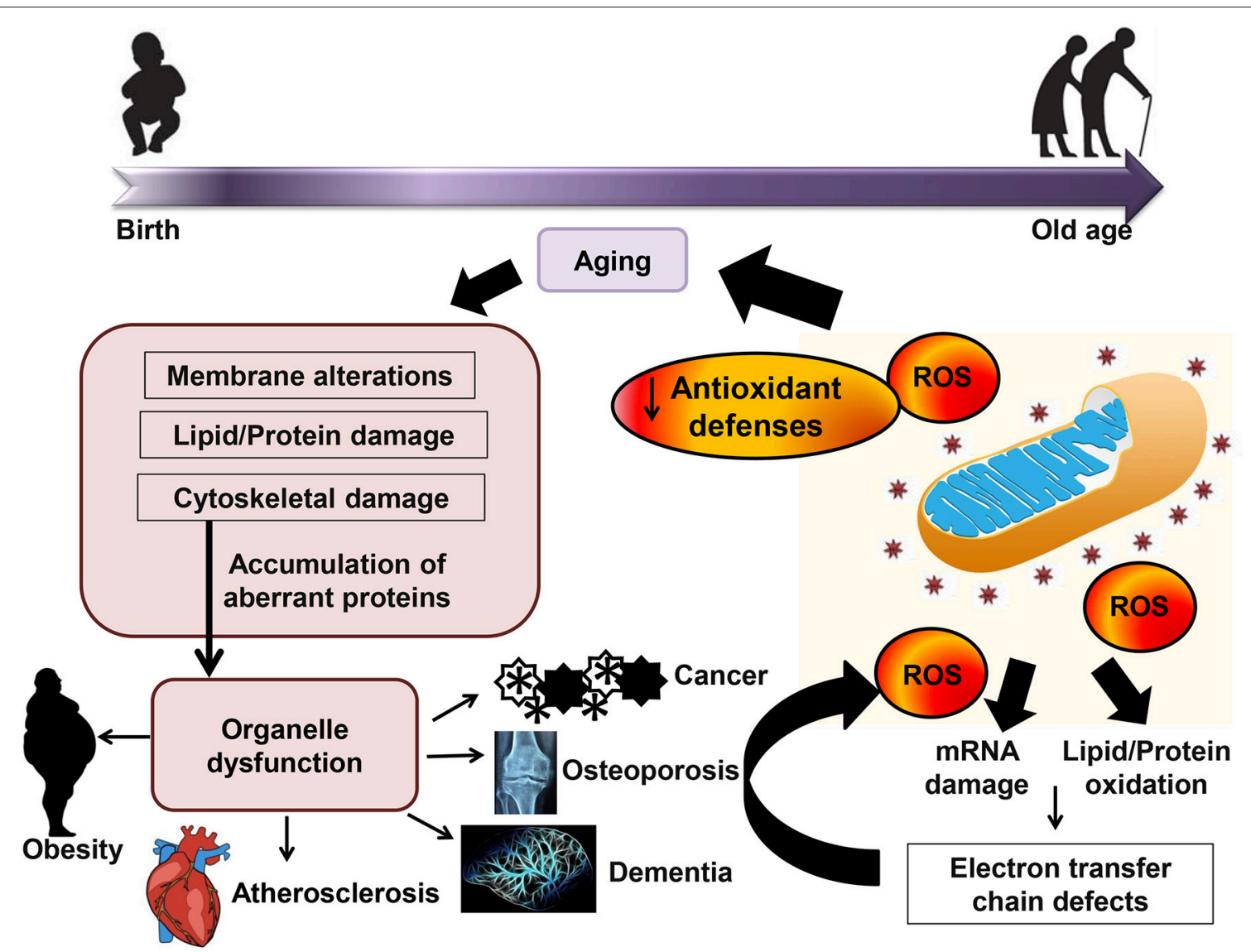

FIGURE 1 | Effect of oxidative stress and the interaction of aging and age-related diseases. Accumulation of reactive oxygen species (ROS) leads to mRNA damage and lipid/protein oxidation and subsequently causes a decrease in mitochondrial function, and ultimately produces more oxidative stress. Mitochondrial function decline and oxidative stress response in aging may subsequently contribute to age-related diseases.

produces prostaglandin $\mathrm{H}_{2}\left(\mathrm{PGH}_{2}\right)$ from arachidonic acid (Shehzad et al., 2015). Reactive species are generated during the conversion of prostaglandin $\mathrm{G} 2\left(\mathrm{PGG}_{2}\right)$ to prostaglandin $\mathrm{H} 2$ $\left(\mathrm{PGH}_{2}\right)$ (Rashid, 2017). The production of reactive species via PG synthesis pathway contributes significantly to the overall reactive species pool in both pathological and normal states, especially during aging (Nita and Grzybowski, 2016).

Research evidence has suggested that the molecular inflammatory process plays a vitally important role during the aging process and age-related diseases (Davalli et al., 2016). COX-derived reactive species and transcriptional activity of interleukin-1beta $(I L-1 \beta)$, interleukin-6 (IL-6), tumor necrosis factor- $\alpha(T N F-\alpha)$, cyclooxygenase-2 (COX-2), and inducible nitric oxide synthase (iNOS) are increased during aging (Michaud et al., 2013; Zhang and Jiang, 2015; PuzianowskaKuznicka et al., 2016). Other pro-inflammatory proteins such as vascular cell adhesion molecule 1 (VCAM-1), P- and Eselectin, and intercellular adhesion molecule 1 (ICAM-1), are all enhanced during aging (Biswas, 2016).

The nuclear factor-kappa B (NF-кB) transcription factor has been identified as the key factor during inflammation which can be stimulated by oxidative stimuli. In fact, the stimulation of NF- $\mathrm{B}$-dependent genes is a principal culprit that is responsible for the systemic inflammatory process (Golia et al., 2014). Under high- stress circumstances, proinflammatory genes encode proinflammatory proteins, including chemokines, growth factors, and cytokines. NF-кB activity is mediated by numerous signaling pathways such as mitogen-activated protein kinases (MAPKs) and IкB kinase (IKK). The upregulation of IKK complexes phosphorylate the I $\mathrm{B}$ subunits of NF- $\mathrm{B} / \mathrm{I} \kappa \mathrm{B}$ and subsequently activate the NF- $\kappa \mathrm{B}$ (Jain et al., 2016). IKK activity is triggered during aging by NF- $\mathrm{KB}$ (Kim et al., 2002), which further modulates the p38 MAPK, extracellular signal-regulated kinase (ERK), and c-Jun N-terminal kinases (JNKs) pathways that modulate the NF- $\kappa \mathrm{B}$-dependent transcriptional activity during the inflammatory reaction. ROS production during the aging process has been associated with p38 MAPK, JNK, and ERK activities (Zhang et al., 2015). Nonetheless, uncontrolled input signal during aging may cause chronic proinflammatory conditions that are conducive to various chronic diseases (Fougère et al., 2017). Aging is also linked to the elevation of inflammatory cell (monocytes and neutrophil) counts and C-reactive protein (CRP) levels (Tang et al., 2017). High IL6 plasma levels were shown to have a greater likelihood of 
mortality, morbidity, and disability in the elderly (PuzianowskaKuznicka et al., 2016). Indeed, high plasma level of TNF- $\alpha$ is associated with a marked increase in CRP and IL-6, suggesting an interrelated stimulation of the entire inflammatory cascade (Xia et al., 2016).

In addition, compelling evidence suggests that DNA damage response (DDR) signaling is a predominant mechanism associated with the build-up of DNA damage, aging, and cell senescence (Malaquin et al., 2015). This study indicates the involvement of epigenetic modifications such as small, non-coding RNAs and microRNAs, which contributes to post-transcriptional regulation. These modifications have been hypothesized to play a crucial role in the diffusion of DNA damage response/senescence-associated secretory phenotype (DDR/SAPS) signaling to non-damaged surrounding cells during aging, suggesting that DDR/SASP signaling components may contribute to the development of novel therapeutic interventions against age-related diseases (Olivieri et al., 2015). Moreover, microRNAs may also be harnessed as an innovative tool to identify target senescent cells and to develop therapeutic interventions that can delay the proinflammatory programme stimulated in senescent endothelial cells (Prattichizzo et al., 2016).

\section{ACCELERATED-AGING SYNDROMES}

Progerias or accelerated-aging syndromes are partially recapitulated normal aging (Burtner and Kennedy, 2010). Most of the accelerated-aging syndromes are induced by modification of nuclear envelope or by defects in DNA repair systems. Werner syndrome is the most common acceleratedaging syndrome derived from DNA repair defects, caused by the mutations of Werner syndrome ATP-dependent helicase $(W R N)$, a gene coding for a protein implicated in telomere maintenance and homology-dependent recombination repair (Osorio et al., 2011). Another common accelerated-aging syndrome is Hutchinson-Gilford progeria syndrome (HGPS), caused by the defects in nuclear envelope proteins due to the mutations in the processing protease FACE1/ZMPSTE24 or genes encoding lamin A (Worman, 2012). Compared to HGPS, the onset of Werner syndrome is slightly slower, in which the pathology accompanies with Werner syndrome resembles a premature aging. Clinical pathology of Werner syndrome starting from 10 to 20 years of age including early graying, short stature, hair loss, and bilateral cataracts. The cellular phenotypes linked to the Werner syndrome demonstrate significant overlap with laminopathies. Further, cells in the absence of WRN have defects in DNA double-strand breaks, especially those bound with DNA replication fork arrest.

Interestingly, the generation of ROS is increased in HGPS fibroblasts (Viteri et al., 2010) and this phenomenon is similar to normal aged fibroblasts. High ROS level in HGPS cells could be attributed to the large DNA damage and subsequently resulting in an underlying defect in early senescence in HGPS cells (Huang et al., 2005; Gonzalez-Suarez et al., 2009). HGPS cells also show persistent markers of high basal DNA damage, such as nuclear ataxia telangiectasia mutated (ATM) foci (Liu Y. et al., 2006). The previous study showed that fibroblasts isolated from individuals with HGPS demonstrate lamin A has an ability to repair DNA lesions (Burtner and Kennedy, 2010).

Mutation in lamin A/C (LMNA) has been identified as the target gene for HGPS. Fibroblasts from patients with HGPS show increased levels of basal phosphorylated histone variant $\mathrm{H} 2 \mathrm{AX}(\gamma \mathrm{H} 2 \mathrm{AX})$ and increased amounts of phosphorylated checkpoint kinase 1 (CHK1) and CHK2, compared with unaffected fibroblasts (Liu Y. et al., 2006). In addition, fibroblasts from individuals affected by HGPS, or from mice lacking ZmPSTe24, demonstrate a marked delay in the recruitment of p53 binding protein 1 (53BP1) to sites of DNA repair upon exposure to DSB-inducing irradiation (Liu et al., 2005). The delay in 53BP1 recruitment to DSBs in these cells and the accumulation of irreparable damage may be a potent physiological genotoxic stress in individuals with HGPS. Collectively, increased levels of DNA damage may have important consequences in vivo.

\section{ANTIOXIDANT AND AGE-RELATED DISEASES}

Antioxidants control the autoxidation by interrupting the propagation of free radicals or by inhibiting the formation of free radicals via different mechanisms. These compounds help in scavenging the species that initiate the peroxidation, breaking the autoxidative chain reaction, quenching $\bullet \mathrm{O}_{2}^{-}$, and preventing the formation of peroxides (Gaschler and Stockwell, 2017). The most effective antioxidants are those possessing the ability to interfere with the free radical chain reaction. They contain phenolic or aromatic rings which allow these antioxidants donate $\mathrm{H} \bullet$ to the free radicals formed during oxidation. The radical intermediate is then stabilized by the resonance delocalization of the electron within the aromatic ring (Wojtunik-Kulesza et al., 2016).

Antioxidant plays a central role in the termination of oxidative chain reactions by removing the free radical intermediates (Gholamian-Dehkordi et al., 2017). Many studies indicate that cellular redox status is crucial for ROS-mediated signaling and mitochondrial function (Fang et al., 2018). Depletion of intracellular glutathione (GSH) markedly promotes mitochondrial ROS production and triggers mitochondrial membrane depolarization (Lohan et al., 2018). Stimulation of the Nrf2/ARE pathway is fundamental for the induction of antioxidant defense enzyme and the modulation of the intracellular GSH in response to stress (Liu et al., 2018a). Administration of $\mathrm{N}$-acetylcysteine reverses GSH depletion and restores ARE-associated transcriptional activity to basal levels (Limón-Pacheco et al., 2007). Appropriate intracellular levels of ROS plays a crucial role in physiological redox signaling via activation and regulation of endogenous defenses by protecting cells from nitrosative, oxidative, and electrophilic stress (Moldogazieva et al., 2018). Indeed, supplementation with exogenous antioxidants depletes exercise-triggered improvements in insulin sensitivity and antioxidant gene expression (Ji et al., 2006), suggesting the importance of ROS induced endogenous antioxidant enzymes in restoring 
physiological redox balance. Additionally, overexpression of thioredoxin (Trx) has been demonstrated to inhibit the progression of insulin resistance in both type 1 and type 2 diabetes in vivo (Yamamoto et al., 2008). Recent findings suggest that a protective role of $\mathrm{Nrf} 2$ on oxidative stress in aging (de Oliveira et al., 2018). Depletion of Nrf2 activity has been identified to contribute to the development of age-related diseases (Cuadrado et al., 2018).

Several studies as reported by Tan et al. (2018) have shown that oxidative stress and obesity-associated non-communicable diseases (NCDs) can be mediated by nutrient-rich in antioxidants. Indeed, a unique complex of bioactive constituents can provide protection against oxidative stress, which can cause in inflammation (Tan et al., 2015a,b; Tan and Norhaizan, 2017). In support of this, numerous epidemiological studies including European paradox study (Bellizzi et al., 1994), WHO/MONICA study (Gey and Puska, 1989), NHS study (Stampfer et al., 1993), and Harvard HPSF (Rimm et al., 1993) have shown that antioxidant was negatively associated with many NCDs including cardiovascular diseases. In this regard, the antioxidant capacity in natural products has drawn attention among scientists in academia and industry in the prevention of age-related diseases. Figure 2 summarizes the dietary intake of antioxidants in relation to oxidative stress in aging.

Mitochondria-targeted antioxidants have great potential against the damage caused by ROS generation. The ability of mitochondria-targeted antioxidants confers greater protection against oxidative damage has been attributed to their abilities to cross the phospholipid bilayer of mitochondria and thus eliminating ROS (Oyewole and Birch-Machin, 2015). In principle, a broad range of antioxidants could be targeted to mitochondria via conjugation of triphenylphosphonium (TPP) moiety (Smith and Murphy, 2011). In particular, ubiquinol (MitoQ) is the best-characterized antioxidant targeted to mitochondria by conjugation to the TPP cation (Smith and Murphy, 2011). The role of MitoQ will be described in the ubiquinone section.

\section{ROLE OF ANTIOXIDANTS IN THE PREVENTION OF AGE-RELATED DISEASES}

\section{Low Molecular Weight Antioxidant}

Low molecular weight is defined as small molecule biological compound (<900 daltons) which regulates body physiological process (Veber et al., 2002; Macielag, 2012). Low molecular weight antioxidants such as minerals, vitamins, carotenoids, cofactors, glutathione, and polyphenols are crucial for antioxidative defense mechanisms of cells and organisms (Grune et al., 2004). Ascorbic acid (vitamin C) and tocopherol (vitamin E) are the most important low molecular weight antioxidants that cannot be synthesized by a human (Podda and Grundmann-Kollmann, 2001). There are several molecules that are synthesized in the human body and possess an antioxidant effect including glutathione, lipoic acid, uric acid, taurine, keto acids, melatonin, coenzyme Q, and melanins. Among these antioxidants, glutathione is one of the major cellular antioxidant (Sifuentes-Franco et al., 2017).

\section{Glutathione}

Glutathione is a pivotal antioxidant present in the microorganisms, plants, and animals. Glutathione prevents the cell damage induced by ROS including lipid peroxides, peroxides, free radicals, and heavy metals (Pisoschi and Pop, 2015). Glutathione can scavenge ROS via non-enzymatic and enzymatic reactions. The non-enzymatic antioxidant activity is contributed by the free thiol group of glutathione (Winterbourn, 2016). Additionally, glutathione also detoxifies oxidants and electrophiles via enzymatic reactions which involve glutathione reductase, glutathione peroxidase, and glutathione-S transferase (Farhat et al., 2018). Glutathione plays a crucial role in regulating redox state of the cell, specifically via modulation of the proper tertiary structure of proteins through thiol-disulfide exchange concomitantly with glutaredoxin and protein disulfide isomerases (Ye et al., 2017). Besides antioxidant properties, glutathione also involves hormones metabolisms such as estrogens, leukotrienes, and prostaglandins and signal transduction for transcription (Rotar et al., 2014). Alteration of glutathione concentration has been linked to adverse health impacts such as dysregulation of cell proliferation, transcription of detoxification enzymes, and apoptosis (Aquilano et al., 2014).

Glutathione is categorized as a non-essential nutrient for humans, as it can be synthesized in the body from the amino acids such as L-glutamic acid, L-cysteine, and glycine (Lu S. et al., 2016). The structure of glutathione consists of gamma peptide bond linked to a tripeptide between the amine group of cysteine and carboxyl group of the glutamate side-chain (Figure 3). The carboxyl group of cysteine is linked to a glycine by peptide bond (Gu et al., 2012). The sulfhydryl group of cysteine serves as a proton donor and allows the glutathione to act as an antioxidant (Gümüșay et al., 2015). Sulfur is the second chalcogen after oxygen in the periodic table with a vacant $3 \mathrm{~d}$ orbital. The sulfur atom in the sulfhydryl functional group is in its low oxidation state (García-Santamarina et al., 2014), and thereby sulfhydryl is strongly susceptible to oxidation even without the presence of the enzyme.

Homeostasis of intracellular glutathione is not solely regulated by de novo synthesis, but it also by several factors including cellular export, utilization, and recycling (Lu S. C. et al., 2016). This redox cycle is recognized as the glutathione cycle which comprises of glutathione, together with other redox-related enzymes acts as the first defense against overproduction of harmful ROS in addition to repairing ROS-induced damage (Schieber and Chandel, 2014). There are three groups of enzymes involve in the glutathione cycle, namely glutathione reductase, glutathione oxidase, and glutathione peroxidase (Reczek and Chandel, 2015). By serving as an electron donor, glutathione reduces disulfide bonds formed between proteins and cytoplasm to cysteines. In this process, two molecules of glutathione are converted to an oxidized form, either glutathione oxidase or glutathione peroxidase. Once oxidized, glutathione reductase is capable to regenerate glutathione from glutathione disulfide via NADPH-dependent process (Reczek and Chandel, 2015). 

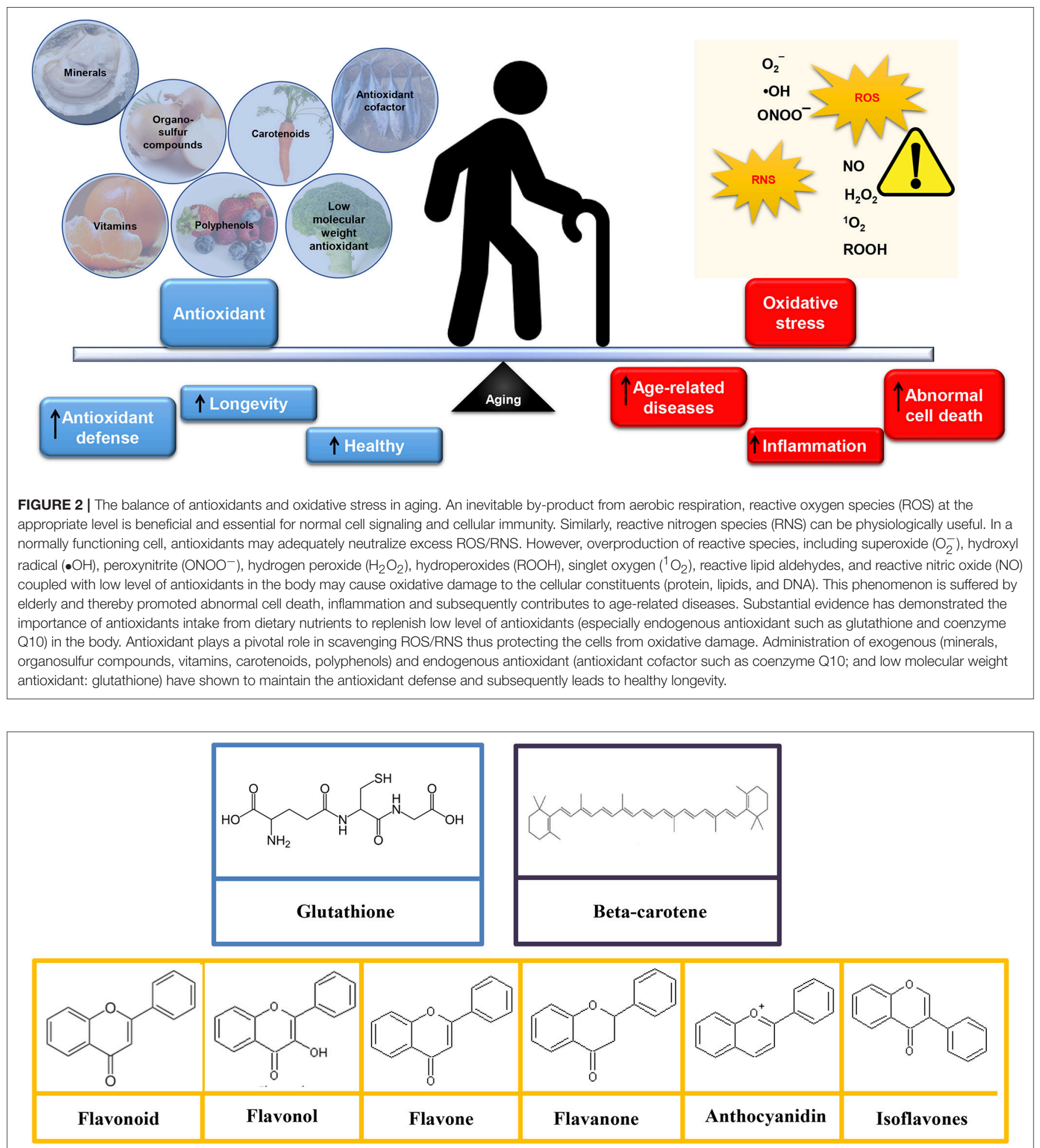

FIGURE 3 | Molecular structures of glutathione, polyphenols (flavonoid, flavonol, flavone, flavanone, anthocyanidin, and isoflavones), and beta-carotene.

Further, glutathione tends to react with cysteine residues in proteins through the formation of mixed disulfides. Yet, these unstable molecules can easily be reverted to a normal state by glutathione S-transferase (Carvalho et al., 2016). Alternatively, the cells export glutathione disulfide to the extracellular medium to restore redox imbalance (Heidari et al., 2016). Indeed, the de novo synthesis of glutathione is essential for adaptive response toward oxidative stress. Many toxic by-products produced from 
normal cellular metabolism processes can be detoxified by glutathione. A toxic compound, methylglyoxal, generated from the glycolytic process is implicated in ROS production (Chan et al., 2016). Glutathione detoxifies methylglyoxal by serving as a cofactor of enzyme glyoxalases (Nahar et al., 2015). Besides scavenging ROS, glutathione is also involved in protecting against reactive nitrogen species-mediated damage (Cassia et al., 2018). NO reacts with the cysteine of glutathione to form Snitroglutathione (GSNO). GSNO reductase converts GSNO to glutathione disulphide, and subsequently reduces to glutathione by glutathione reductase (Cassia et al., 2018).

The modulation of glutathione metabolism is a useful adjuvant therapy for many diseases such as cardiovascular diseases, diabetes, and brain disorders. A study analyzed of 134 cardiovascular disease cases involving 435 individuals revealed that glutathione can affect the risk of cardiovascular diseases (Shimizu et al., 2004). The data showed that the total plasmic glutathione content is lower in cardiovascular diseases patients (cerebral infarction and cerebral hemorrhage) compared to healthy subjects (Shimizu et al., 2004). Further, glutathione peroxidase was found to be inversely correlated with cardiovascular disease risk (Espinola-Klein et al., 2007). Although research has demonstrated a negative association between glutathione peroxidase and cardiovascular disease risk, not all data demonstrated such a link. Mills et al. (2000) did not identify an association of glutathione level and atherosclerosis.

Maintaining a normal level of glutathione is important for diabetic patients. Diabetes induces an alteration in glutathione peroxidase and glutathione reductase activity (González de Vega et al., 2016). Intake of glutathione in patients with type 2 diabetes mellitus increase the platelet constitutive nitric oxide synthase activity and reduce plasminogen activator inhibitor-1 (PAI-1; Martina et al., 2001). PAI-1 is an inhibitor of fibrinolysis which increases the risk of thrombosis (Tofler et al., 2016). This study indicates that glutathione may play a vital role in the pathophysiology of diabetes. Further, nephropathy is a lifethreatening complication suffered by both Type 1 and Type 2 diabetes patients (Hadjadj et al., 2016). Diabetic nephropathy is often linked to low renal glutathione levels. Dietary supplementation with glutathione has been demonstrated to protect against pathologies associated with diabetic nephropathy (Lash, 2015).

In the brain, glutathione is only presented in millimolar concentrations, and thus makes this organ prone to oxidative damage compared to other tissues in the body (Settineri et al., 2018). A disruption in glutathione homeostasis could induce oxidative stress and lead to neurodegenerative diseases including Parkinson's disease (Mischley et al., 2013), Alzheimer's disease (Braidy et al., 2015), and dementia (Duffy et al., 2015) which impaired motor and cognitive functions. Parkinson's disease is a dopamine deficiency condition resulted from the destruction of dopaminergic neurons in the midbrain region (Zucca et al., 2017). ROS is generated during dopamine normal metabolism (Guo et al., 2018). The decline of glutathione levels in Alzheimer's patient was associated with downregulation of glutathione homeostasis (Braidy et al., 2015). Parkinson's patients suffer depletion of glutathione levels coupled with an increase of ROS within the midbrain (Mischley et al., 2015). Removal of ROS by glutathione can facilitate the regulation of redox potential of the midbrain. In a clinical condition, patients with Parkinson's disease were improved following supplementation of reduced glutathione (Mischley et al., 2013, 2015).

As opposed to the role of the other antioxidants, glutathione has a complex function in the cancer cells. The level of glutathione was elevated in several human cancer cells such as colon, bone marrow, breast, and lung cancers. In colon cancer cells, the mRNA and protein expressions of glutathione and enzyme involved in the metabolism of glutathione were significantly higher as compared to the normal colonic cell line (Kim et al., 2015). In support of this, $60 \%$ of colon cancer patients expressed high levels of glutathione particularly in tumor tissue (Kim et al., 2015). Similarly, the study reported by Harris et al. (2015) has also revealed that glutathione is recruited especially during cancer initiation. Interestingly, glutathione synthesis is only effective during the early stage of cancer, it is not observed in the established tumor (Nguyen et al., 2016). Due to glutathione antioxidant activity, there has been a tremendous interest in the study of glutathione and its related compounds in diseases suffered by elderly. The vital role played by glutathione is nonetheless worth study in-depth in order to understand the pathophysiology pathway underlying in age-related diseases.

\section{Polyphenol}

Polyphenols (also known as polyhydroxyphenols) are characterized by the multiples of phenol structural units (Nascimento-Souza et al., 2018). The numbers and characteristics of these phenol structures contribute to the unique features of polyphenol compound in term of chemical, physical, and biological (Scalbert and Williamson, 2000). In brief, polyphenols are secondary metabolites (Kabera et al., 2014) produced by plants, which is widely found in fruits and vegetables are thought to protect against ultraviolet radiation (Zbikowska et al., 2016) and pathogens invasion (Nagpala et al., 2016). Polyphenols also affect the flavor, color, and odor which contribute to the sensory perception of the food (Ju et al., 2017). Of all polyphenolic compounds, the flavonoid is the most common polyphenol classes (Nascimento-Souza et al., 2018).

Flavonoids are comprised of the most studied group of polyphenol. The basic structure of flavonoid is a diphenylpropane skeleton, which composed of two benzene rings (rings A and B) connected by three-carbon chains that form a closed pyran ring (heterocyclic ring containing oxygen, ring $\mathrm{C}$; Das et al., 2017). The structure of flavonoids is denoted as C6-C3-C6 (Das et al., 2017). Generally, B ring is bonded to position 2 of $C$ ring, but some of them are attached at position 3/4. Flavonoids are subdivided into different subgroups (flavonols, flavones, flavanonols, flavanones, catechins, anthocyanins, and chalcones; Figure 3) based on the carbon and the degree of unsaturation (Gonzales et al., 2015). The physiological function of the flavonoids is depends on the structural characteristics as well as the pattern of glycosylation and hydroxylation of the three rings (Gonzales et al., 2015).

There are around 6,000 flavonoids that form the colorful pigments of herbs, fruits, vegetables, and medicinal plants. 
Flavonoids are known for its broad spectrum of healthpromoting effects on human and animal (Panche et al., 2016). The antioxidative, antimutagenic, anti-inflammatory, and anticarcinogenic properties coupled with their abilities to regulate key cellular enzyme function have drawn attention from the pharmaceutical industry, which attempts to design the prevention and treatment of certain diseases (Panche et al., 2016). The antioxidant activities of flavonoids include (1) scavenging ROS (Shokoohinia et al., 2015); (2) suppressing generation of ROS by inhibition of enzymes (Nile et al., 2016) and chelating trace elements (Catapano et al., 2017); and (3) upregulating antioxidant defenses. The low redox potential of flavonoids enables the reduction of highly oxidized free radicals such as superoxide, alkoxyl, hydroxyl, and peroxyl radicals by proton donation (Kovacic and Somanathan, 2011). Flavonoids inhibit the enzymes such as xanthine oxidase (Nile et al., 2016) and protein kinase C (Maurya and Vinayak, 2015) which are responsible for the generation of superoxide anion. Flavonoids have also been reported to inhibit other ROS generating enzymes including COX, microsomal monooxygenase, lipoxygenase, mitochondrial succinoxidase, and NADH oxidase (Pietta, 2000). Therefore, the ability of flavonoids in chelating trace metals plays an important role in the oxygen metabolism (Catapano et al., 2017).

Flavonoids have beneficial biochemical and antioxidant effects in relation to several oxidative stress-induced diseases in elderly for instance cancer (Chien et al., 2015), diabetic (Ding et al., 2014), cardiovascular diseases (Roohbakhsh et al., 2015), Alzheimer's disease (Swinton et al., 2018), and dementia (Swinton et al., 2018). Several flavonoids such as naringin (Ahmad et al., 2015), apigenin (Erdogan et al., 2016), and isorhamnetin (Manu et al., 2015) have been demonstrated to reduce the inflammatory mediators production via the blockade of NF- $\kappa$ B pathway. Flavonoids were found to negatively correlate with several types of cancer in human based on numerous studies. In woman aged 75 years old and above, high total flavonoids intake reduced the risk of cancer mortality compared to those with low total flavonoids consumption (Ivey et al., 2015). A decrease in breast cancer risk among postmenopausal women was found to be associated with flavonoids intake specifically, flavan-3-ols, flavones, flavonols, and lignans (Fink et al., 2006). While for colorectal cancer, $\mathrm{He}$ and Sun (2016) found that 2 flavonoid subclasses, namely procyanidins and isoflavones exert preventive effects toward the risk of colorectal cancer. However, there was limited evidence of the lower risk of colorectal cancer via flavonoid consumption (He and Sun, 2016; Grosso et al., 2017; Zamora-Ros et al., 2017).

Many studies demonstrated that a flavonoid-rich diet is related to a lower risk of cardiovascular disease. Flavonoids prevent cardiovascular disease via a few mechanisms such as antioxidant, anti-inflammatory, antiplatelet, and increasing high-density lipoprotein (HDL) level (Nunes et al., 2016). A study found that the intake of soy isoflavone reduces the risk of cardiovascular disease due to chronic inflammation. This favorable effect could be attributed to the downregulation of the TNF- $\alpha$ at the endothelial level (Nadadur et al., 2016). Studies have shown the ability of isoflavone to alleviate hypertension via modulation of vasodilation. Isoflavone improves brachial artery flow through interaction with the estrogen-response element of genes related to endothelial NO synthase (Ramdath et al., 2017). Compared to those who consume placebo, supplementation of isoflavone in postmenopausal women for 6 months improved endothelial vasodilation and lowered the cellular adhesion molecules such as E-selectin, ICAM1 , and vascular cell adhesion protein 1 (Colacurci et al., 2005). A recent study by Grosso et al. (2017) showed that intakes of dietary flavonoids (flavonols, flavones, flavanones, anthocyanidins, and proanthocyanidins) are associated with decreased risk of cardiovascular disease mortality. These data suggest that dietary flavonoids as natural cardiovascular protectors.

Diabetes mellitus is suffered by elderly and can lead to severe complication such as diabetic peripheral neuropathy. A study reported by Ganugapati et al. (2011) showed that green tea flavonoids and epicatechin activate the insulin receptor and reduce the harmful effects of diabetes. Grape seed proanthocyanidin alleviates type 2 diabetes mellitus in the rat through ameliorating of hyperglycemia and increases $\mathrm{Ca}^{2+}$ ATPase activity in sciatic nerve (Ding et al., 2014). Quercetin is another bioflavonoid available in red wine and many plants. Intake of quercetin was shown a neuroprotective effect in the diabetic rats against high glucose-induced injury on the glia and myenteric neurons at the cecum. The neuroprotective effects could be attributed to NF- $\kappa \mathrm{B}$ inhibition and nuclear factor E2-related factor 2/heme oxygenase-1 (Nrf-2/HO-1) activation (Sandireddy et al., 2016). In another study, Kwak et al. (2017) revealed that baicalein, a flavonoid found in traditional Chinese herbal medicine can inhibit the oxidative-nitrosative stress and p38 MAPK activation and subsequently lead to alleviation of diabetic peripheral neuropathy.

Many studies revealed that flavonoids from cocoa (Swinton et al., 2018), green tea (Swinton et al., 2018), and citrus fruit (Braidy et al., 2017) exert beneficial effects to the brain. Emerging evidence has suggested that flavonoids protect against neural injuries and degeneration in Alzheimer's disease and dementia. In the brain, flavonoids act as a potent antioxidant, anti-inflammatory, anti-apoptotic and signaling pathways modulatory agents via interactions with the ERK and PI3kinase/Akt signaling pathways (Jiang et al., 2016). Further, increased cerebral brain blood flow by flavonoids may also enhance cognition (Grassi et al., 2016). In addition, flavonoids have also been reported to slow down the development of Alzheimer's disease-like pathophysiology and related neurodegenerative disorders through disrupting amyloid $\beta$ protein production, activating of $\alpha$-secretase (ADAM10), and inhibiting of $\beta$-secretase (BACE-1) (Folch et al., 2018). Together, the evidence showed that flavonoids have outstanding potential to block the initiation and progression of age-related diseases and pathologies. High intake of flavonoids should be included in the dietary of elderly via supplementation or flavonoid-rich containing food. Table 1 summarizes some of the clinical trials of antioxidants in preventing agerelated diseases and the failure of clinical trials involving antioxidants. 
TABLE 1 | Clinical studies conducted in several antioxidants and their effects in age-related diseases.

\begin{tabular}{|c|c|c|c|}
\hline Antioxidants & Age-related diseases & Findings & References \\
\hline \multirow[t]{7}{*}{ Glutathione } & Atherosclerosis & No effect & Mills et al., 2000 \\
\hline & Cardiovascular disease & $\begin{array}{l}\text { Total plasmic glutathione content is lower in cardiovascular } \\
\text { diseases patients (cerebral infarction and cerebral } \\
\text { hemorrhage) compared to healthy subjects }\end{array}$ & Shimizu et al., 2004 \\
\hline & & $\downarrow$ Cardiovascular disease risk & Espinola-Klein et al., 2007 \\
\hline & Type 2 diabetes mellitus & $\begin{array}{l}\text { APlatelet constitutive nitric oxide synthase activity and reduce } \\
\text { plasminogen activator inhibitor-1 (PAl-1) } \\
\text { Protect against pathologies associated with diabetic } \\
\text { nephropathy }\end{array}$ & Martina et al., 2001; Lash, 2015 \\
\hline & Alzheimer's patient & $\begin{array}{l}\downarrow \text { Glutathione levels in Alzheimer's patient were associated } \\
\text { with downregulation of glutathione homeostasis }\end{array}$ & Braidy et al., 2015 \\
\hline & Parkinson's disease & $\downarrow$ Free radicals involved in neurological complications & Mischley et al., 2015 \\
\hline & Cancer & $\begin{array}{l}60 \% \text { of colon cancer patients expressed high levels of } \\
\text { glutathione particularly in tumor tissue }\end{array}$ & Kim et al., 2015 \\
\hline \multirow[t]{4}{*}{ Polyphenols } & Cancer & $\downarrow$ \Risk of colorectal cancer & $\begin{array}{l}\text { Grosso et al., 2017; Zamora-Ros } \\
\text { et al., } 2017\end{array}$ \\
\hline & Cardiovascular disease & $\downarrow$ Risk of cardiovascular disease mortality & Grosso et al., 2017 \\
\hline & & $\begin{array}{l}\downarrow \text { Vascular endothelial dysfunction and regulating lipid } \\
\text { metabolism }\end{array}$ & Rasines-Perea and Teissedre, 2017 \\
\hline & Diabetes & Improve glucose control and insulin sensitivity & Vitale et al., 2018 \\
\hline \multirow[t]{12}{*}{ Carotenoids } & Alzheimer's disease and dementia & $\downarrow$ Risk of Alzheimer's disease mortality and dementia & Min and Min, 2014; Feart et al., 2015 \\
\hline & Rheumatoid & १Mortality rate & Bjelakovic et al., 2012 \\
\hline & Cardiovascular disease & $\begin{array}{l}\text { \Risk in stroke, coronary artery disease, and cardiovascular } \\
\text { disease }\end{array}$ & $\begin{array}{l}\text { Leermakers et al., 2016; } \\
\text { Valderas-Martinez et al., } 2016\end{array}$ \\
\hline & & Inversely correlated with oxidized LDL & Nakazato et al., 2014 \\
\hline & & $\uparrow$ Mortality rate & $\begin{array}{l}\text { Bjelakovic et al., 2012; Kishimoto } \\
\text { et al., } 2017\end{array}$ \\
\hline & Hypertension & $\downarrow$ Baseline blood pressure & Perrone et al., 2016 \\
\hline & Age-related macular degeneration & $\downarrow$ Risk in individuals who consume a carotenoid-rich diet & Eisenhauer et al., 2017 \\
\hline & Osteoporosis & $\downarrow$ ¿one density and fracture risk & $\begin{array}{l}\text { Rao and Rao, 2015; Hayhoe et al., } \\
2017\end{array}$ \\
\hline & & Whip fracture risk by $28 \%$ & Xu et al., 2017 \\
\hline & Cancer & †Lycopene intake can prevent prostate cancer & Zu et al., 2014 \\
\hline & & $\begin{array}{l}\uparrow \text { The incidence of lung cancer in the treatment group ( } 30 \mathrm{mg} \\
\text { of beta-carotene and } 25,000 \mathrm{IU} \text { of retinol daily) in the smokers } \\
\text { and workers in asbestos mines compared to the placebo } \\
\text { group }\end{array}$ & Omenn et al., 1994 \\
\hline & & $\begin{array}{l}\uparrow \text { The incidence of lung cancer in male smokers (50-69 years) } \\
\text { who received beta-carotene }\end{array}$ & Blumberg and Block, 1994 \\
\hline \multirow[t]{4}{*}{ Zinc } & Type 2 diabetes mellitus & \Plasma thiobarbituric acid reactive substances & Anderson et al., 2001 \\
\hline & & Improved insulin sensitivity & Vashum et al., 2014 \\
\hline & Age-related macular degeneration & $\begin{array}{l}\text { Delay the development of age-related macular degeneration } \\
\text { and vision loss in individuals older than } 55 \text { years }\end{array}$ & Group, 2001; Gorusupudi et al., 2017 \\
\hline & & $\begin{array}{l}\text { Low intake of zinc was associated with age-related macular } \\
\text { degeneration }\end{array}$ & Aoki et al., 2016 \\
\hline \multirow[t]{6}{*}{ Ascorbic acid } & $\begin{array}{l}\text { Diabetes mellitus and coronary artery } \\
\text { disease }\end{array}$ & ^Forearm vasodilator response & Antoniades et al., 2004 \\
\hline & Cardiovascular disease & $\downarrow$ Cardiovascular disease & Wang et al., 2013 \\
\hline & & $\begin{array}{l}\text { Supplementation with a dosage }>500 \mathrm{mg} / \mathrm{d} \text { shows a better } \\
\text { endothelial function }\end{array}$ & Ashor et al., 2014 \\
\hline & & $\downarrow$ Endothelial dysfunction and improve lipid profile & Moser and Chun, 2016 \\
\hline & $\begin{array}{l}\text { Age-related neurodegenerative } \\
\text { diseases }\end{array}$ & $\begin{array}{l}\text { Ascorbate shortage may contribute to the dysregulation of } 5 \\
\mathrm{hmC}\end{array}$ & Al-Mahdawi et al., 2014 \\
\hline & Cancer & Exert antitumor activity & Ma Y. et al., 2014; Yun et al., 2015 \\
\hline
\end{tabular}


TABLE 1 | Continued

\begin{tabular}{|c|c|c|c|}
\hline Antioxidants & Age-related diseases & Findings & References \\
\hline \multirow{9}{*}{$\begin{array}{l}\text { Tocopherols and } \\
\text { tocotrienols }\end{array}$} & Cancer & No effect & Lonn et al., 2005 \\
\hline & Alzheimer's disease & $\begin{array}{l}\downarrow \text { Lipid peroxidation by up to } 60 \% \text { compared with that of the } \\
\text { control }\end{array}$ & Morris et al., 2005 \\
\hline & & Positively associated with perceptual speed & Hensley et al., 2011 \\
\hline & & Stimulate phosphoprotein phosphatase 2A (PP2A) & Voronkov et al., 2011 \\
\hline & Cardiovascular disease & $\downarrow$ Cardiovascular mortality risk & Schwingshackl et al., 2017 \\
\hline & & No effect & Lonn et al., 2005 \\
\hline & Myocardial infarction & $\begin{array}{l}\text { } C \text { Chronic heart failure in patients with left ventricular } \\
\text { dysfunction }\end{array}$ & Marchioli et al., 2006 \\
\hline & Vascular disease & 个Risk of heart failure & Wannamethee et al., 2013 \\
\hline & Osteoporosis & $\begin{array}{l}\text { Positive relationship between bone mineral density and } \\
\alpha \text {-tocopherol level in an elderly Chinese population }\end{array}$ & Shi et al., 2016 \\
\hline \multirow[t]{10}{*}{ Ubiquinone } & Parkinson's disease & $\begin{array}{l}\text { Slow down the functional decline experienced by early-stage } \\
\text { of Parkinson's disease patients }\end{array}$ & Shults et al., 2002 \\
\hline & & $\begin{array}{l}\downarrow \text { Cellular pathophysiological alterations linked to a } \\
\text { mitochondrial dysfunction in Parkinson’s disease patients }\end{array}$ & Cooper et al., 2012 \\
\hline & & No effect & Snow et al., 2010 \\
\hline & Type 2 diabetes mellitus & $\begin{array}{l}\text { Enhances nerve conduction parameters of diabetic } \\
\text { polyneuropathy and ameliorates oxidative stress }\end{array}$ & Hernández-Ojeda et al., 2012 \\
\hline & & $\begin{array}{l}\text { ANitric oxide production in patients received } 200 \text { mg } \\
\text { CoQ10/day for } 12 \text { weeks }\end{array}$ & Watts et al., 2002 \\
\hline & & $\begin{array}{l}\text { Increases insulin sensitivity and improves beta cell function in } \\
\text { diabetic patients }\end{array}$ & Raygan et al., 2016 \\
\hline & & $\begin{array}{l}\text { Improve vascular dysfunction and decrease the glycemic } \\
\text { response }\end{array}$ & Mantle, 2017 \\
\hline & Coronary artery disease & $\uparrow$ Antioxidant enzymes activities and inflammation & Lee et al., 2013 \\
\hline & Congestive heart failure & Improve the quality of life in patients & Oleck and Ventura, 2016 \\
\hline & & ฟRisk of mortality & Lei and Liu, 2017 \\
\hline \multirow[t]{2}{*}{ Sulfur compounds } & Type 2 diabetes mellitus & Improve glucose control & Sobenin et al., 2008 \\
\hline & & No hypoglycemic effects & Afkhami-Ardekani et al., 2006 \\
\hline
\end{tabular}

\section{Carotenoids}

Carotenoids are naturally occurring organic pigments that are produced in the plastids of plants and algae, several bacteria, and fungi (Alós et al., 2016). The only animals known to produce carotenoids are spider mite (Tetranychus urticae) and the red pea aphid (Acyrthosiphon pisum), which have acquired the ability to synthesize the carotenoids from fungi via gene transfer ( $\mathrm{Du}$ et al., 2017). In general, carotenoids absorb wavelengths between 400 and 550 nanometers, thus the compounds appear in yellow, orange, or red color (Gauger et al., 2015).

Currently, there are more than 600 carotenoids that have been discovered to perform a range of functions (Paliwal et al., 2016). Carotenoids are divided into two classes, namely carotenes and xanthophylls based on their chemistry constitute (Yaroshevich et al., 2015). Hydrocarbononly carotenoids ( $\alpha$-carotene, $\beta$-carotene, and lycopene) are known as carotenes (Figure 3); whereas oxygenated derivatives are called xanthophylls. On the other hands, oxygen substituents (lutein and zeaxanthin), keto/oxo groups (echinenone and canthaxanthin), epoxide groups (violaxanthin, antheraxanthin, and neoxanthin), and aldehyde groups ( $\beta$-citraurin) are classified as complex xanthophylls (Berman et al., 2015).
Most carotenoids are tetraterpenoids, derive from 8 isoprene molecules and contain 40 carbon atoms (Harrison and Curley, 2016). All carotenoids have polyisoprenoid structure comprised of a long-conjugated chain adjacent toward the multiple double bonds with near symmetry on the central double bond. This basic acyclic structure can be altered by oxygen-rich functional groups (Gabriel et al., 2015). The electron-rich conjugated system of the polyene structure allows the carotenoids function as efficient radical scavengers by quenching the singlet oxygen and trapping peroxyl radicals (Nishino et al., 2016).

Carotenoids are not only exerted antioxidant properties, they are also facilitated in the modulation of cell cycle, apoptosis, and cell differentiation (Gloria et al., 2014), enhancement of immune system (Karadas et al., 2016), regulate of cell signaling pathways (Kim et al., 2016), promote growth factors (Diener and Rohrmann, 2016), and adhesion molecules (Llorente et al., 2017). Carotenoids are highly lipophilic molecules that reside intracellularly to shield the membrane from oxidative stress (Fiedor and Burda, 2014). Carotenoids are well-recognized as an eye-sight protecting agent. Such carotenoids are classified as pro-vitamin $\mathrm{A}$ which contains unsubstituted $\beta$-ionone ring ( $\alpha$-carotene, $\beta$-cryptoxanthin, $\beta$-carotene, and $\gamma$-carotene) and 
can be converted into retinal (Sandmann, 2015). Vitamin A deficiency affects immunity and subsequently leads to the damage of light-sensitive receptors (Gonçalves et al., 2016). Individual with vitamin A deficiency may acquire a permanent blindness known as xerophthalmia (West, 2015). Carotenoids such as lutein and zeaxanthin which is localized in the eye macula may protect against harmful blue and near-ultraviolet light (Ma et al., 2016). Age-related macular degeneration (AMD) is the main cause of blindness suffered by people aged 75 years and above in developed countries. AMD accounts for nearly $8.7 \%$ of all blindness worldwide (Wong et al., 2014). Research findings have predicted that the percentage of patients with AMD tends to double between 2010 and 2050 (Eisenhauer et al., 2017). Oxidative stress within the retina has been implicated in the pathogenesis of AMD. Compared to the other cells, nonproliferative postmitotic cells such as photoreceptors and retinal pigment epithelium cells are extremely sensitive to oxidative damage due to the absence of DNA damage detection systems (Blasiak et al., 2014). Further, the macular environment can also stimulate ROS generation. The macula is continuously exposed to high oxidative stress from the high partial pressure of choriocapillaris and oxidized polyunsaturated fatty acids (PUFAs) of the retinal outer segments (Schmidt-Erfurth, 2005). Compared to those who never or rarely consume carotenoids, individuals who consume a carotenoid-rich diet have a relatively low risk of age-related macular degeneration (Eisenhauer et al., 2017).

In addition to the oxidants scavenging ability, lutein also inhibits the activation of $\mathrm{NF}-\kappa \mathrm{B}$ which plays a significant role in the pathogenesis of various human diseases. NF- $\kappa \mathrm{B}$ enters the nucleus, downregulates the inducible gene transcription and triggers the production of inflammatory markers such as iNOS, chemokines, and cytokines (Serasanambati and Chilakapati, 2016). The antioxidant and anti-inflammatory properties of lutein are not limited to only eyes but it also decreases the risk of cardiovascular diseases (Maria et al., 2015), coronary artery disease (Nakazato et al., 2014), and cancers (Rafi et al., 2015) in older people. Previous studies have demonstrated that intake of lutein was inversely correlated with oxidized LDL, suggesting that lutein may protect against the development of atherosclerosis (Kishimoto et al., 2017). Increased plasma lutein levels also decrease baseline blood pressure, which subsequently reduces the risk of hypertension (Perrone et al., 2016). The data from the previous study further demonstrated that lutein shields the myocardium from ischemia injury by reducing apoptosis and oxidative stress (Maria et al., 2015). A metaanalysis conducted by Leermakers et al. (2016) showed that high dietary intake of lutein is negatively linked to stroke and coronary heart disease. However, Bjelakovic et al. (2012) reported that $\beta$ carotene increases the mortality rate of cardiovascular disease and rheumatoid.

Lutein not only reduces cardiovascular disease but it also inhibits age-related cancers such as breast cancer via modulation of NrF2/ARE and NF-кB pathways (Chang et al., 2018). Another common carotenoid, lycopene is widely accepted as a potent antioxidant and reduces the risk of certain cancers such as lung (Aizawa et al., 2016), prostate (Graff et al., 2016), colon (Huang R. F. et al., 2015). Lycopene suppresses the progression of carcinogenesis via its anti-inflammatory actions (Carini et al., 2017). A follow-up study conducted from 1986 to 2010 involving 49,898 of males revealed that higher lycopene intake can prevent prostate cancer ( $\mathrm{Zu}$ et al., 2014). The preventive role of lycopene toward cancer is more likely due to its antioxidant effect. Yet, the anticancer ability of lycopene is mediated through several mechanisms including modulation of cell cycle arrest, apoptosis, growth factor signaling, and phase II detoxifying enzymes (Aizawa et al., 2016). However, several studies demonstrated that smokers or workers in asbestos mines who received $\beta$-carotene or $\alpha$-tocopherol alone is susceptible to lung cancer compared to the placebo group (Blumberg and Block, 1994; Omenn et al., 1994).

Bone loss in the elderly leads to osteoporosis. Studies in both human and animal models have suggested that carotenoids could reduce the risk of osteoporosis (Rao and Rao, 2015). Carotenoids have shown a positive impact on bone cells. For instance, $\beta$-carotene was significantly inhibited the bone marrowderived macrophages viability (Wang et al., 2017). Beta-carotene decreased the receptor activator of nuclear factor kappa B ligand (RANKL)-induced osteoclastogenesis via inhibition of NF-кB pathway (Wang et al., 2017). Other carotenoids such as $\beta$ cryptoxanthin, $\alpha$-carotene, lutein, and lycopene also facilitate the alleviation of bone loss. A meta-analysis involving 140,265 participants and 4,324 cases suggested that high dietary intake of total carotenoids reduced the hip fracture risk by $28 \%$ (Xu et al., 2017). Another study conducted by Hayhoe et al. (2017) also showed that bone density and fracture risk is inversely correlated with dietary intake of carotenoids.

Carotenoids have been demonstrated to prevent many degenerative diseases induced by an oxidative stress such as Alzheimer's disease and dementia (Mohammadzadeh Honarvar et al., 2017). The implication of carotenoids toward the pathophysiology of Alzheimer's disease and dementia has been extensively studied in both in vitro and in vivo models (Masisi et al., 2016). Carotenoids delay disease progression via multiple pathways such as suppress oxidative stress (Wang et al., 2018), promote $\mathrm{A} \beta$ peptide production (Lin et al., 2017), and inhibit pro-inflammatory cytokines (Hadad and Levy, 2017). Betacarotene is an Alzheimer's disease antagonist due to its high binding energy toward Alzheimer's disease-related receptors (P53 kinase receptor and histone deacetylase; Krishnaraj et al., 2016). A marine carotenoid, fucoxanthin suppresses $A \beta$ formation and destabilizes $A \beta$ fibril (Xiang et al., 2017). A study reported by Ono and Yamada (2012) further revealed that both vitamin A and $\beta$-carotene can block the oligomerization of $A \beta 40$ and $A \beta 42$ during $A \beta$ peptide formation. Another carotenoid, lycopene was shown to reduce the $A \beta 42$-induced inflammatory cytokine such as IL- $1 \beta$, NF- $\kappa \mathrm{B}$, transforming growth factor beta (TGF$\beta$ ), and TNF- $\alpha$ in the brain (Sachdeva and Chopra, 2015). Data from the human studies revealed that higher plasma levels of lutein reduced the risk of Alzheimer's disease and dementia (Feart et al., 2015). High level of carotenoids (lutein, zeaxanthin, and lycopene) in serum has also been associated with a lower risk of Alzheimer's disease mortality (Min and Min, 2014).

The health-promoting values of carotenoids revealed the link between carotenoid-rich diets and age-related illnesses. The intake of raw tomato (Solanum lycopersicum) shields against 
cancers (esophagus, stomach, colon, and rectum) (Berman et al., 2015), cardiovascular diseases (Valderas-Martinez et al., 2016), as well as Alzheimer's disease (Oboh et al., 2015). Based on the evidence, dietary intakes of certain antioxidants such as carotenoids can reduce the risk of age-related diseases. The effects of multiple carotenoids in diet offer healthy aging in term of nutrition.

\section{Dietary Minerals}

Minerals are naturally occurring elements with universal structures and definite chemical formulas. Dietary minerals are the chemical substances required by all living organisms. Adequate intake of each dietary mineral is essential to maintain physical health. Minerals play a crucial role in bone formation, hormones synthesis, regulation of heartbeat and others (MorrisNaumann and Wark, 2015). Most of the minerals in human diet come from food and drinking water. Mineral supplements are made available in the market for those who did not meet the daily dietary intake of mineral (Schwalfenberg and Genuis, 2015).

Dietary minerals are categorized into two different groups, which are macrominerals and trace minerals. Macrominerals including phosphorus, calcium, sodium, magnesium, potassium, and chloride in which the body needs in larger amounts. By contrast, trace elements are dietary minerals that are required in minimal amounts for regular cellular function, such as copper, selenium, zinc, iodine, fluoride, and iron (Siddiqui et al., 2014). Most of these trace elements are the functional part of enzymes. Yet, intakes of a large amount of trace elements are noxious to both human and animals (Mikulewicz et al., 2017). For instance, trivalent chromium is responsible for glucose metabolism by acting as a cofactor for insulin action. However, massive inhalation of hexavalent chromium, a toxic industrial pollutant is carcinogenic to both animals and human. Chromium exposure has been associated with various cancers in lung, central nervous system, and gastrointestinal tract (Bhattacharya et al., 2016).

Minerals such as copper, magnesium, zinc, and selenium possess antioxidant properties. Zinc functions as an antioxidant in the body via regulation of glutathione metabolism (Stelmach et al., 2014), inhibition of nicotinamide adenine dinucleotide phosphate-oxidase (NADPH-oxidase) enzyme (Marreiro et al., 2017), modulation of metallothionein expression (Alvarez et al., 2016), and serves as a cofactor for superoxide dismutase enzyme (Marklund et al., 1982).

The non-enzymatic antioxidants taking part in the first line of defense belong to preventive antioxidants. These antioxidants inhibit the formation of new reactive species by interacting with the transition metal ions (Mironczuk-Chodakowska et al., 2018). Non-enzymatic antioxidants are not only involved in the first line of defense, it also involved in the second line of defense against ROS that is represented by molecules characterized by the ability to inactivate oxidants and radicals (Mironczuk-Chodakowska et al., 2018).

Abundance level of zinc can be found in the retina which implicated the antioxidant defense systems of the eye (Ugarte et al., 2014). Zinc carries out its antioxidant functions and serves as a cofactor in enzymes such as retinol dehydrogenase, an enzyme for vitamin A cycle. Several studies have reported the importance of dietary zinc and age-related macular degeneration. A human study involving 369 participants revealed that a low intake of zinc was associated with age-related macular degeneration (Aoki et al., 2016). A follow-up study for 6 years including 3,640 participants had revealed a significant role of zinc in age-related macular degeneration (Group, 2001). It has been shown that for individuals older than 55 years, zinc supplements may delay the development of agerelated macular degeneration and vision loss (Group, 2001). Similarly, a meta-analysis of 23,099 individuals demonstrated that dietary zinc blocks the progression of age-related macular degeneration and delay its progression (Gorusupudi et al., 2017).

In addition to the effects mentioned above, zinc supplementation has been reported to suppress the oxidative stress in type 2 diabetes via several mechanisms. These favorable effects could be attributed to the activity of zinc which is involved in the insulin production, secretion, and action processes by acting as a catalytic cofactor for carboxypeptidase $\mathrm{H}$ enzyme. Carboxypeptidase $\mathrm{H}$ enzyme is responsible for the conversion of proinsulin (inactive form) into insulin (active form). Further, zinc also facilitates the phosphorylation of the insulin receptor by transporting more glucose into the cells. In human studies, a significant decrease in plasma thiobarbituric acid reactive substances, an oxidative stress indicator was found in patients with type 2 diabetes supplemented with zinc (Anderson et al., 2001). Zinc also improved insulin sensitivity and subsequently reduces the chronic hyperglycemia in type 2 diabetes mellitus (Vashum et al., 2014). Overall, zinc plays a significant role as an antioxidant nutrient that regulates metabolic control in type 2 diabetes mellitus pathophysiology.

Notably, data from epidemiologic studies found that dietary zinc intake may reduce the risk of cancer (Costello and Franklin, 2016). Zinc suppresses the proliferation of cancerous cells via several mechanisms. In cancer cells, zinc inhibits mitochondrial terminal oxidation and respiration and stimulates apoptogenesis of mitochondria (Costello and Franklin, 2016). Further, zinc also prevents the migration of malignant cells through activation of intracellular signaling pathways. In prostate cancer cells, zinc is accumulated in the expression of the zinc uptake transporter, ZIP1 (Franklin and Costello, 2007). The accumulated zinc exerts its antiproliferative activity toward the prostate cancer cells via activation of MAPKs and inhibition the growth of cancer cells (Beyersmann and Haase, 2001). In colorectal cancer, zinc was found to activate Raf-1-MEK-MAPK kinases followed by the activation of Elk-1 dependent transreporter gene expression (Park et al., 2002). The downregulation of cancer cell growth by zinc indicates that the therapeutic potential of zinc to regulate the growth of cancers. Taken together, minerals are a good antioxidant which is best supplied by ingesting specific foods rich with that chemical element of interest. The beneficial effect of mineral on aging is worth attention. However, an overdose of mineral intake is not recommended and may cause a detrimental impact on health. 


\section{Ascorbic Acid}

Ascorbic acid, also known as vitamin C, is one of the most ubiquitous hydrosoluble antioxidants. In physiological $\mathrm{pH}$ conditions, vitamin $\mathrm{C}$ exists mainly as an ascorbate anion (Camarena and Wang, 2016). Ascorbic acid has $4-\mathrm{OH}$ groups (Figure 4) that can donate hydrogen to an oxidizing system. Due to the $-\mathrm{OH}$ groups (2 pairs of 2) are on adjacent toward the carbon atoms, ascorbic acid is susceptible to chelate metal ions $\left(\mathrm{Fe}^{++}\right)$. Ascorbic acid serves as a reducing agent, scavenge free radicals, and quench $\bullet \mathrm{O}_{2}^{-}$. At high levels of ascorbic acid $(>1,000 \mathrm{mg} / \mathrm{kg})$, it tends to shift the balance between ferric iron $\left(\mathrm{Fe}^{3+}\right)$ and ferrous $\left(\mathrm{Fe}^{2+}\right)$ and thereby scavenge the oxygen and inhibit oxidation (Brewer, 2011). Ascorbic acid is a cofactor for many enzyme-catalyzed reactions such as maintaining of connective and vascular tissue's integrity, enhancing the collagen biosynthesis and iron absorption, modulating the leukocyte and hematopoiesis functioning, neuroprotection, and hydroxylation of lysine and proline (May and Harrison, 2013; Spector and Johanson, 2014).

Data from both animal and population-based studies have shown that a correlation between the process of aging and reducing ascorbate levels in tissues (Michels and Hagen, 2004; Dixit et al., 2015). The mechanisms that implicate the declining of age-related ascorbate are complex and involve multiple cell signaling pathways such as accelerated turnover, increased usage, reduced cellular uptake, and decreased absorption/reabsorption. For instance, ascorbate level reduces for nearly $50 \%$ in leukocytes in individuals at age 85 and above compared to those at age 60 (Attwood et al., 1978). Despite the limited available evidence on ascorbate level in human brains, the previous study has reported that ascorbate level in the cerebral cortex is declined for nearly $77 \%$ from an individual at age 80 and older, compared to that individual at age 50 and younger (Schaus, 1957). A study reported by Al-Mahdawi et al. (2014) has shown that ascorbate shortage may contribute to the dysregulation of $5 \mathrm{hmC}$, which subsequently contributes to the age-related neurodegenerative diseases. Research evidence has demonstrated the potential protective function of ascorbate in neurodegenerative diseases (Barnham et al., 2004; Ruszkiewicz and Albrecht, 2015). Ascorbate supplementation markedly improves the differentiation of midbrain derived neural stem cell against dopaminergic neurons, which is associated with the TET-mediated $5 \mathrm{hmC}$ generation and Jmjd3 catalyzed loss of $\mathrm{H} 3 \mathrm{~K} 27 \mathrm{~m} 3$ ( $\mathrm{He}$ et al., 2015). In this regard, these findings imply that ascorbate plays a critical role in dopaminergic neuron differentiation (Camarena and Wang, 2016).

In addition to the effects mentioned above, ascorbic acid has the potential to protect against cancers. High concentration of ascorbic acid induces cytotoxicity against cancer cells in vitro (Vuyyuri et al., 2013; Tian et al., 2014) and delays tumor growth in xenograft models (Kim et al., 2012; Ma Y. et al., 2014). The animal model study further demonstrated that feeding Apc/Kras ${ }^{G 12 D}$ mutant mice high-dose ascorbic acid may impair tumor growth (Yun et al., 2015). Consistent with the data reported by Yun et al. (2015) and Ma Y. et al. (2014), Wu et al. (2017) identify an antitumor activity of ascorbic acid in a clinical study. Although the molecular link underlying ascorbic acid and anticancer activity require further elucidation, most of the experimental studies indicate that modulating oxidative stress could play a crucial role (Badgujar et al., 2015; Huang et al., 2017). In this regard, a key mode of action to explain this relationship is via glucose transporter type 1 (GLUT1) which increases uptake of the oxidized form of ascorbic acid, dehydroascorbate and subsequently depletes glutathione (Yun et al., 2015).

Compared to those who rarely or deficient in ascorbic acid, adults who supplemented with ascorbic acid is negatively associated with adiposity (Hosseini et al., 2017). Several studies have corroborated this finding and found that ascorbic acid suppressed leptin stimulation from adipocytes, particularly in insulin-secreted cells (Garcia-Diaz et al., 2010). Reduction in leptin may trigger a significant reduction in hypertension (Lane and Vesely, 2013). Intriguingly, leptin deficiency is linked to the early-onset of obesity, indicating that ratio of leptin to insulin is fundamental in the homeostatic balance of fat and glucose metabolism (Wabitsch et al., 2015).

Data from a meta-analysis included a study from inception to May 2013 demonstrated that an ascorbic acid supplementation with a dosage $>500 \mathrm{mg} / \mathrm{d}$ shows a better endothelial function (Ashor et al., 2014). In a further study focused on cardiovascular disease outcomes, Wang et al. (2013) showed that high ascorbic acid intake is negatively linked to cardiovascular disease. In another meta-analysis of randomized controlled trials, Ashor et al. (2014) found that a relatively low risk for incidence of cardiovascular disease for those with a greater intake of ascorbic acid supplements. Importantly, cellular adhesion molecules are biochemical markers of endothelial dysfunction concomitantly with inflammation. Ascorbic acid was effective by neutralizing the oxidized-low density lipoprotein (oxLDL) activity, which is known as the trigger of the initiator of atherosclerosis and inflammatory process in the endothelial tissue (Ellulu, 2017). Notably, some research has emerged to suggest that ascorbic acid improved endothelial function in diabetic patients (Ashor et al., 2014). The previous study stated that patients with diabetes had relatively low amounts of circulating ascorbic acid concentrations or known as latent scurvy (Price et al., 1996). Taken together, ascorbic acid may be a useful nutritional intervention for the secondary prevention of age-related diseases.

\section{Vitamin E}

Vitamin E consists a group of eight structurally associated lipophilic chromanol congeners. Vitamin E usually found naturally in food including four tocopherols and four tocotrienols, all of which possess saturated and three double bonds in their phytyl tails, respectively. Both tocopherols and tocotrienols are further classified into $\alpha-, \beta-, \gamma$-, and $\delta$ - based on the methyl and hydroxyl substitution in their phenolic rings (Figure 4) (Joshi and Pratic, 2012). Among all isoforms of vitamin $\mathrm{E}, \alpha$-tocopherol is predominantly found in mammalian tissue; conversely, $\gamma$-tocopherol is the primary form of vitamin $\mathrm{E}$ in the diet and exerts potent antioxidant property (Joshi and Pratic, 2012).

The activity of several protein kinases, and particularly of protein kinase $\mathrm{C}$ (PKC) sub-family members can be modulated in human neuronal cells supplemented with tocopherols and 


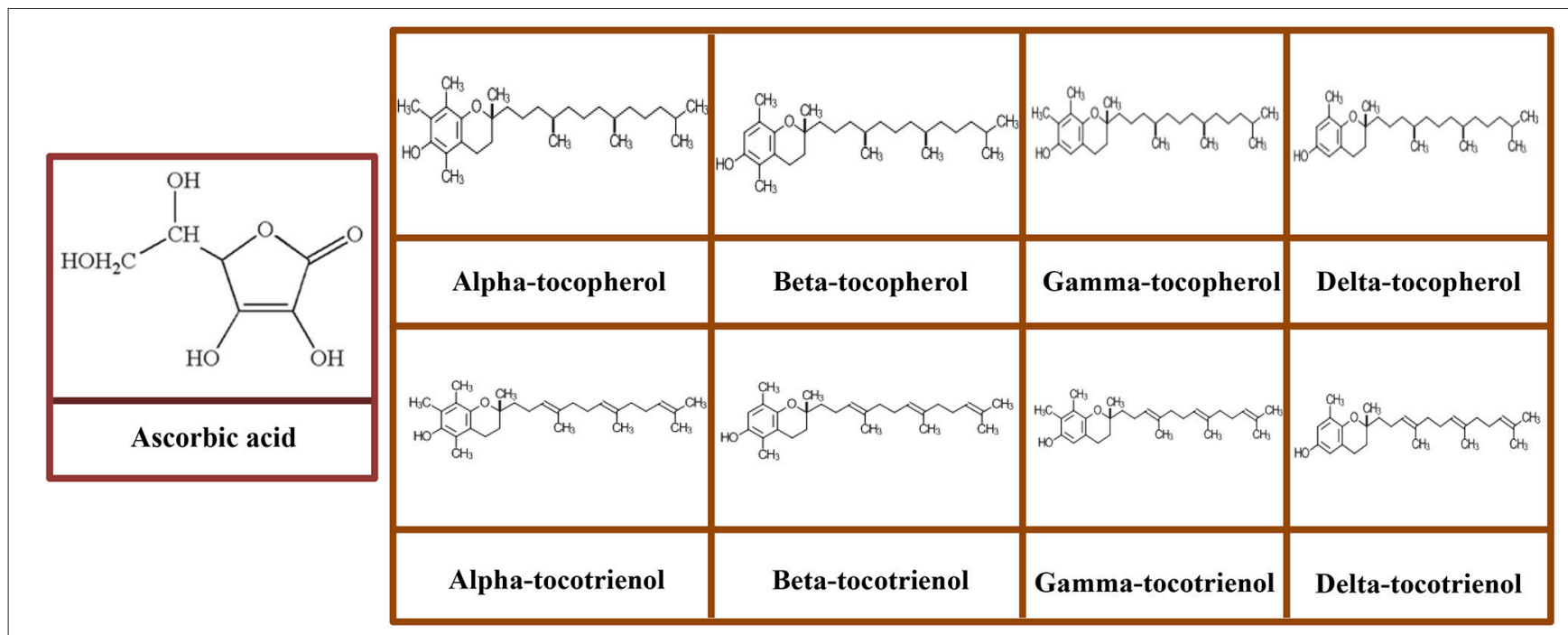

FIGURE 4 | Molecular structures of ascorbic acid and vitamin E congeners including tocopherols ( $\alpha$-tocopherol, $\beta$-tocopherol, $\gamma$-tocopherol, and $\delta$-tocopherol) and tocotrienols ( $\alpha$-tocotrienol, $\beta$-tocotrienol, $\gamma$-tocotrienol, and $\delta$-tocotrienol).

tocotrienols (Galli et al., 2017). This signaling influences apoptotic cell death and cell cycle regulation in different cell line models such as human neurons and glioblastoma cells with a strong effect of $\alpha$ - and $\gamma$-tocopherol on the phosphorylative stimulation of pro-survival MAPK-ERK isoforms. In a close similarity with the results obtained for $\alpha$-tocotrienols in the postischemic brain (Park et al., 2011), $\alpha$-tocotrienols protect mouse hippocampal and cortical neurons from cell death via modulation of neurodegenerative signaling cascades, and thereby preserve the function of that brain area (Ambrogini et al., 2014). A study by Khanna et al. (2010) and Sen et al. (2007) further supported the role of $\alpha$-tocotrienol in the modulation of phospholipase A2 activities and 12-lipoxygenase, which are involved in glutamateinduced neuronal cell death.

An emerging role for tocopherols and tocotrienols in response to neuroinflammation has been demonstrated and the occurrence of its positive effects on oxidative damage and Alzheimer pathology has been proposed. The proposed aspects in the neuroinflammatory activity of this vitamin including the regulation of Alzheimer-associated enzymes such as COX-2, 5-lipoxygenase (5-LOX), and nicotinamide adenine dinucleotide phosphate (NADPH) oxidase (Block, 2008; Chu and Praticò, 2011). Further, research evidence indicates that tocopherols and tocotrienols are of benefit in the stimulation of phosphoprotein phosphatase 2A (PP2A), a phosphatase that plays a crucial role in tau homeostasis which is lowered in human Alzheimer's disease brains (Voronkov et al., 2011). Moreover, data from clinical evidence have shown that tocopherols and tocotrienols supplementation in Alzheimer's patients reduces lipid peroxidation by up to $60 \%$ compared with that of the control (Morris et al., 2005). In this regard, post-mortem analysis of cerebrospinal fluid found that $\alpha$-tocopherol levels were positively associated with perceptual speed and Alzheimer's disease pathology in patients (Hensley et al., 2011). Overall, both tocopherols and tocotrienols may induce therapeutic effects via modulation of enzymatic and non-enzymatic pathways to reduce the impairment of neurological function.

Besides its effects on neuroinflammation, previous studies have demonstrated the role of this vitamin as a factor essential for other crucial functions and the development of organs and tissues for example bones, demonstrating the enormous functional potential of tocopherols and tocotrienols. In the context of osteoporosis, tocotrienols therapy has provided significant beneficial outcomes. Gamma-tocotrienol significantly enhanced the secretion levels of osteocalcin and osteonectin, increased alkaline phosphatase activity, and upregulated collagen type I mRNA and Runx2 protein expressions in osteoblastic MC3T3-E1 cells (Xu et al., 2018). Several studies have also reached a similar finding, in which tocopherol and tocotrienol have an antiosteoporotic activity. An animal study has shown that a diet supplemented with $\gamma$-tocopherol increased bone mass in male rats (Shuid et al., 2010). Muhammad et al. (2012) and Mohamad et al. (2012) further revealed that feeding with a diet containing $\alpha$-tocopherol promotes fracture healing and preserves bone mass in the estrogen-deficient rat. Findings from a population-based study mirror some of those from preclinical data obtained from an in vivo study. Data from a cross-sectional study showed a positive relationship between bone mineral density and $\alpha$-tocopherol level in elderly Chinese population (Shi et al., 2016).

In addition to the effects observed on neuroinflammation and osteoporosis, a beneficial effect of tocopherols and tocotrienols supplementation has also been documented on the incidence of cardiovascular disease. The formation of macrophage foam cells is a characteristic and an early onset of atherosclerosis (Yang et al., 2017). The aortas of cholesterol-administered rabbits have typical atherosclerotic lesions and show increased in CD36 mRNA expression. Administration of tocopherols 
and tocotrienols decreased cholesterol-induced atherosclerotic lesions and downregulated CD36 mRNA expression. The decrease of CD36 scavenger receptor expression, indicating the role of tocopherols and tocotrienols in the reduction of foam cell formation and atherosclerosis (Ozer et al., 2006). These data are in line with the previous study reported in vitro for macrophages and human smooth muscle cells, in which $\alpha$-tocopherol inhibits uptake of oxLDL by downregulating CD36 expression (Devaraj et al., 2001). Previous studies have also reported that feeding Apoe (-/-) mice with tocopherols and tocotrienols downregulated the expression of CD36 and upregulated the transcriptional activity of $L X R \alpha, A B C A 1$, and peroxisome proliferator-activated receptor gamma $(P P A R \gamma)$ (Tang et al., 2014). A similar dietary supplementation was also found to decrease the phosphorylation of PPAR $\gamma$ and nuclear factor E2-related factor 2 (Nrf2) and induce upregulation of their downstream targets including $\alpha$-glutathione S-transferase (GST $\alpha$ ) and adenosine triphosphate-binding cassette transporter A1 (ABCA1) through inhibition of matrix metalloproteinase-1 (MMP-1) (Bozaykut et al., 2014). Indeed, data from a metaanalysis included randomized-controlled trials from 1985 to 2015, including 287,304 participants demonstrated that a diet containing tocopherols and tocotrienols is negatively linked to cardiovascular mortality risk (Schwingshackl et al., 2017).

Another age-related disease is arthritis, which causes pain during movement and subsequently promotes loss of function in the affected limb (Espejo-Antúnez et al., 2013). Rossato et al. (2015) reported that tocopherols and tocotrienols reduced pain reversed debilitating symptoms elicited by painful inflammation. The reduction of cytokine production has also been demonstrated in animal models of inflammation and in humans with arthritis (Bhattacharya et al., 2012). Overall, tocopherols and tocotrienols might be promising tools for the alleviation of oxidative stress and preventing age-related diseases. The potential implications of tocopherols and tocotrienols on the age-related diseases worth of further investigation in comparative randomized clinical trials.

\section{Ubiquinone}

Ubiquinone (UQ), also known as coenzyme Q10, is synthesized within the body cells or can also be obtained from the diet (Quinzii et al., 2007) (Figure 5). Fish and meat are the richest sources of dietary UQ (Pravst et al., 2010). UQ also can be found in liver, kidney, beef, heart, sardines, soy oil, and peanuts. UQ is a naturally occurring vitamin-like molecule formed from redoxactive benzoquinone head group conjugated to a poly-isoprenoid side chain of species-specific length (6-10 subunits) (Wang and Hekimi, 2016). UQ is a potent antioxidant to neutralize ROS and protect the inner lining of the lymph, blood vessels, and endothelium (Motohashi et al., 2017). However, UQ levels reduce with advancing age and subsequently develop to some of the symptoms related to aging. The reduction of UQ levels during aging could be one of the predominant factors to develop chronic diseases (Motohashi et al., 2017).

Compared to other tissue, heart muscle utilizes more energy and usually has the highest UQ level and a relatively sensitive to UQ deficiency. The weakening of the heart muscle may lead to the swelling of the lower legs and feet, lung, liver, and the lining of the intestine (Motohashi et al., 2017). Heart failure is characterized by a loss of contractile function caused by energy depletion in mitochondria linked to a low level of UQ. It was evident that UQ oral supplementation alleviated the endothelial dysfunction and the cardiac contractility (Peres et al., 2017). Congestive heart failure is associated with a low level of UQ in tissues and blood. An animal study showed that UQ reduces the lipid hydroperoxides concentration in atherosclerotic lesions and the atherosclerotic lesions in the aorta (Littarru and Tiano, 2007). Frei et al. (1990) exploring the impact of UQH2 on oxidative stress using liposomes. The data showed that UQH2 protects membrane lipid peroxidation, with similar efficiency as $\alpha$-tocopherol. oxLDL has been associated with coronary artery disease (Ivanova et al., 2017). Previous study found that the lipid peroxidation rate of human low-density lipoprotein (LDL) is inhibited concomitantly with UQH2 administration following exposure to peroxyl radicals (Stocker et al., 1991). These observations imply that UQ could be one of the most active antioxidants in the modulation of LDL (Wang and Hekimi, 2016). Likewise, data from a population-based study reported that patients with heart failure who consume UQ had a lower risk of mortality in addition to increasing exercise capacity (Lei and Liu, 2017). UQ supplementation may also improve the quality of life in patients with congestive heart failure (Oleck and Ventura, 2016).

In addition to the effects mentioned above, a beneficial role of UQ supplementation has also been observed on the incidence of type 2 diabetes. Data from randomized controlled clinical trials have demonstrated that supplementation with UQ can significantly improve vascular dysfunction and decrease the glycemic response (Mantle, 2017). From the study reviewed, it showed that UQ reduces oxidative stress and did not lead to any adverse effects. Consistent with the study reported by Mantle (2017), Hernández-Ojeda et al. (2012) also found that UQ enhances nerve conduction parameters of diabetic polyneuropathy and ameliorates oxidative stress without significant undesirable effects. A study by Raygan et al. (2016) further supported that UQ increases insulin sensitivity and improves beta cell function in diabetic patients.

UQ plays a central role in the cellular dysfunction of Parkinson's disease patients (Zhu et al., 2017). UQ levels were relatively low in the plasma, platelet-mitochondria, and blood of Parkinson's disease patients (Sohmiya et al., 2004). Treatment with UQ reduced the cellular pathophysiological alterations linked to a mitochondrial dysfunction in Parkinson's disease patients (Cooper et al., 2012). Shults et al. (2002) further demonstrated that high concentration UQ administration may slow down the functional decline experienced by earlystage of Parkinson's disease patients. Overall, lipid profiles, systemic inflammation, and insulin sensitivity were improved after administration of UQ and thus may provide a useful approach for the alleviation of age-related diseases.

To protect mitochondrial oxidative damage, several mitochondrial-targeted antioxidants have been developed and a great potential mitochondrial-targeted antioxidant is MitoQ. MitoQ is a derivative of ubiquinone which linked to TPP 


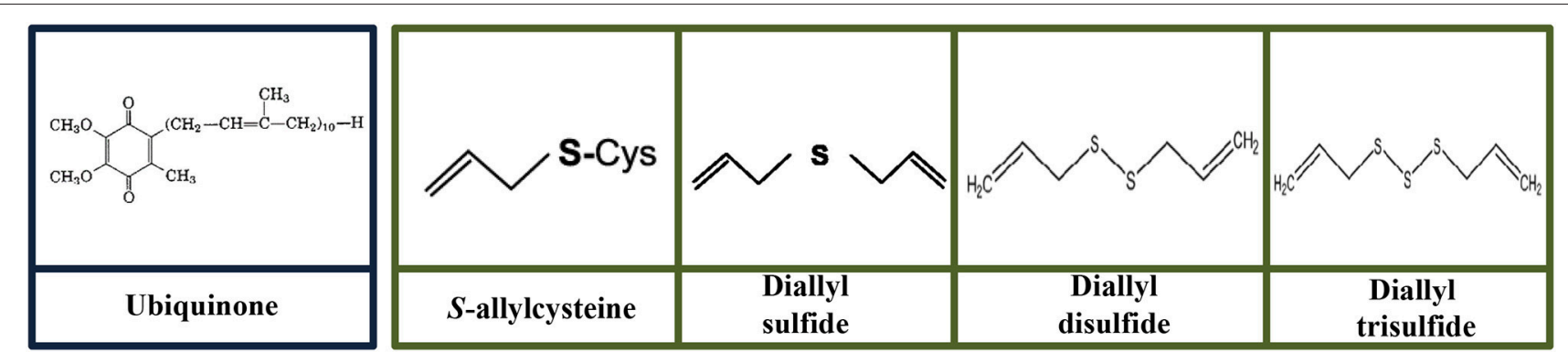

FIGURE 5 | Molecular structures of ubiquinone and organosulfur compounds (S-allylcysteine, diallyl sulfide, diallyl disulfide, and diallyl trisulfide).

moiety by a 10-carbon alkyl chain (Murphy and Smith, 2007). Much information indicates that the ubiquinol moiety of MitoQ can react with superoxide and protect against peroxynitrite (Liu et al., 2018b). Animal studies have revealed that MitoQ protects against oxidative damage such as hypertension (Pak et al., 2018) and neurodegenerative disease (Yin et al., 2016). A study by Junior et al. (2018) further supported that MitoQ improves mitochondrial dysfunction in heart dysfunction induced by pressure overload, by reducing hydrogen peroxide formation in rats. Emerging research evidence indicates that MitoQ may possess beneficial effects on tubular injury (Dare et al., 2015). Notably, data from an animal study have stated that MitoQ inhibited amyloid- $\beta$ peptide $(\mathrm{A} \beta)$ induced oxidative stress, a critical component of Alzheimer's disease, and reversed early cognitive decline (Zhang et al., 2018). Despite the beneficial effects of MitoQ on neurodegenerative disease was reported in vivo, not all studies demonstrated such a link. Data from the double-blind clinical trial of Parkinson disease patients failed to show any benefit in delaying the pathologic process of Parkinson disease during 12 months administration of MitoQ (Snow et al., 2010). Overall, these findings demonstrated that MitoQ might be promising tools for pathological changes of mitochondrial oxidative damage associated with age-related diseases.

\section{Organosulfur Compounds}

Organosulfur compounds mainly present in vegetable species belonging to Allium genus and Brassicaceae family. Functional organosulfur compounds in Allium have been used in folk and traditional medicine in the last centuries (Petropoulos et al., 2017). Sulfur compounds from Allium play a critical role in defense (Nwachukwu et al., 2012). Sulfur is the compound of Fe$S$ clusters and several amino acids for enzymes activity (Gruhlke and Slusarenko, 2012). Fe-S clusters are vitally important for the origin of life, particularly acetyl-CoA, RNA, and DNA (Fuss et al., 2015). Organosulfur compounds (Figure 5) usually present in onion, garlic, and Chinese chive, which may benefit a certain group of the population because they appear to combat oxidative stress associated age-related diseases such as cardiovascular disease ( $\mathrm{Lu}$ et al., 2015; Seki and Hosono, 2015; Wang et al., 2015), diabetes (Akash et al., 2014; Sambu et al., 2015), obesity (Lai et al., 2014), and neuroinflammation (Colín-González et al., 2015; Wen and Zhu, 2015). Organosulfur compounds such as $S$-allylcysteine has anti-apoptotic, anti-oxidation, and anti-inflammation (Colín-González et al., 2015) in addition to alleviating several diseases (Kodai et al., 2015).

Several studies reported by Arreola et al. (2015) and Kim et al. (2001) evaluated S-allylcysteine in relation to proinflammatory cytokine production and inflammatory markers. The data showed that S-allylcysteine inhibits NO production and iNOS expression in vitro study. Data reported by Liu K. L. et al. (2006) have shown that diallyl disulfide inhibits the production of NO and prostaglandin E2 (PGE2) in lipopolysaccharide (LPS)stimulated BV2 microglia in a dose-dependent manner. In a further study focused on inflammation outcomes, Liu K. L. et al. (2006) compared different groups of RAW 264.7 cell line murine macrophages that treated with diallyl trisulfide, diallyl disulfide, and diallyl sulfide, respectively. The data demonstrated that diallyl sulfide showed the most suppressive effect on NO production and iNOS expression, suggesting that it was linked to the number of sulfur atoms of the organosulfur compounds.

Organosulfur compounds not only modulate glutathione and phase II enzymes and inhibit inflammatory mediators, they also inhibit several cancers. Previous findings suggest that a diet supplemented with diallyl trisulfide, diallyl disulfide, and diallyl sulfide suppressed cancers induced by chemical carcinogens (Huang J. et al., 2015; Su et al., 2016; Kiesel and Stan, 2017). In support of this, an animal study has demonstrated that oral administration of diallyl trisulfide at a dosage of 1-2 mg per day for 13 weeks significantly suppressed the progression of invasive carcinoma and multiplicity of pulmonary metastasis (Singh et al., 2008). Several studies have also reached a similar finding, in which diallyl trisulfide and diallyl sulfide have an antiproliferative activity against bladder, pancreatic, and skin cancers (Ma H. B. et al., 2014; Shin et al., 2014; Shan et al., 2016). Collectively, regular consumption of food rich in organosulfur compounds may become a safe and successful strategy to alleviate oxidative stress and improve age-related chronic disease conditions.

Despite antioxidants pharmacological properties were reported in vitro and in vivo, some of the clinical expectations of antioxidant-based therapies have been frequently disappointed. Low stability and the poor aqueous solubility limit the therapeutic potential of antioxidants. This complication has hampered the quantity of antioxidant absorbed, which severely limit its bioavailability. Nanotechnology has emerged as a promising drug delivery system (Dehghanizade et al., 2018; García Calavia et al., 2018). Nanotechnology has received 
a great attention as it can resolve problems linked to the conventional therapeutic agents, such as lack of targeting capability, poor water solubility, systemic toxicity, and nonspecific distribution (Sreelakshmi et al., 2018). Hence, the application of nanotechnology could enhance the efficacy and improve their bioavailability by increasing solubility, enhancing plasma half-life, preventing degradation in the intestinal environment, and elevating permeation in the small intestine (Hu et al., 2017).

\section{CONCLUSIONS AND FUTURE PERSPECTIVE}

Despite a large part of literature exploring on the accumulation and the origin of ROS, current antioxidant-based therapies lack of specificity for dysfunctional tissues, cells, and organelles, and thus may not reach an effective concentration at the target site of pathologic oxidative stress. Additionally, antioxidants target huge amounts of reactive oxygen intermediates and are unable to modulate specific intermediate in the oxidative reaction, and subsequently leading several therapeutic strategies are unfocused. Mitochondria-targeted antioxidants hold great promising and may serve as a useful approach for the alleviation of agerelated diseases. However, further investigations are warranted to improve the potency of antioxidant-based therapies. Moreover, it is worth to underline the need of exploring the role of ironmediated oxidative damage through Fenton reaction to further ascertain the contribution of mitochondrial dysfunction and iron accumulation to the progression and pathologic development of age-related diseases. Data available on the interaction between chelating agents and antioxidants are limited, and further investigation may lead to the development of potent therapeutic agents and novel biomarkers targeting specific disease tissues, additionally to identify the downstream mediators of oxidative pathways.

Oxidative stress caused by an overproduction of ROS, mainly due to an imbalance of oxidative to reducing species. It has been suggested that excessive ROS production may lead to an upregulation of oncogene gene and the formation of mutagen compounds, which trigger proatherogenic activity and inflammation. Yet, longevity is not merely embedded in the genes; in fact, food rich in antioxidants may play an essential role in the immune system, production of cellular energy, as well as scavenge the ROS. The broad spectrum of processes in which the antioxidant molecules are involved suggests that a protective role of antioxidants in the pathogenesis of age-related diseases. Thus, an antioxidant can be a useful approach for healthspan extension as well as lifespan extension. Despite antioxidant may not serve as drugs, they hold great promising and indirectly provide leads in future use to combat age-related diseases. The potential implication of antioxidant in relation to age-related diseases to replace conventional therapies could be significant and is warranted to be elucidated in long-term clinical trials.

\section{AUTHOR CONTRIBUTIONS}

BT and W-P-PL conceived and designed the review and wrote the manuscript. MN edited the manuscript. HS wrote the manuscript. All authors read and approved the final manuscript.

\section{ACKNOWLEDGMENTS}

We would like to thank the Ministry of Science, Technology, and Innovation (MOSTI), Malaysia (project no. 02-01-04SF2141) for financial support and Putra Grant (UPM/7002/1/GPB/2017/9549900).

\section{REFERENCES}

Abbas, G., Salman, A., Rahman, S. U., Ateeq M.K., Usman. M., Sajid., S. et al. (2017). Aging mechanisms: linking oxidative stress, obesity and inflammation. Matrix Sci. Medica 1, 30-33. doi: 10.26480/msm.01.2017.30.33

Afkhami-Ardekani, M., Kamali-Ardekani, A., and Shojaoddiny-Ardekani, A. (2006). Effects of garlic on serum lipids and blood glucose of type 2 diabetic patients. Int. J. Diab. Dev. Ctries. 26, 86-88. doi: 10.4103/0973-3930. 28279

Ahmad, S. F., Attia, S. M., Bakheet, S. A., Zoheir, K. M., Ansari, M. A., Korashy, H. M., et al. (2015). Naringin attenuates the development of carrageenaninduced acute lung inflammation through inhibition of NF-кb, STAT3 and pro-inflammatory mediators and enhancement of I $\mathrm{B} \alpha$ and anti-inflammatory cytokines. Inflamm. 38, 846-857. doi: 10.1007/s10753-014-9994-y

Aizawa, K., Liu, C., Tang, S., Veeramachaneni, S., Hu, K. Q., Smith, D. E., et al. (2016). Tobacco carcinogen induces both lung cancer and nonalcoholic steatohepatitis and hepatocellular carcinomas in ferrets which can be attenuated by lycopene supplementation. Int. J. Cancer 139, 1171-1181. doi: 10.1002/ijc.30161

Akash, M. S., Rehman, K., and Chen, S. (2014). Spice plant Allium cepa: Dietary supplement for treatment of type 2 diabetes mellitus. Nutr. 30, 1128-1137. doi: 10.1016/j.nut.2014.02.011

Al-Mahdawi, S., Virmouni, S. A., and Pook, M. A. (2014). The emerging role of 5-hydroxymethylcytosine in neurodegenerative diseases. Frontiers Neurosci. 8, 397. doi: 10.3389/fnins.2014.00397

Alós, E., Rodrigo, M. J., and Zacarias, L. (2016). "Manipulation of carotenoid content in plants to improve human health," in Carotenoids in Nature. Springer), 311-343.

Alvarez, L., García, M., Rodríguez, S., Fernández, B., Pereiro, R., Sanz-Medel, A., et al. (2016). The zinc-metallothionein redox system in human retina and RPE. Acta Ophthalmologica 94:S256. doi: 10.1111/j.1755-3768.2016.0560

Ambrogini, P., Minelli, A., Galati, C., Betti, M., Lattanzi, D., Ciffolilli, S., et al. (2014). Post-seizure $\alpha$-tocopherol treatment decreases neuroinflammation and neuronal degeneration induced by status epilepticus in rat hippocampus. Mol. Neurobiol. 50, 246-256. doi: 10.1007/s12035-014-8648-2

Ambrosio, G., Zweier, J. L., Duilio, C., Kuppusamy, P., Santoro, G., Elia, P. P., et al. (1993). Evidence that mitochondrial respiration is a source of potentially toxic oxygen free radicals in intact rabbit hearts subjected to ischemia and reflow. J. Biol. Chem. 268, 18532-18541.

Anderson, R. A., Roussel, A. M., Zouari, N., Mahjoub, S., Matheau, J. M., and Kerkeni, A. (2001). Potential antioxidant effects of zinc and chromium supplementation in people with type 2 diabetes mellitus. J. Am. Coll. Nutr. 20, 212-218.

Antoniades, C., Tousoulis, D., Tountas, C., Tentolouris, C., Toutouza, M., Vasiliadou, C., et al. (2004). Vascular endothelium and inflammatory process, in patients with combined Type 2 diabetes mellitus and coronary atherosclerosis: the effects of vitamin C. Diabet. Med. 21, 552-558. doi: 10.1111/j.1464-5491.2004.01201.x

Aoki, A., Inoue, M., Nguyen, E., Obata, R., Kadonosono, K., Shinkai, S., et al. (2016). Dietary n-3 fatty acid, $\alpha$-tocopherol, zinc, vitamin D, vitamin C, and 
$\beta$-carotene are associated with age-related macular degeneration in Japan. Sci. Rep. 6:20723. doi: 10.1038/srep20723

Aquilano, K., Baldelli, S., and Ciriolo, M. R. (2014). Glutathione: new roles in redox signaling for an old antioxidant. Frontiers Pharmacol. 5:196. doi: 10.3389/fphar.2014.00196

Arreola, R., Quintero-Fabián, S., López-Roa, R. I., Flores-Gutiérrez, E. O., ReyesGrajeda, J. P., Carrera-Quintanar, L., et al. (2015). Immunomodulation and anti-inflammatory effects of garlic compounds. J. Immunol. Res. 2015, article ID 401630, 13 pages. doi: 10.1155/2015/401630

Ashor, A. W., Lara, J., Mathers, J. C., and Siervo, M. (2014). Effect of vitamin $\mathrm{C}$ on endothelial function in health and disease: a systematic review and meta-analysis of randomised controlled trials. Atherosclerosis 235, 9-20. doi: 10.1016/j.atherosclerosis.2014.04.004

Attwood, E., ROBEY, E., Kramer, J., Ovenden, N., Snape, S., ROSS, J., et al. (1978). A survey of the haematological, nutritional and biochemical state of the rural elderly with particular reference to vitamin C. Age Ageing 7, 46-56.

Badgujar, P. C., Pawar, N. N., Chandratre, G. A., Telang, A., and Sharma, A. (2015). Fipronil induced oxidative stress in kidney and brain of mice: protective effect of vitamin E and vitamin C. Pesticide Biochem. Physiol. 118, 10-18. doi: 10.1016/j.pestbp.2014.10.013

Baker, D. J., Wijshake, T., Tchkonia, T., LeBrasseur, N. K., Childs, B. G., van de Sluis, B., et al. (2011). Clearance of p16Ink4a-positive senescent cells delays ageing-associated disorders. Nature 479, 232-236. doi: 10.1038/nature 10600

Barnham, K. J., Masters, C. L., and Bush, A. I. (2004). Neurodegenerative diseases and oxidative stress. Nat. Rev. Drug Discov. 3:205. doi: 10.1038/nrd1330

Bellizzi, M., Franklin, M., Duthie, G., and James, W. (1994). Vitamin E and coronary heart disease: the European paradox. Eur. J. Clin. Nutr. 48, 822-831.

Berman, J., Zorrilla-López, U., Farré, G., Zhu, C., Sandmann, G., Twyman, R. M., et al. (2015). Nutritionally important carotenoids as consumer products. Phytochem. Rev. 14, 727-743. doi: 10.1007/s11101-0149373-1

Beyersmann, D., and Haase, H. (2001). Functions of zinc in signaling, proliferation and differentiation of mammalian cells. Biometals 14, 331-341.

Bhattacharya, I., Saxena, R., and Gupta, V. (2012). Efficacy of vitamin E in knee osteoarthritis management of North Indian geriatric population. Ther. Adv Musculoskeletal Disease 4, 11-19. doi: 10.1177/1759720X11424458

Bhattacharya, P. T., Misra, S. R., and Hussain, M. (2016). Nutritional aspects of essential trace elements in oral health and disease: an extensive review. Scientifica 2016:5464373. doi: 10.1155/2016/5464373

Biagi, E., Candela, M., Franceschi, C., and Brigidi, P. (2011). The aging gut microbiota: new perspectives. Ageing Res Rev. 10, 428-429. doi: 10.1016/j.arr.2011.03.004

Biswas, S. K. (2016). Does the interdependence between oxidative stress and inflammation explain the antioxidant paradox? Oxid. Med. Cell. Longev. 2016, article ID 5698931, 9 pages. doi: 10.1155/2016/5698931

Bjelakovic, G., Nikolova, D., Gluud, L. L., Simonetti, R. G., and Gluud, C. (2012). Antioxidant supplements for prevention of mortality in healthy participants and patients with various diseases. Cochrane Database Syst. Rev. 14:CD007176. doi: 10.1002/14651858.CD007176.pub2

Blaser, H., Dostert, C., Mak, T. W., and Brenner, D. (2016). TNF and ROS crosstalk in inflammation. Trends Cell Biol. 26, 249-261. doi: 10.1016/j.tcb.2015.12.002

Blasiak, J., Petrovski, G., Veréb, Z., Facskó, A., and Kaarniranta, K. (2014). Oxidative stress, hypoxia, and autophagy in the neovascular processes of agerelated macular degeneration. BioMed Res. Int. 2014, article ID 768026, 7 pages. doi: $10.1155 / 2014 / 768026$

Block, M. L. (2008). NADPH oxidase as a therapeutic target in Alzheimer's disease. BMC Neurosci. 9:S8. doi: 10.1186/1471-2202-9-S2-S8

Blumberg, J., and Block, G. (1994). The alpha-tocopherol, beta-carotene cancer prevention study in Finland. Nutr. Rev. 52, 242-245.

Bozaykut, P., Karademir, B., Yazgan, B., Sozen, E., Siow, R. C., Mann, G. E., et al. (2014). Effects of vitamin $\mathrm{E}$ on peroxisome proliferatoractivated receptor $\gamma$ and nuclear factor-erythroid 2-related factor 2 in hypercholesterolemia-induced atherosclerosis. Free Radic. Biol. Med. 70, 174-181. doi: 10.1016/j.freeradbiomed.2014.02.017

Braidy, N., Behzad, S., Habtemariam, S., Ahmed, T., Daglia, M., Mohammad Nabavi, S., et al. (2017). Neuroprotective effects of citrus fruit-derived flavonoids, nobiletin and tangeretin in alzheimer's and parkinson's disease. CNS Neurol. Disord. Drug Targets 16, 387-397. doi: 10.2174/1871527316666170328113309

Braidy, N., Zarka, M., Welch, J., and Bridge, W. (2015). Therapeutic approaches to modulating glutathione levels as a pharmacological strategy in Alzheimer's disease. Curr. Alzheimer Res. 12, 298-313. doi: $10.2174 / 1567205012666150302160308$

Brewer, M. (2011). Natural antioxidants: sources, compounds, mechanisms of action, and potential applications. Compr. Rev. Food Sci. Food Saf. 10, 221-247. doi: 10.1111/j.1541-4337.2011.00156.x

Buffenstein, R., Edrey, Y. H., Yang, T., and Mele, J. (2008). The oxidative stress theory of aging: embattled or invincible? Insights from non-traditional model organisms. Age (Dordr) 30, 99-109. doi: 10.1007/s11357-008-9058-z

Burtner, C. R., and Kennedy, B. K. (2010). Progeria syndromes and ageing: what is the connection? Nat. Rev. Mol. Cell. Biol. 11, 567-578. doi: 10.1038/nrm2944

Camarena, V., and Wang, G. (2016). The epigenetic role of vitamin C in health and disease. Cell. Mol. Life Sci. 73, 1645-1658. doi: 10.1007/s00018-016-2145-x

Carini, F., David, S., Tomasello, G., Mazzola, M., Damiani, P., Rappa, F., et al. (2017). Colorectal cancer: an update on the effects of lycopene on tumor progression and cell proliferation. J. Biol. Regul. Homeost. Agents 31, 769-774.

Carvalho, A. N., Marques, C., Guedes, R. C., Castro-Caldas, M., Rodrigues, E., Horssen, J., et al. (2016). S-Glutathionylation of Keap1: a new role for glutathione S-transferase pi in neuronal protection. FEBS Lett. 590, 1455-1466. doi: 10.1002/1873-3468.12177

Cassia, R., Nocioni, M., Correa-Aragunde, N., and Lamattina, L. (2018). Climate change and the impact of greenhouse gasses: CO2 and NO, friends and foes of plant oxidative stress. Frontiers Plant Sci. 9:273. doi: 10.3389/fpls.2018.00273

Catapano, M. C., Tvrdý, V., Karličková, J., Migkos, T., Valentová, K., Kren, V., et al. (2017). The stoichiometry of isoquercitrin complex with iron or copper is highly dependent on experimental conditions. Nutrients 9:1193. doi: $10.3390 /$ nu9111193

Chan, C. M., Huang, D. Y., Huang, Y. P., Hsu, S. H., Kang, L. Y., Shen, C. M., et al. (2016). Methylglyoxal induces cell death through endoplasmic reticulum stress-associated ROS production and mitochondrial dysfunction. J. Cell. Mol. Med. 20, 1749-1760. doi: 10.1111/jcmm.12893

Chang, C. H., Lee, K.-Y., and Shim, Y. H. (2017). Normal aging: definition and physiologic changes. J. Korean Med. Assoc. 60, 358-363. doi: 10.5124/jkma.2017.60.5.358

Chang, J., Zhang, Y., Li, Y., Lu, K., Shen, Y., Guo, Y., et al. (2018). NrF2/ARE and NF- $\kappa$ B pathway regulation may be the mechanism for lutein inhibition of human breast cancer cell. Future Oncol. (00). doi: 10.2217/fon-2017-0584

Chien, S.-T., Shi, M.-D., Lee, Y.-C., Te, C.-C., and Shih, Y.-W. (2015). Galangin, a novel dietary flavonoid, attenuates metastatic feature via PKC/ERK signaling pathway in TPA-treated liver cancer HepG2 cells. Cancer Cell Int. 15:15. doi: 10.1186/s12935-015-0168-2

Chistiakov, D. A., Sobenin, I. A., Revin, V. V., Orekhov, A. N., and Bobryshev, Y. V. (2014). Mitochondrial aging and age-related dysfunction of mitochondria. BioMed Res. Int. 2014, article ID 238463, 7 pages. doi: 10.1155/2014/ 238463

Chu, J., and Praticò, D. (2011). 5-lipoxygenase as an endogenous modulator of amyloid beta formation in vivo. Ann. Neurol. 69, 34-46. doi: 10.1002/ana. 22234

Chung, H. Y., Cesari, M., Anton, S., Marzetti, E., Giovannini, S., Seo, A. Y., et al. (2009). Molecular inflammation: underpinnings of aging and age-related diseases. Ageing Res. Rev. 8, 18-30. doi: 10.1016/j.arr.2008.07.002

Colacurci, N., Chiàntera, A., Fornaro, F., de Novellis, V., Manzella, D., Arciello, A., et al. (2005). Effects of soy isoflavones on endothelial function in healthy postmenopausal women. Menopause 12, 299-307. doi: 10.1097/01.GME.0000147017.23173.5B

Colín-González, A. L., Ali, S. F., Túnez, I., and Santamaría, A. (2015). On the antioxidant, neuroprotective and anti-inflammatory properties of S-allyl cysteine: an update. Neurochem. Int. 89, 83-91. doi: 10.1016/j.neuint.2015.06.011

Conti, V., Izzo, V., Corbi, G., Russomanno, G., Manzo, V., De Lise, F., et al. (2016). Antioxidant supplementation in the treatment of aging-associated diseases. Front. Pharmacol. 7:24 doi: 10.3389/fphar.2016.00024

Cooper, O., Seo, H., Andrabi, S., Guardia-Laguarta, C., Graziotto, J., Sundberg, M., et al. (2012). Pharmacological rescue of mitochondrial deficits in iPSC-derived 
neural cells from patients with familial Parkinson's disease. Science translational medicine 4, 141-190. doi: 10.1126/scitranslmed.3003985

Coppé, J. P., Desprez, P. Y., Krtolica, A., and Campisi, J. (2010). The senescenceassociated secretory phenotype: the dark side of tumor suppression. Annu. Rev. Pathol. 5, 99-118. doi: 10.1146/annurev-pathol-121808-102144

Corbi, G., Acanfora, D., Iannuzzi, G. L., Longobardi, G., Cacciatore, F., Furgi, G., et al. (2008). Hypermagnesemia predicts mortality in elderly with congestive heart disease: relationship with laxative and antacid use. Rejuvenation Res. 11, 129-138. doi: 10.1089/rej.2007.0583

Costello, L. C., and Franklin, R. B. (2016). A comprehensive review of the role of zinc in normal prostate function and metabolism; and its implications in prostate cancer. Arch. Biochem. Biophys. 611, 100-112. doi: 10.1016/j.abb.2016.04.014

Cross, C. E., Hasegawa, G., Reddy, K. A., and Omaye, S. (1977). Enhanced lung toxicity of $\mathrm{O} 2$ in selenium-deficient rats. Res. Commun. Chem. Pathol. Pharmacol. 16, 695-706.

Cuadrado, A., Manda, G., Hassan, A., Alcaraz, M. J., Barbas, C., Daiber, A., et al. (2018). Transcription factor NRF2 as a therapeutic target for chronic diseases: a systems medicine approach. Pharmacol. Rev. 70, 348-383. doi:10.1124/pr.117.014753

Dabhade, P., and Kotwal, S. (2013). Tackling the aging process with biomolecules: a possible role for caloric restriction, food-derived nutrients, vitamins, amino acids, peptides, and minerals. J. Nutr. Gerontol. Geriatr. 32, 24-40. doi: 10.1080/21551197.2012.753777

Dai, D. F., Chiao, Y. A., Marcinek, D. J., Szeto, H. H., and Rabinovitch, P. S. (2014). Mitochondrial oxidative stress in aging and healthspan. Longevity and healthspan 3:6. doi: 10.1186/2046-2395-3-6

Dare, A. J., Bolton, E. A., Pettigrew, G. J., Bradley, J. A., Saeb-Parsy, K., and Murphy, M. P. (2015). Protection against renal ischemia-reperfusion injury in vivo by the mitochondria targeted antioxidant MitoQ. Redox Biol. 5, 163-168. doi: 10.1016/j.redox.2015.04.008

Das, A., Majumder, D., and Saha, C. (2017). Correlation of binding efficacies of DNA to flavonoids and their induced cellular damage. J. Photochem. Photobiol. B: Biol. 170, 256-262. doi: 10.1016/j.jphotobiol.2017.04.019

Davalli, P., Mitic, T., Caporali, A., Lauriola, A., and D’Arca, D. (2016). ROS, cell senescence, and novel molecular mechanisms in aging and age-related diseases. Oxid. Med. Cell. Longev. 2016:3565127. doi: 10.1155/2016/3565127

de Oliveira, M. R., da Costa Ferreira, G., Basil, F. B., and Peres, A. (2018). Pinocembrin suppresses $\mathrm{H}_{2} \mathrm{O}_{2}$-induced mitochondrial dysfunction by a mechanism dependent on the Nrf2/HO-1 axis in SH-SY5Y cells. Mol. Neurobiol. 55, 989-1003. doi: 10.1007/s12035-016-0380-7

DeBalsi, K. L., Hoff, K. E., and Copeland, W. C. (2017). Role of the mitochondrial DNA replication machinery in mitochondrial DNA mutagenesis, aging and age-related diseases. Ageing Res. Rev. 33, 89-104. doi: 10.1016/j.arr.2016.04.006

Dehghanizade, S., Arasteh, J., and Mirzaie, A. (2018). Green synthesis of silver nanoparticle using Anthemis atropatana extract: characterization and in vitro biological activities. Artif. Cells Nanomed. Biotechnol. 46, 160-168. doi: 10.1080/21691401.2017.1304402

Devaraj, S., Hugou, I., and Jialal, I. (2001). $\alpha$-Tocopherol decreases CD36 expression in human monocyte-derived macrophages. J. Lipid Res. 42, 521-527.

Dias, V., Junn, E., and Mouradian, M. M. (2013). The role of oxidative stress in Parkinson's disease. J. Parkinson's Disease 3, 461-491. doi: 10.3233/JPD-130230

Dice, J. F. (1993). Cellular and molecular mechanisms of aging. Physiol. Rev. 73, 149-159. doi: 10.1152/physrev.1993.73.1.149

Diener, A., and Rohrmann, S. (2016). Associations of serum carotenoid concentrations and fruit or vegetable consumption with serum insulin-like growth factor (IGF)-1 and IGF binding protein-3 concentrations in the Third National Health and Nutrition Examination Survey (NHANES III). J. Nutr. Sci. 5:e13. doi: 10.1017/jns.2016.1

Ding, Y., Dai, X., Jiang, Y., Zhang, Z., and Li, Y. (2014). Functional and morphological effects of grape seed proanthocyanidins on peripheral neuropathy in rats with type 2 diabetes mellitus. Phytother. Res. 28, 1082-1087. doi: $10.1002 /$ ptr.5104

Dixit, S., Bernardo, A., Walker, J. M., Kennard, J. A., Kim, G. Y., Kessler, E. S., et al. (2015). Vitamin C deficiency in the brain impairs cognition, increases amyloid accumulation and deposition, and oxidative stress in APP/PSEN1 and normally aging mice. ACS Chem. Neurosci. 6, 570-581. doi: 10.1021/ cn500308h
Du, X., Song, K., Wang, J., Cong, R., Li, L., and Zhang, G. (2017). Draft genome and SNPs associated with carotenoid accumulation in adductor muscles of bay scallop (Argopecten irradians). J. Genomics 5:83. doi: 10.7150/jgen.19146

Duffy, S. L., Lagopoulos, J., Terpening, Z., Lewis, S. J., Hickie, I. B., Grunstein, R., et al. (2015). In vivo glutathione relates to sleep apnoea severity and oxygen desaturation in older adults 'at risk'of developing dementia. Alzheimer's and Dementia: J. Alzheimer's Assoc. 11:P863. doi: 10.1016/j.jalz.2015.08.043

Eckmann, J., Eckert, S. H., Leuner, K., Muller, W. E., and Eckert, G. P. (2013). Mitochondria: mitochondrial membranes in brain ageing and neurodegeneration. Int. J. Biochem. Cell Biol. 45, 76-80. doi: 10.1016/j.biocel.2012.06.009

Eisenhauer, B., Natoli, S., Liew, G., and Flood, V. M. (2017). Lutein and Zeaxanthin-Food sources, bioavailability and dietary variety in age-related macular degeneration protection. Nutrients 9:120. doi: 10.3390/nu9020120

Ellulu, M. S. (2017). Obesity, cardiovascular disease, and role of vitamin $\mathrm{C}$ on inflammation: a review of facts and underlying mechanisms. Inflammopharmacol. 25, 313-328. doi: 10.1007/s10787-017-0314-7

Erdogan, S., Doganlar, O., Doganlar, Z. B., Serttas, R., Turkekul, K., Dibirdik, I., et al. (2016). The flavonoid apigenin reduces prostate cancer CD44+ stem cell survival and migration through PI3K/Akt/NF-кB signaling. Life Sci. 162, 77-86. doi: 10.1016/j.lfs.2016.08.019

Espejo-Antúnez, L., Cardero-Durán, M. A., Garrido-Ardila, E. M., TorresPiles, S., and Caro-Puértolas, B. (2013). Clinical effectiveness of mud pack therapy in knee osteoarthritis. Rheumatol. 52, 659-668. doi: 10.1093/rheumatology/kes322

Espinola-Klein, C., Rupprecht, H. J., Bickel, C., Schnabel, R., Genth-Zotz, S., Torzewski, M., et al. (2007). Glutathione peroxidase-1 activity, atherosclerotic burden, and cardiovascular prognosis. Am. J. Cardiol. 99, 808-812. doi: 10.1016/j.amjcard.2006.10.041

Espinosa-Diez, C., Miguel, V., Mennerich, D., Kietzmann, T., Sánchez-Pérez, P., Cadenas, S., et al. (2015). Antioxidant responses and cellular adjustments to oxidative stress. Redox Biol. 6, 183-197. doi: 10.1016/j.redox.2015.07.008

Fang, W.-J., Wang, C.-J., He, Y., Zhou, Y.-,l., Peng, X.-,d., and Liu, S.-,k. (2018). Resveratrol alleviates diabetic cardiomyopathy in rats by improving mitochondrial function through PGC-1 $\alpha$ deacetylation. Acta Pharmacol. Sinica 39, 59-73.

Farhat, Z., Browne, R. W., Bonner, M. R., Tian, L., Deng, F., Swanson, M., et al. (2018). How do glutathione antioxidant enzymes and total antioxidant status respond to air pollution exposure? Environ. Int. 112, 287-293. doi: 10.1016/j.envint.2017.12.033

Feart, C., Letenneur, L., Helmer, C., Samieri, C., Schalch, W., Etheve, S., et al. (2015). Plasma carotenoids are inversely associated with dementia risk in an elderly French cohort. J. Gerontol. Series A: Biomed. Sci. Med. Sci. 71, 683-688. doi: 10.1093/gerona/glv135

Fiedor, J., and Burda, K. (2014). Potential role of carotenoids as antioxidants in human health and disease. Nutrients 6, 466-488. doi: 10.3390/nu6020466

Fink, B. N., Steck, S. E., Wolff, M. S., Britton, J. A., Kabat, G. C., Schroeder, J. C., et al. (2006). Dietary flavonoid intake and breast cancer risk among women on Long Island. Am. J. Epidemiol. 165, 514-523. doi: 10.1093/aje/kwk033

Folch, J., Ettcheto, M., Petrov, D., Abad, S., Pedrós, I., Marin, M., et al. (2018). Review of the advances in treatment for Alzheimer disease: strategies for combating $\beta$-amyloid protein. Neurologia 33, 47-58. doi: 10.1016/j.nrl.2015.03.012

Fougère, B., Boulanger, E., Nourhashémi, F., Guyonnet, S., and Cesari, M. (2017). Chronic inflammation: accelerator of biological aging. J. Gerontol. A Biol. Sci. Med. Sci. 72, 1218-1225. doi: 10.1093/gerona/glw240

Franceschi, C., and Campisi, J. (2014). Chronic inflammation (inflammaging) and its potential contribution to age-associated diseases. J. Gerontol. A Biol. Sci. Med. Sci. 69, S4-S9. doi: 10.1093/gerona/glu057

Franklin, R. B., and Costello, L. C. (2007). Zinc as an anti-tumor agent in prostate cancer and in other cancers. Arch. Biochem. Biophys. 463, 211-217. doi: 10.1016/j.abb.2007.02.033

Frei, B., Kim, M. C., and Ames, B. N. (1990). Ubiquinol-10 is an effective lipidsoluble antioxidant at physiological concentrations. Proc. Natl Acad. Sci. 87, 4879-4883. doi: 10.1073/pnas.87.12.4879

Fuss, J. O., Tsai, C.-L., Ishida, J. P., and Tainer, J. A. (2015). Emerging critical roles of Fe-S clusters in DNA replication and repair. Biochimica et Biophysica Acta (BBA)-Mol. Cell Res. 1853, 1253-1271. doi: 10.1016/j.bbamcr.2015.01.018 
Gabriel, H. B., Silva, M. F., Kimura, E. A., Wunderlich, G., Katzin, A. M., and Azevedo, M. F. (2015). Squalestatin is an inhibitor of carotenoid biosynthesis in Plasmodium falciparum. Antimicrobial Agents Chemother. 59, 3180-3188. doi: 10.1128/AAC.04500-14

Galli, F., Azzi, A., Birringer, M., Cook-Mills, J. M., Eggersdorfer, M., Frank, J., et al. (2017). Vitamin E: Emerging aspects and new directions. Free Radic. Biol. Med.102, 16-36. doi: 10.1016/j.freeradbiomed.2016.09.017

Ganugapati, J., Mukkavalli, S., and Sahithi, A. (2011). Docking studies of green tea flavonoids as insulin mimetics. Int. J. Comp. App. 30, 48-52.

García Calavia, P., Chambrier, I., Cook, M. J., Haines, A. H., Field, R. A., and Russell, D. A. (2018). Targeted photodynamic therapy of breast cancer cells using lactose-phthalocyanine functionalized gold nanoparticles. J. Colloid Interface Sci. 512, 249-259. doi: 10.1016/j.jcis.2017.10.030

Garcia-Diaz, D. F., Campion, J., Milagro, F., Boque, N., Moreno-Aliaga, M. J., and Martinez, J. A. (2010). Vitamin C inhibits leptin secretion and some glucose/lipid metabolic pathways in primary rat adipocytes. J. Mol. Endocrinol. 45, 33-43. doi: 10.1677/JME-09-0160

García-Santamarina, S., Boronat, S., and Hidalgo, E. (2014). Reversible cysteine oxidation in hydrogen peroxide sensing and signal transduction. Biochem. 53, 2560-2580. doi: 10.1021/bi401700f

Gaschler, M. M., and Stockwell, B. R. (2017). Lipid peroxidation in cell death. Biochem. Biophys. Res. Commun. 482, 419-425. doi: 10.1016/j.bbrc.2016.10.086

Gauger, T., Konhauser, K., and Kappler, A. (2015). Protection of phototrophic iron (II)-oxidizing bacteria from UV irradiation by biogenic iron (III) minerals: Implications for early Archean banded iron formation. Geol. 43, 1067-1070. doi: 10.1130/G37095.1

Gey, K. F., and Puska, P. (1989). Plasma vitamins E and A inversely correlated to mortality from ischemic heart disease in cross-cultural epidemiology. Ann. New York Acad. Sci. 570, 268-282. doi: 10.1111/j.1749-6632.1989.tb14926.x

Ghezzi, P., Jaquet, V., Marcucci, F., and Schmidt, H. H. (2017). The oxidative stress theory of disease: levels of evidence and epistemological aspects. Br. J. Pharmacol. 174, 1784-1796. doi: 10.1111/bph.13544

Gholamian-Dehkordi, N., Luther, T., Asadi-Samani, M., and Mahmoudian-Sani, M. R. (2017). An overview on natural antioxidants for oxidative stress reduction in cancers; a systematic review. Immunopathol. Persa 3:e12.

Gloria, N. F., Soares, N., Brand, C., Oliveira, F. L., Borojevic, R., and Teodoro, A. J. (2014). Lycopene and beta-carotene induce cell-cycle arrest and apoptosis in human breast cancer cell lines. Anticancer Res. 34, 1377-1386.

Golia, E., Limongelli, G., Natale, F., Fimiani, F., Maddaloni, V., Pariggiano, I., et al. (2014). Inflammation and cardiovascular disease: from pathogenesis to therapeutic target. Curr. Atheroscler. Rep. 16:435. doi: 10.1007/s11883-014-0435-Z

Gonçalves, A., Estevinho, B. N., and Rocha, F. (2016). Microencapsulation of vitamin A: a review. Trends Food Sci. Tech. 51, 76-87. doi: 10.1016/j.tifs.2016.03.001

Gonzales, G. B., Smagghe, G., Grootaert, C., Zotti, M., Raes, K., and Camp, J. V. (2015). Flavonoid interactions during digestion, absorption, distribution and metabolism: a sequential structure-activity/property relationship-based approach in the study of bioavailability and bioactivity. Drug Metab. Rev. 47, 175-190. doi: 10.3109/03602532.2014.1003649

González de Vega, R. Fernández-Sánchez, M. L., Fernández, J. C., Menéndez, F. V. Á., and Sanz-Medel, A. (2016). Selenium levels and glutathione peroxidase activity in the plasma of patients with type II diabetes mellitus. J. Trace Elements Med. Biol. 37, 44-49. doi: 10.1016/j.jtemb.2016.06.007

Gonzalez-Suarez, I., Redwood, A. B., and Gonzalo, S. (2009). Loss of A-type lamins and genomic instability. Cell Cycle 8, 3860-3865. doi: 10.4161/cc.8.23.10092

Gorusupudi, A., Nelson, K., and Bernstein, P. S. (2017). The age-related eye disease 2 study: micronutrients in the treatment of macular degeneration. Adv. Nutr. 8, 40-53. doi: 10.3945/an.116.013177

Graff, R. E., Pettersson, A., Lis, R. T., Ahearn, T. U., Markt, S. C., Wilson, K. M., et al. (2016). Dietary lycopene intake and risk of prostate cancer defined by ERG protein expression. Am. J. Clin. Nutr. 103, 851-860. doi: 10.3945/ajcn.115.118703

Grassi, D., Ferri, C., and Desideri, G. (2016). Brain protection and cognitive function: cocoa flavonoids as nutraceuticals. Curr. Pharm. Design 22, 145-151. doi: 10.2174/1381612822666151112145730

Grosso, G., Micek, A., Godos, J., Pajak, A., Sciacca, S., Galvano, F., et al. (2017). Dietary flavonoid and lignan intake and mortality in prospective cohort studies:
Systematic review and dose-response meta-analysis. Am. J. Epidemiol. 185, 1304-1316. doi: 10.1093/aje/kww207

Group, A.-R. E. D. S. R. (2001). A randomized, placebo-controlled, clinical trial of high-dose supplementation with vitamins $\mathrm{C}$ and $\mathrm{E}$, beta carotene, and zinc for age-related macular degeneration and vision loss: AREDS report no. 8. Arch. Ophthalmol. 119:1417.

Gruhlke, M. C., and Slusarenko, A. J. (2012). The biology of reactive sulfur species (RSS). Plant Physiol. Biochem. 59, 98-107. doi: 10.1016/j.plaphy.2012.03.016

Grune, T., Schröder, P., and Biesalski, H. K. (2004). "Low molecular weight antioxidants," In: Grune, T. Reaction, Processes. The Handbook of Environmental Chemistry, Springer, Berlin, Heidelberg.

Gu, L., Zhao, M., Li, W., You, L., Wang, J., Wang, H., et al. (2012). Chemical and cellular antioxidant activity of two novel peptides designed based on glutathione structure. Food Chem. Toxicol. 50, 4085-4091. doi: 10.1016/j.fct.2012.08.028

Gümüșay, Ö. A., Borazan, A. A., Ercal, N., and Demirkol, O. (2015). Drying effects on the antioxidant properties of tomatoes and ginger. Food Chem. 173, 156-162. doi: 10.1016/j.foodchem.2014.09.162

Guo, J. D., Zhao, X., Li, Y., Li, G. R., and Liu, X. L. (2018). Damage to dopaminergic neurons by oxidative stress in Parkinson's disease. Int. J. Mol. Med. 41, 1817-1825. doi: 10.3892/ijmm.2018.3406

Hadad, N., and Levy, R. (2017). Combination of EPA with carotenoids and polyphenol synergistically attenuated the transformation of microglia to M1 phenotype via inhibition of NF-кB. Neuromol. Med. 19, 436-451. doi: 10.1007/s12017-017-8459-5

Hadjadj, S., Cariou, B., Fumeron, F., Gand, E., Charpentier, G., Roussel, R., et al. (2016). Death, end-stage renal disease and renal function decline in patients with diabetic nephropathy in French cohorts of type 1 and type 2 diabetes. Diabetol. 59, 208-216. doi: 10.1007/s00125-015-3785-3

Harman, D. (1956). Aging: a theory based on free radical and radiation chemistry. J. Gerontol. 11, 298-300. doi: 10.1093/geronj/11.3.298

Harris, I. S., Treloar, A. E., Inoue, S., Sasaki, M., Gorrini, C., Lee, K. C., et al. (2015). Glutathione and thioredoxin antioxidant pathways synergize to drive cancer initiation and progression. Cancer Cell 27, 211-222. doi: 10.1016/j.ccell.2014.11.019

Harrison, E. H., and Curley, R. W. (2016). "Carotenoids and retinoids: nomenclature, chemistry, and analysis," in The Biochemistry of Retinoid Signaling II. Springer), 1-19.

Hayhoe, R. P. G., Lentjes, M. A. H., Mulligan, A. A., Luben, R. N., Khaw, K. T., and Welch, A. A. (2017). Carotenoid dietary intakes and plasma concentrations are associated with heel bone ultrasound attenuation and osteoporotic fracture risk in the European Prospective Investigation into Cancer and Nutrition (EPIC)Norfolk cohort. Br. J. Nutr. 117, 1439-1453. doi: 10.1017/S0007114517001180

He, F., and Zuo, L. (2015). Redox roles of reactive oxygen species in cardiovascular diseases. Int. J. Mol. Sci. 16, 27770-27780. doi: 10.3390/ijms161126059

He, X., and Sun, L. M. (2016). Dietary intake of flavonoid subclasses and risk of colorectal cancer: evidence from population studies. Oncotarget 7:26617. doi: 10.18632/oncotarget.8562

He, X. B., Kim, M., Kim, S. Y., Yi, S. H., Rhee, Y. H., Kim, T., et al. (2015). Vitamin $\mathrm{C}$ facilitates dopamine neuron differentiation in fetal midbrain through TET1and JMJD3-dependent epigenetic control manner. Stem Cells 33, 1320-1332. doi: 10.1002/stem.1932

Heidari, H., Kamalinejad, M., Noubarani, M., Rahmati, M., Jafarian, I., Adiban, H., et al. (2016). Protective mechanisms of cucumis sativus in diabetesrelated modelsof oxidative stress and carbonyl stress. BioImpacts: BI 6:33. doi: 10.15171/bi.2016.05

Hensley, K., Barnes, L. L., Christov, A., Tangney, C., Honer, W. G., Schneider, J. A., et al. (2011). Analysis of postmortem ventricular cerebrospinal fluid from patients with and without dementia indicates association of vitamin E with neuritic plaques and specific measures of cognitive performance. J. Alzheimer's Disease 24, 767-774. doi: 10.3233/JAD-2011-101995

Hernández-Ojeda, J., Cardona-Muñoz, E. G., Román-Pintos, L. M., TroyoSanromán, R., Ortiz-Lazareno, P. C., Cárdenas-Meza, M. A., et al. (2012). The effect of ubiquinone in diabetic polyneuropathy: a randomized doubleblind placebo-controlled study. J. Diabetes Complications 26, 352-358. doi: 10.1016/j.jdiacomp.2012.04.004

Hosseini, B., Saedisomeolia, A., and Allman-Farinelli, M. (2017). Association between antioxidant intake/status and obesity: a systematic review 
of observational studies. Biol. Trace Element Res. 175, 287-297. doi: 10.1007/s12011-016-0785-1

Hu, B., Liu, X., Zhang, C., and Zeng, X. (2017). Food macromolecule based nanodelivery systems for enhancing the bioavailability of polyphenols. J. Food Drug Anal. 25, 3-15. doi: 10.1016/j.jfda.2016.11.004

Huang, J., Yang, B., Xiang, T., Peng, W., Qiu, Z., Wan, J., et al. (2015). Diallyl disulfide inhibits growth and metastatic potential of human triple-negative breast cancer cells through inactivation of the $\beta$-catenin signaling pathway. Mol. Nutr. and Food Res. 59, 1063-1075. doi: 10.1002/mnfr.201400668

Huang, R. F., Wei, Y. J., Inbaraj, B. S., and Chen, B. H. (2015). Inhibition of colon cancer cell growth by nanoemulsion carrying gold nanoparticles and lycopene. Int. J. Nanomed. 10:2823. doi: 10.2147/IJN.S79107

Huang, S., Chen, L., Libina, N., Janes, J., Martin, G. M., Campisi, J., et al. (2005). Correction of cellular phenotypes of Hutchinson-Gilford progeria cells by RNA interference. Hum. Genet. 118, 444-450. doi: 10.1007/s00439-005-0051-7

Huang, Y.-N., Yang, L.-Y., Wang, J.-Y., Lai, C.-C., Chiu, C.-T., and Wang, J.-Y. (2017). L-Ascorbate protects against methamphetamine-induced neurotoxicity of cortical cells via inhibiting oxidative stress, autophagy, and apoptosis. Mol. Neurobiol. 54, 125-136. doi: 10.1007/s12035-015-9561-z

Islam, M. T. (2017). Oxidative stress and mitochondrial dysfunctionlinked neurodegenerative disorders. Neurol. Res. 39, 73-82. doi: 10.1080/01616412.2016.1251711

Ivanova, E. A., Myasoedova, V. A., Melnichenko, A. A., Grechko, A. V., and Orekhov, A. N. (2017). Small dense low-density lipoprotein as biomarker for atherosclerotic diseases. Oxid. Med. Cell. Longev. 2017, article ID 1273042, 10 pages, doi: 10.1155/2017/1273042

Ivey, K. L., Hodgson, J. M., Croft, K. D., Lewis, J. R., and Prince, R. L. (2015). Flavonoid intake and all-cause mortality. Am. J. Clin. Nutr. 101, 1012-1020. doi: $10.3945 /$ ajcn.113.073106

Jain, H., Dhingra, N., Narsinghani, T., and Sharma, R. (2016). Insights into the mechanism of natural terpenoids as NF- $\mathrm{\kappa B}$ inhibitors: an overview on their anticancer potential. Exp. Oncol. 38, 158-168

Ji, L. L., Gomez-Cabrera, M. C., and Vina, J. (2006). Exercise and hormesis: activation of cellular antioxidant signaling pathway. Ann. N Y Acad. Sci. 1067, 425-435. doi: 10.1196/annals.1354.061

Jiang, W., Luo, T., Li, S., Zhou, Y., Shen, X. Y., He, F., et al. (2016). Quercetin protects against Okadaic acid-induced injury via MAPK and PI3K/Akt/GSK3 $\beta$ signaling pathways in HT22 hippocampal neurons. PLoS One 11:e0152371. doi: 10.1371/journal.pone.0152371

Jin, K., Simpkins, J. W., Ji, X., Leis, M., and Stambler, I. (2015). The critical need to promote research of aging and aging-related diseases to improve health and longevity of the elderly population. Aging Disease 6:1. doi: 10.14336/AD.2014.1210

Joshi, Y. B., and Pratic,ò, D. (2012). Vitamin E in aging, dementia, and Alzheimer's disease. Biofactors 38, 90-97. doi: 10.1002/biof.195

Ju, J., Wang, C., Qiao, Y., Li, D., and Li, W. (2017). Effects of tea polyphenol combined with nisin on the quality of weever (Lateolabrax japonicus) in the initial stage of fresh-frozen or chilled storage state. J. Aquat. Food Product Technol. 26, 543-552. doi: 10.1080/10498850.2016.1233472

Junior, R. F. R., Dabkowski, E. R., Shekar, K. C., O'Connell, K. A., Hecker, P. A., and Murphy, M. P., (2018). MitoQ improves mitochondrial dysfunction in heart failure induced by presure overload. Free Radic. Biol. Med. 117, 18-29. doi: 10.1016/j.freeradbiomed.2018.01.012

Kabera, J. N., Semana, E., Mussa, A. R., and He, X. (2014). Plant secondary metabolites: biosynthesis, classification, function and pharmacological properties. J. Pharm. Pharmacol. 2, 377-392.

Karadas, F., Erdogan, S., Kor, D., Oto, G., and Uluman, M. (2016). The effects of different types of antioxidants (Se, vitamin $\mathrm{E}$ and carotenoids) in broiler diets on the growth performance, skin pigmentation and liver and plasma antioxidant concentrations. Revista Brasileira de Ciencia Avicola 18, 101-116. doi: 10.1590/18069061-2015-0155

Kawahara, K., Hohjoh, H., Inazumi, T., Tsuchiya, S., and Sugimoto, Y. (2015). Prostaglandin E 2-induced inflammation: Relevance of prostaglandin E receptors. Biochimica et Biophysica Acta (BBA)-Mol. Cell Biol. Lipids 1851, 414-421. doi: 10.1016/j.bbalip.2014.07.008

Khanna, S., Parinandi, N. L., Kotha, S. R., Roy, S., Rink, C., Bibus, D., et al. (2010). Nanomolar vitamin E $\alpha$-tocotrienol inhibits glutamate-induced activation of phospholipase A2 and causes neuroprotection. J. Neurochem. 112, 1249-1260. doi: $10.1111 /$ j.1471-4159.2009.06550.x

Kiesel, V. A., and Stan, S. D. (2017). Diallyl trisulfide, a chemopreventive agent from Allium vegetables, inhibits alpha-secretases in breast cancer cells. Biochem. Biophys. Res. Commun. 484, 833-838. doi: 10.1016/j.bbrc.2017.01.184

Kim, A. D., Zhang, R., Han, X., Kang, K. A., Piao, M. J., Maeng, Y. H., et al. (2015). Involvement of glutathione and glutathione metabolizing enzymes in human colorectal cancer cell lines and tissues. Mol. Med. Rep. 12, 4314-4319. doi: $10.3892 / \mathrm{mmr} .2015 .3902$

Kim, H. J., Jung, K. J., Yu, B. P., Cho, C. G., Choi, J. S., and Chung, H. Y. (2002). Modulation of redox-sensitive transcription factors by calorie restriction during aging. Mech. Ageing Dev. 123, 1589-1595. doi: 10.1016/S0047-6374(02)00094-5

Kim, J., Lee, S. D., Chang, B., Jin, D. H., Jung, S. I., Park, M. Y., et al. (2012). Enhanced antitumor activity of vitamin C via p53 in cancer cells. Free Radic. Biol. Med. 53, 1607-1615. doi: 10.1016/j.freeradbiomed.2012.07.079

Kim, J. S., Lee, W. M., Rhee, H. C., and Kim, S. (2016). Red paprika (Capsicum annuum L.) and its main carotenoids, capsanthin and $\beta$ carotene, prevent hydrogen peroxide-induced inhibition of gap-junction intercellular communication. Chemico-Biol. Interac. 254, 146-155. doi: 10.1016/j.cbi.2016.05.004

Kim, K.-M., Chun, S.-B., Koo, M.-S., Choi, W.-J., Kim, T.-W., Kwon, Y.-G., et al. (2001). Differential regulation of NO availability from macrophages and endothelial cells by the garlic component S-allyl cysteine. Free Radic. Biol. Med. 30, 747-756. doi: 10.1016/S0891-5849(01)00460-9

Kishimoto, Y., Taguchi, C., Saita, E., Suzuki-Sugihara, N., Nishiyama, H., Wang, W., et al. (2017). Additional consumption of one egg per day increases serum lutein plus zeaxanthin concentration and lowers oxidized low-density lipoprotein in moderately hypercholesterolemic males. Food Res. Int. 99, 944-949. doi: 10.1016/j.foodres.2017.03.003

Knorre, D. G., Kudryashova, N. V., and Godovikova. (2009). Chemical and functional aspects of posttranslational modification of proteins. Acta Naturae $1,29-51$.

Kodai, S., Takemura, S., Kubo, S., Azuma, H., and Minamiyama, Y. (2015). Therapeutic administration of an ingredient of aged-garlic extracts, S-allyl cysteine resolves liver fibrosis established by carbon tetrachloride in rats. J. Clin. Biochem. Nutr. 56, 179-185. doi: 10.3164/jcbn.14-108

Kovacic, P., and Somanathan, R. (2011). Cell signaling and receptors with resorcinols and flavonoids: redox, reactive oxygen species, and physiological effects. J. Recept. Signal Transduct. 31, 265-270. doi: 10.3109/10799893.2011.586353

Krishnaraj, R. N., Kumari, S. S., and Mukhopadhyay, S. S. (2016). Antagonistic molecular interactions of photosynthetic pigments with molecular disease targets: a new approach to treat AD and ALS. J. Recept. Signal Transduct. 36, 67-71. doi: 10.3109/10799893.2015. 1024851

Kwak, H. J., Yang, D., Hwang, Y., Jun, H.-S., and Cheon, H. G. (2017). Baicalein protects rat insulinoma INS-1 cells from palmitate-induced lipotoxicity by inducing HO-1. PLoS One 12:e0176432. doi: 10.1371/journal.pone.0176432

Lai, Y. S., Chen, W. C., Ho, C. T., Lu, K. H., Lin, S. H., Tseng, H. C., et al. (2014). Garlic essential oil protects against obesity-triggered nonalcoholic fatty liver disease through modulation of lipid metabolism and oxidative stress. J. Agric. Food Chem. 62, 5897-5906. doi: 10.1021/jf500803c

Lane, M. L., and Vesely, D. L. (2013). Reduction of leptin levels by four cardiac hormones: Implications for hypertension in obesity. Exp. Ther. Med. 6, 611-615. doi: 10.3892/etm.2013.1173

Lash, L. H. (2015). Mitochondrial glutathione in diabetic nephropathy. J. Clin. Med. 4, 1428-1447. doi: 10.3390/jcm4071428

Lee, B. J., Tseng, Y. F., Yen, C. H., and Lin, P. T. (2013). Effects of coenzyme Q10 supplementation (300 mg/day) on antioxidation and antiinflammation in coronary artery disease patients during statins therapy: a randomized, placebo-controlled trial. Nutr. J. 12, 142. doi: 10.1186/1475-2891$12-142$

Leermakers, E. T., Darweesh, S. K., Baena, C. P., Moreira, E. M., Melo van Lent, D., Tielemans, M. J., et al. (2016). The effects of lutein on cardiometabolic health across the life course: a systematic review and meta-analysis, 2. Am. J. Clin. Nutr. 103, 481-494. doi: 10.3945/ajcn.115.120931 
Lei, L., and Liu, Y. (2017). Efficacy of coenzyme Q10 in patients with cardiac failure: a meta-analysis of clinical trials. BMC Cardiovasc. Disord. 17:196. doi: 10.1186/s12872-017-0628-9

Lennicke, C., Rahn, J., Lichtenfels, R., Wessjohann, L. A., and Seliger, B. (2015). Hydrogen peroxide-production, fate and role in redox signaling of tumor cells. Cell Commun. Signal. 13:39. doi: 10.1186/s12964-015-0118-6

Limón-Pacheco, J. H., Hernandez, N. A., Fanjul-Moles, M. L., and Gonsebatt, M. E. (2007). Glutathione depletion activates mitogen-activated protein kinase (MAPK) pathways that display organ-specific responses and brain protection in mice. Free Radic. Biol. Med. 43, 1335-1347.

Lin, H.-C., Lin, M.-H., Liao, J.-H., Wu, T.-H., Lee, T.-H., Mi, F.-L., et al. (2017). Antroquinonol, a ubiquinone derivative from the mushroom Antrodia camphorata, inhibits colon cancer stem cell-like properties: insights into the molecular mechanism and inhibitory targets. J. Agric. Food Chem. 65, 51-59. doi: 10.1021/acs.jafc.6b04101

Littarru, G. P., and Tiano, L. (2007). Bioenergetic and antioxidant properties of coenzyme Q 10: recent developments. Mol. Biotechnol. 37, 31-37.

Liu, B., Wang, J., Chan, K. M., Tjia, W. M., Deng, W., Guan, X., et al. (2005). Genomic instability in laminopathy-based premature aging. Nat. Med. 11, 780-785.

Liu, K. L., Chen, H.-W., Wang, R.-Y., Lei, Y.-P., Sheen, L.-Y., and Lii, C.-K. (2006). DATS reduces LPS-induced iNOS expression, NO production, oxidative stress, and NF-kB activation in RAW 264.7 macrophages. J. Agric. Food Chem. 54, 3472-3478. doi: 10.1021/jf060043k

Liu, X., Chen, K., Zhu, L., Liu, H., Ma, T., Xu, Q., et al. (2018a). Soyasaponin $\mathrm{Ab}$ protects against oxidative stress in HepG2 cells via $\mathrm{Nrf} 2 / \mathrm{HO}-1 / \mathrm{NQO} 1$ signaling pathways. J. Funct. Foods 45, 110-117. doi: 10.1016/j.jff.2018. 03.037

Liu, X., Murphy, M. P., Xing, W., Wu, H., Zhang, R., et al. (2018b). Mitochondria-targeted antioxidant MitoQ reduced renal damage caused by ischemia-reperfusion injury in rodent kidneys: Longitudinal observations of $\mathrm{T}_{2}$-weighted imaging and dynamic contrast-enhanced MRI. Magn. Reson. Med.79, 1559-1567. doi: 10.1002/mrm.26772

Liu, Y., Rusinol, A., Sinensky, M., Wang, Y., and Zou, Y. (2006). DNA damage responses in progeroid syndromes arise from defective maturation of prelamin A. J. Cell Sci.119, 4644-4649. doi: 10.1242/jcs. 03263

Liu, Z., Zhou, T., Ziegler, A. C., Dimitrion, P., and Zuo, L. (2017). Oxidative stress in neurodegenerative diseases: from molecular mechanisms to clinical applications. Oxid. Med. Cell. Longev. 2017:2525967. doi: $10.1155 / 2017 / 2525967$

Llorente, B., Martinez-Garcia, J. F., Stange, C., and Rodriguez-Concepcion, M. (2017). Illuminating colors: regulation of carotenoid biosynthesis and accumulation by light. Curr. Opin. Plant Biol. 37, 49-55. doi: 10.1016/j.pbi.2017.03.011

Lohan, S. B., Vitt, K., Scholz, P., Keck, C. M., and Meinke, M. C. (2018). ROS production and glutathione response in keratinocytes after application of $\beta$-carotene and VIS/NIR irradiation. Chemico Biol. Interac. 280, 1-7. doi: 10.1016/j.cbi.2017.12.002

Lonn, E., Bosch, J., Yusuf, S., Sheridan, P., Pogue, J., Arnold, J. M., et al. (2005). Effects of long-term vitamin E supplementation on cardiovascular events and cancer: a randomized controlled trial. JAMA 293, 1338-1347. doi: 10.1001/jama.293.11.1338

López-Otín, C., Blasco, M. A., Partridge, L., Serrano, M., and Kroemer, G. (2013). The hallmarks of aging. Cell. 153, 1194-1217. doi: 10.1016/j.cell.2013. 05.039

Lu, S., Wu, D., Li, G., Lv, Z., Chen, Z., Chen, L., et al. (2016). Carbon dotsbased ratiometric nanosensor for highly sensitive and selective detection of mercury (II) ions and glutathione. RSC Adv. 6, 103169-103177. doi: 10.1039/C6RA21309J

Lu, S. C., Mato, J. M., Espinosa-Diez, C., and Lamas, S. (2016). MicroRNAmediated regulation of glutathione and methionine metabolism and its relevance for liver disease. Free Radic. Biol. Med. 100, 66-72. doi: 10.1016/j.freeradbiomed.2016.03.021

Lu, T. M., Chiu, H. F., Shen, Y. C., Chung, C. C., Venkatakrishnan, K., and Wang, C.-K. (2015). Hypocholesterolemic efficacy of quercetin rich onion juice in healthy mild hypercholesterolemic adults: a pilot study. Plant Foods Human Nutr. 70, 395-400. doi: 10.1007/s11130-015-0507-4
Ma, H.-B., Huang, S., Yin, X.-R., Zhang, Y., and Di, Z.-L. (2014). Apoptotic pathway induced by diallyl trisulfide in pancreatic cancer cells. World Journal of Gastroenterology: World J. Gastrol. 20:193. doi: 10.3748/wjg.v20.i1.193

Ma, L., Liu, R., Du, J. H., Liu, T., Wu, S. S., and Liu, X. H. (2016). Lutein, zeaxanthin and meso-zeaxanthin supplementation associated with macular pigment optical density. Nutrients 8:426. doi: 10.3390/nu8070426

Ma, Y., Chapman, J., Levine, M., Polireddy, K., Drisko, J., and Chen, Q. (2014). High-dose parenteral ascorbate enhanced chemosensitivity of ovarian cancer and reduced toxicity of chemotherapy. Sci. Transl. Med. 6, 218-222. doi: $10.1126 /$ scitranslmed.3007154

Macielag, M. J. (2012). "Chemical properties of antimicrobials and their uniqueness," in Antibiotic Discov. Dev. Springer), 793-820.

Malaquin, N., Carrier-Leclerc, A., Dessureault, M., and Rodier, F. (2015). DDRmediated crosstalk between DNA damaged cells and their microenvironment. Front. Genet. 6:94. doi: 10.3389/fgene.2015.00094

Mantle, D. (2017). Coenzyme Q10 supplementation for diabetes and its complications: an overview. Br. J. Diabetes 17, 145-148. doi: $10.15277 /$ bjd.2017.149

Manu, K. A., Shanmugam, M. K., Ramachandran, L., Li, F., Siveen, K. S., Chinnathambi, A., et al. (2015). Isorhamnetin augments the anti-tumor effect of capeciatbine through the negative regulation of NF- $\mathrm{kB}$ signaling cascade in gastric cancer. Cancer Lett. 363, 28-36. doi: 10.1016/j.canlet.2015.03.033

Marchioli, R., Levantesi,G., Macchia, A., Marfisi, R. M., and Nicolosi, G. L., Tavazzi, L., et al. (2006). Vitamin $\mathrm{E}$ increases the risk of developing heart failure after myocardial infarction: results from the GISSI-Prevenzione trial. J. Cardiovasc. Med. (Hagerstown) 7, 347-350. doi: 10.2459/01.JCM.0000223257.09062.17

Maria, A. G., Graziano, R., and Nicolantonio, D. O. (2015). Carotenoids: potential allies of cardiovascular health? Food Nutr. Res. 59:26762. doi: $10.3402 /$ fnr.v59.26762

Marklund, S. R., Westman, N. G., Lundgren, E., and Ross, G. (1982). Copperand zinc-containing superoxide-dismutase, manganese-containing superoxide dismutase, catalase and gtutathione peroxidase in normal and neoplastic human cell lines and normal tissue. Cancer Res. 42, 1955-1961.

Marreiro, D. D., Cruz, K. J., Morais, J. B., Beserra, J. B., Severo, J. S., and de Oliveira, A. R. S. (2017). Zinc and oxidative stress: current mechanisms. Antioxidants 6:24. doi: $10.3390 /$ antiox6020024

Martina, V., Bruno, G., Zumpano, E., Origlia, C., Quaranta, L., and Pescarmona, G. (2001). Administration of glutathione in patients with type 2 diabetes mellitus increases the platelet constitutive nitric oxide synthase activity and reduces PAI-1. J. Endocrinol. Invest. 24, 37-41. doi: 10.1007/BF03343806

Masisi, K., Beta, T., and Moghadasian, M. H. (2016). Antioxidant properties of diverse cereal grains: A review on in vitro and in vivo studies. Food Chem. 196, 90-97. doi: 10.1016/j.foodchem.2015.09.021

Maurya, A. K., and Vinayak, M. (2015). Anticarcinogenic action of quercetin by downregulation of phosphatidylinositol 3-kinase (PI3K) and protein kinase C (PKC) via induction of p53 in hepatocellular carcinoma (HepG2) cell line. Mol. Biol. Rep. 42, 1419-1429. doi: 10.1007/s11033-015-3921-7

May, J. M., and Harrison, F. E. (2013). Role of vitamin C in the function of the vascular endothelium. Antioxid. and Redox Signal. 19, 2068-2083. doi: 10.1089 /ars.2013.5205

Michaud, M., Balardy, L., Moulis, G., Gaudin, C., Peyrot, C., Vellas, B., et al. (2013). Proinflammatory cytokines, aging, and age-related diseases. J. Am. Med. Direct. Assoc. 14, 877-882. doi: 10.1016/j.jamda.2013.05.009

Michels, A. J., and Hagen, T. M. (2004). Vitamin C status decline with age. Vitamin C: its function and biochemistry in animals and plants. Garland Science/BIOS Scientific Publishers, 203-228.

Mikulewicz, M., Chojnacka, K., Kawala, B., and Gredes, T. (2017). Trace elements in living systems: from beneficial to toxic effects. BioMed Res. Int. 2017:8297814. doi: 10.1155/2017/8297814doi: 10.1155/2017/8297814

Mills, B. J., Weiss, M. M., Lang, C. A., Liu, M. C., and Ziegler, C. (2000). Blood glutathione and cysteine changes in cardiovascular disease. J. Lab. Clin. Med. 135, 396-401. doi: $10.1067 / \mathrm{mlc} .2000 .105976$

Min, J. Y., and Min, K. B. (2014). Serum lycopene, lutein and zeaxanthin, and the risk of Alzheimer's disease mortality in older adults. Dement. Geriatr. Cogn. Disord. 37, 246-256. doi: 10.1159/000356486

Mironczuk-Chodakowska, I., Witkowska, A. M., and Zujko, M. E. (2018). Endogenous non-enzymatic antioxidants in the human body. Adv. Med. Sci. 63, 68-78. doi: 10.1016/j.advms.2017.05.005 
Mischley, L. K., Leverenz, J. B., Lau, R. C., Polissar, N. L., Neradilek, M. B., Samii, A., et al. (2015). A randomized, double-blind phase I/IIa study of intranasal glutathione in Parkinson's disease. Movement Disord. 30, 1696-1701. doi: $10.1002 / \mathrm{mds} .26351$

Mischley, L. K., Vespignani, M. F., and Finnell, J. S. (2013). Safety survey of intranasal glutathione. J. Altern. Complem. Med. 19, 459-463. doi: $10.1089 / \mathrm{acm} .2011 .0673$

Mohamad, S., Shuid, A. N., Mohamed, N., Fadzilah, F. M., Mokhtar, S. A., Abdullah, S., et al. (2012). The effects of alpha-tocopherol supplementation on fracture healing in a postmenopausal osteoporotic rat model. Clin. 67, 1077-1085. doi: 10.6061/clinics/2012(09)16

Mohammadzadeh Honarvar, N. Saedisomeolia, A., Abdolahi, M., Shayeganrad, A., Sangsari, G. T., Rad, B. H., et al. (2017). Molecular antiinflammatory mechanisms of retinoids and carotenoids in Alzheimer's disease: A review of current evidence. J. Mol. Neurosci. 61, 289-304. doi: 10.1007/s12031-016-0857-x

Moldogazieva, N. T., Mokhosoev, I. M., Feldman, N. B., and Lutsenko, S. K. (2018). ROS and RNS signalling: adaptive redox switches through oxidative/nitrosative protein modifications. Free Redic. Res. 52, 507-543. doi: 10.1080/10715762.2018.1457217

Morris, M. C., Evans, D. A., Tangney, C. C., Bienias, J. L., Wilson, R. S., Aggarwal, N. T., et al. (2005). Relation of the tocopherol forms to incident Alzheimer disease and to cognitive change. Am. J. Clin. Nutr. 81, 508-514. doi: 10.1093/ajcn.81.2.508

Morris-Naumann, F. L., and Wark, J. D. (2015). "Exercise, nutrition, and bone health," in Nutr. Bone Health. Springer), 543-560.

Moser, M. A., and Chun, O. K. (2016). Vitamin C and heart health: a review based on findings from epidemiologic studies. Int. J. Mol. Sci. 17:1328. doi: 10.3390/ijms17081328

Motohashi, N., Gallagher, R., Anuradha, V., and Gollapudi, R. (2017). Co-enzyme Q10 (Ubiquinone): It's implication in improving the life style of the elderly. Med. Clin. Rev. 3:10. doi: 10.21767/2471-299X.1000052

Muhammad, N., Luke, D. A., Shuid, A. N., Mohamed, N., and Soelaiman, I. N. (2012). Two different isomers of vitamin e prevent bone loss in postmenopausal osteoporosis rat model. Evid-based Complem. Altern. Med. 2012, article ID 161527, 7 pages. doi: 10.1155/2012/161527

Murphy, M. P., and Smith, R. A. (2007). Targeting antioxidants to mitochondria by conjugation to lipophilic cations. Annu. Rev. Pharmacol. Toxicol. 47, 629-656. doi: 10.1146/annurev.pharmtox.47.120505.105110

Nadadur, M., Stanczyk, F. Z., Tseng, C.-C., Kim, L., and Wu, A. H. (2016). The effect of reduced dietary fat and soy supplementation on circulating adipocytokines in postmenopausal women: a randomized controlled 2-month trial. Nutr. Cancer 68, 554-559. doi: 10.1080/01635581.2016. 1158294

Nagpala, E. G., Guidarelli, M., Gasperotti, M., Masuero, D., Bertolini, P., Vrhovsek, U., et al. (2016). Polyphenols variation in fruits of the susceptible strawberry cultivar alba during ripening and upon fungal pathogen interaction and possible involvement in unripe fruit tolerance. J. Agric. Food Chem. 64, 1869-1878. doi: 10.1021/acs.jafc.5b06005

Nahar, K., Hasanuzzaman, M., Alam, M. M., and Fujita, M. (2015). Exogenous glutathione confers high temperature stress tolerance in mung bean (Vigna radiata L.) by modulating antioxidant defense and methylglyoxal detoxification system. Environm. Exp. Botany 112, 44-54. doi: 10.1016/j.envexpbot.2014.12.001

Nakazato, R., Arsanjani, R., Achenbach, S., Gransar, H., Cheng, V. Y., Dunning, A., et al. (2014). Age-related risk of major adverse cardiac event risk and coronary artery disease extent and severity by coronary CT angiography: results from 15 187 patients from the International Multisite CONFIRM Study. Eur. Heart J. Cardiovasc. Imaging 15, 586-594. doi: 10.1093/ehjci/jet132

Nascimento-Souza, M. A., de Paiva, P. G., Pérez-Jiménez, J., do Carmo Castro Franceschini, S. and Ribeiro, A. Q. (2018). Estimated dietary intake and major food sources of polyphenols in elderly of Viçosa, Brazil: a population-based study. Eur. J. Nutr. 57, 617-627. doi: 10.1007/s00394-016-1348-0

Nguyen, A., Loo, J. M., Mital, R., Weinberg, E. M., Man, F. Y., Zeng, Z., et al. (2016). PKLR promotes colorectal cancer liver colonization through induction of glutathione synthesis. J. Clin. Invest. 126, 681-694. doi: 10.1172/JCI83587

Nile, S. H., Ko, E. Y., Kim, D. H., and Keum, Y.-S. (2016). Screening of ferulic acid related compounds as inhibitors of xanthine oxidase and cyclooxygenase-2 with anti-inflammatory activity. Revista Brasileira de Farmacognosia 26, 50-55. doi: 10.1016/j.bjp.2015.08.013

Nishino, A., Yasui, H., and Maoka, T. (2016). Reaction of paprika carotenoids, capsanthin and capsorubin, with reactive oxygen species. J. Agric. Food Chem. 64, 4786-4792. doi: 10.1021/acs.jafc.6b01706

Nita, M., and Grzybowski, A. (2016). The role of the reactive oxygen species and oxidative stress in the pathomechanism of the age-related ocular diseases and other pathologies of the anterior and posterior eye segments in adults. Oxid. Med. Cell. Longev. 2016, article ID 3164734, 23 pages. doi: $10.1155 / 2016 / 3164734$

Nunes, M. A., Pimentel, F., Costa, A. S., Alves, R. C., and Oliveira, M. B. P. (2016). Cardioprotective properties of grape seed proanthocyanidins: An update. Trends Food Sci. Technol. 57, 31-39. doi: 10.1016/j.tifs.2016.08.017

Nwachukwu, I. D., Slusarenko, A. J., and Gruhlke, M. (2012). Sulfur and sulfur compounds in plant defence. Nat. Product Commun. 7, 395-400.

Oboh, G., Bakare, O., Ademosun, A., Akinyemi, A., and Olasehinde, T. (2015). Inhibition of cholinesterases and some pro-oxidant induced oxidative stress in rats brain by two tomato (Lycopersicon esculentum) varieties. Int. J. Biomed. Sci.: IJBS 11:48.

Oleck, S., and Ventura, H. O. (2016). Coenzyme Q10 and utility in heart failure: just another supplement? Curr. Heart Failure Rep. 13, 190-195. doi: 10.1007/s11897-016-0296-6

Olivieri, F., Albertini, M. C., Orciani, M., Ceka, A., Cricca, M., Procopio, A. D., et al. (2015). DNA damage response (DDR) and senescence: Shuttled inflamma-miRNAs on the stage of inflamm-aging. Oncotarget 6, 35509-35521. doi: 10.18632/oncotarget.5899

Omenn, G. S., Goodman, G., Thornquist, M., Grizzle, J., Rosenstock, L., et al. (1994). The $\beta$-carotene and retinol efficacy trial (CARET) for chemoprevention of lung cancer in high risk populations: smokers and asbestos-exposed workers. Cancer Res. 54, 2038s-2043s

Ono, K., and Yamada, M. (2012). Vitamin A and Alzheimer's disease. Geriatrics Gerontol. Int. 12, 180-188. doi: 10.1111/j.1447-0594.2011.00786.x

Osorio, F. G., Navarro, C. L., Cadiñanos, J., López-Mejía, I. C., Quirós, P. M., Bartoli, C., et al. (2011). Splicing-directed therapy in a new mouse model of human accelerated aging. Sci. Transl. Med. 3, 106-107. doi: 10.1126/scitranslmed.3002847

Oyewole, A. O., and Birch-Machin, M. A. (2015). Mitochondria-targeted antioxidants. FASEB J. 29, 4766-4771. doi: 10.1096/fj.15-275404

Ozer, N. K., Negis, Y., Aytan, N., Villacorta, L., and Ricciarelli, R., Zingg, J.-M., et al. (2006). Vitamin E inhibits CD36 scavenger receptor expression in hypercholesterolemic rabbits. Atherosclerosis 184, 15-20. doi: 10.1016/j.atherosclerosis.2005.03.050

Pak, O., Scheibe, S., Esfandiary, A., Gierhardt, M., Sydykov, A., Logan, A., et al. (2018). Impact of the mitochondria-targeted antioxidant MitoQ on hypoxia-induced pulmonary hypertension. Eur. Respir. J. 51, 1701024. doi: 10.1183/13993003.01024-2017

Paliwal, C., Ghosh, T., George, B., Pancha, I., Maurya, R., Chokshi, K., et al. (2016). Microalgal carotenoids: Potential nutraceutical compounds with chemotaxonomic importance. Algal Res. 15, 24-31. doi: 10.1016/j.algal.2016.01.017

Panche, A., Diwan, A., and Chandra, S. (2016). Flavonoids: an overview. J Nutr. Sci. 5. doi: 10.1017/jns.2016.41

Park, H.-A., Kubicki, N., Gnyawali, S., Chan, Y. C., Roy, S., Khanna, S., et al. (2011). Natural vitamin E $\alpha$-tocotrienol protects against ischemic stroke by induction of multidrug resistance-associated protein 1. Stroke 42, 2308-2314. doi: 10.1161/STROKEAHA.110.608547

Park, K. S., Ahn, Y., Kim, J. A., Yun, M. S., Seong, B. L., and Choi, K. Y. (2002). Extracellular zinc stimulates ERK-dependent activation of p21Cip/WAF1 and inhibits proliferation of colorectal cancer cells. Br. J. Pharmacol. 137, 597-607. doi: 10.1038/sj.bjp.0704909

Peres, H. A., Foss, M. C. F., and Pereira, L. R. L. (2017). The role of coenzyme Q10 supplementation with statin drug use and chronic diseases. J. Infect. Dis. Prev. Med. 5:157. doi: 10.4172/2329-8731.1000157

Pérez, V. I., Bokov, A., Van Remmen, H., Mele, J., Ran, Q., Ikeno, Y., et al. (2009a). Is the oxidative stress theory of aging dead? Biochim. Biophys. Acta. 1790, 1005-1014. doi: 10.1016/j.bbagen.2009.06.003

Pérez, V. I., Buffenstein, R., Masamsetti, V., Leonard, S., Salmon, A. B., Mele, J., et al. (2009b). Protein stability and resistance to oxidative stress are 
determinants of longevity in the longest-living rodent, the naked mole-rat. Proc. Natl. Acad. Sci. U S A. 106, 3059-3064. doi: 10.1073/pnas.0809620106

Perrone, S., Tei, M., Longini, M., and Buonocore, G. (2016). The multiple facets of lutein: A call for further investigation in the perinatal period. Oxid. Med. Cell. Longev. 2016:5381540. doi: 10.1155/2016/ 5381540

Petropoulos, S., Di Gioia, F., and Ntatsi, G. (2017). Vegetable organosulfur compounds and their health promoting effects. Curr. Pharm. Design 23, 2850-2875. doi: $10.2174 / 1381612823666170111100531$

Pietta, P. G. (2000). Flavonoids as antioxidants. J. Nat. Products 63, 1035-1042.

Pisoschi, A. M., and Pop, A. (2015). The role of antioxidants in the chemistry of oxidative stress: A review. Eur. J. Med. Chem. 97, 55-74. doi: 10.1016/j.ejmech.2015.04.040

Podda, M., and Grundmann-Kollmann, M. (2001). Low molecular weight antioxidants and their role in skin ageing. Clin. Exp. Dermatol. 26, 578-582. doi: 10.1046/j.1365-2230.2001.00902.x

Prattichizzo, F., Bonaf,è, M., Ceka, A., Giuliani, A., Rippo, M. R., Re, M., et al. (2016). Endothelial cell senescence and inflammaging: MicroRNAs as biomarkers and innovative therapeutic tools. Curr. Drug Targets 17, 388-397. doi: 10.2174/1389450116666150804105659

Pravst, I., Žmitek, K., and Žmitek, J. (2010). Coenzyme Q10 contents in foods and fortification strategies. Crit. Rev. Food Sci. Nutr. 50, 269-280. doi: $10.1080 / 10408390902773037$

Price, K., Price, C., and Reynolds, R. (1996). Hyperglycemiainduced latent scurvy and atherosclerosis: the scorbutic-metaplasia hypothesis. Med. Hypotheses 46, 119-129. doi: 10.1016/S0306-9877(96) 90011-0

Puzianowska-Kuznicka, M., Owczarz, M., Wieczorowska-Tobis, K., Nadrowski, P., Chudek, J., Slusarczyk, P., et al. (2016). Interleukin-6 and C-reactive protein, successful aging, and mortality: the PolSenior study. Immun. Ageing 13:21, doi: 10.1186/s12979-016-0076-x

Quinzii, C. M., DiMauro, S., and Hirano, M. (2007). Human coenzyme Q10 deficiency. Neurochem. Res. 32, 723-727. doi: 10.1007/s11064-006-9190-z

Rafi, M. M., Kanakasabai, S., Gokarn, S. V., Krueger, E. G., and Bright, J. J. (2015). Dietary lutein modulates growth and survival genes in prostate cancer cells. J. Med. Food 18, 173-181. doi: 10.1089/jmf.2014. 0003

Ramdath, D. D., Padhi, E. M., Sarfaraz, S., Renwick, S., and Duncan, A. M. (2017). Beyond the cholesterol-lowering effect of soy protein: a review of the effects of dietary soy and its constituents on risk factors for cardiovascular disease. Nutrients 9:324. doi: 10.3390/nu9040324

Rao, L. G., and Rao, A. V. (2015). "Oxidative stress and antioxidants in the risk of osteoporosis-role of phytochemical antioxidants lycopene and polyphenol-containing nutritional supplements," in Phytochemicals-Isolation, Characterisation and Role in Human Health. InTech).

Rashid, S. (2017). "Major mediators linking inflammation and cancer," in Cancer and Chemoprevention: An Overview. Springer), 35-45.

Rasines-Perea, Z., and Teissedre, P. L. (2017). Grape polyphenols' effects in human cardiovascular diseases and diabetes. Mol. 22: 68. doi: $10.3390 /$ molecules 22010068

Raygan, F., Rezavandi, Z., Tehrani, S. D., Farrokhian, A., and Asemi, Z. (2016). The effects of coenzyme Q10 administration on glucose homeostasis parameters, lipid profiles, biomarkers of inflammation and oxidative stress in patients with metabolic syndrome. Eur. J. Nutr. 55, 2357-2364. doi: 10.1007/s00394-015-1042-7

Reczek, C. R., and Chandel, N. S. (2015). ROS-dependent signal transduction. Curr. Opin. Cell Biol. 33, 8-13. doi: 10.1016/j.ceb.2014.09.010

Ricordi, C., Garcia-Contreras, M., and Farnetti, S. (2015). Diet and inflammation: possible effects on immunity, chronic diseases, and life span. J. Am. Coll. Nutr. 34, 10-13. doi: 10.1080/07315724.2015.1080101

Rimm, E. B., Stampfer, M. J., Ascherio, A., Giovannucci, E., Colditz, G. A., and Willett, W. C. (1993). Vitamin E consumption and the risk of coronary heart disease in men. New Engl. J. Med. 328, 1450-1456. doi: 10.1056/NEJM199305203282004

Roohbakhsh, A., Parhiz, H., Soltani, F., Rezaee, R., and Iranshahi, M. (2015). Molecular mechanisms behind the biological effects of hesperidin and hesperetin for the prevention of cancer and cardiovascular diseases. Life Sci. 124, 64-74. doi: 10.1016/j.lfs.2014.12.030
Rossato, M. F., Hoffmeister, C., Tonello, R., de Oliveira Ferreira, A. P., and Ferreira, J. (2015). Anti-inflammatory effects of vitamin $\mathrm{E}$ on adjuvant-induced arthritis in rats. Inflamm. 38, 606-615. doi: 10.1007/s10753-014-9967-1

Rotar, O., Tenedja, K., Arkhelyuk, A., Rotar, V., Davidencko, I., and Fediv, V. (2014). Preparation of chitosan nanoparticles loaded with glutathione for diminishing tissue ischemia-reperfusion injury. Int. J. Adv. Eng. Nano Technol. $1,19-23$.

Ruszkiewicz, J., and Albrecht, J. (2015). Changes in the mitochondrial antioxidant systems in neurodegenerative diseases and acute brain disorders. Neurochem. Int. 88, 66-72. doi: 10.1016/j.neuint.2014.12.012

Sachdeva, A. K., and Chopra, K. (2015). Lycopene abrogates A $\beta$ (1-42)-mediated neuroinflammatory cascade in an experimental model of Alzheimer's disease. $J$. Nutr. Biochem. 26, 736-744. doi: 10.1016/j.jnutbio.2015.01.012

Sambu, N. K., Kashinath, R., and Ambekar, J. (2015). Effect of diallyl disulphide on diabetes induced dyslipidemia in male albino rats. J. Clin. Diagn. Res.: JCDR 9:BF01. doi: 10.7860/JCDR/2015/13374.5860

Sandireddy, R., Yerra, V. G., Komirishetti, P., Areti, A., and Kumar, A. (2016). Fisetin imparts neuroprotection in experimental diabetic neuropathy by modulating Nrf2 and NF-кB pathways. Cell. Mol. Neurobiol. 36, 883-892. doi: 10.1007/s10571-015-0272-9

Sandmann, G. (2015). Carotenoids of biotechnological importance. Adv. Biochem. Eng. Biotechnol. 148, 449-467. doi: 10.1007/10_2014_277

Santoro, A., Spinelli, C. C., Martucciello, S., Nori, S. L., Capunzo, M., Puca, A. A., et al. (2018). Innate immunity and cellular senescence: the good and the bad in the developmental and aged brain. J. Leukocyte Biol. 103, 509-524. doi: 10.1002/JLB.3MR0118-003R

Scalbert, A., and Williamson, G. (2000). Dietary intake and bioavailability of polyphenols. J. Nutr. 130, 2073S-2085S. doi: 10.1093/jn/130.8.2073S

Schaus, R. (1957). The ascorbic acid content of human pituitary, cerebral cortex, heart, and skeletal muscle and its relation to age. Am. J. Clin. Nutr. 5, 39-41. doi: $10.1093 / \mathrm{ajcn} / 5.1 .39$

Scheibye-Knudsen, M., Fang, E. F., Croteau, D. L., Wilson, D. M., and Bohr, V. A. (2015). Protecting the mitochondrial powerhouse. Trends Cell Biol. 25, 158-170. doi: 10.1016/j.tcb.2014.11.002

Schieber, M., and Chandel, N. S. (2014). ROS function in redox signaling and oxidative stress. Curr. Biol. 24, R453-R462. doi: 10.1016/j.cub.2014.03.034

Schmidt-Erfurth, U. (2005). "Nutrition and retina," in Nutrition and the Eye. Karger Publishers), 120-147

Schwalfenberg, G. K., and Genuis, S. J. (2015). Vitamin D, essential minerals, and toxic elements: exploring interactions between nutrients and toxicants in clinical medicine. Sci. World J. 2015, article ID 318595, 8 pages, doi: $10.1155 / 2015 / 318595$

Schwingshackl, L., Boeing, H., Stelmach-Mardas, M., Gottschald, M., Dietrich, S., Hoffmann, G., et al. (2017). Dietary supplements and risk of causespecific death, cardiovascular disease, and cancer: A systematic review and meta-analysis of primary prevention trials. Adv. Nutr. 8, 27-39. doi: $10.3945 /$ an. 116.013516

Seki, T., and Hosono, T. (2015). Prevention of cardiovascular diseases by garlic-derived sulfur compounds. J. Nutr. Sci. Vitaminol. 61, S83-S85. doi: $10.3177 /$ jnsv.61.S83

Sen, C. K., Khanna, S., Rink, C., and Roy, S. (2007). Tocotrienols: the emerging face of natural vitamin E. Vitamins Hormones 76, 203-261. doi: 10.1016/S0083-6729(07)76008-9

Serasanambati, M., and Chilakapati, S. R. (2016). Function of nuclear factor kappa B (NF-kB) in human diseases-a review. South Ind. J. Biol. Sci. 2, 368-387. doi: 10.22205/sijbs/2016/v2/i4/103443

Servais, S., Boussouar, A., Molnar, A., Douki, T., Pequignot, J. M., and Favier, R. (2009). Age-related sensitivity to lung oxidative stress during ozone exposure. Free Radic. Res. 39, 305-316. doi: 10.1080/107157604000 11098

Settineri, R., Zhou, J., Ji, J., Ellithorpe, R. R., Rosenblatt, S., Jimenez, A., et al. (2018). Hydrogenized water effects on protection of brain cells from oxidative stress and glutamate toxicity. Am. J. Food Nutr. 6, 9-13. doi: 10.12691/ ajfn-6-1-2

Shan, Y., Wei, Z., Tao, L., Wang, S., Zhang, F., Shen, C., et al. (2016). Prophylaxis of diallyl disulfide on skin carcinogenic model via p21-dependent Nrf2 stabilization. Sci. Rep. 6:35676. doi: 10.1038/ srep35676 
Shehzad, A., Lee, J., and Lee, Y. S. (2015). Autocrine prostaglandin E2 signaling promotes promonocytic leukemia cell survival via COX-2 expression and MAPK pathway. BMB Rep. 48:109. doi: 10.5483/BMBRep.2015. 48.2.081

Shi, W. Q., Liu, J., Cao, Y., Zhu, Y. Y., Guan, K., and Chen, Y. M. (2016). Association of dietary and serum vitamin $\mathrm{E}$ with bone mineral density in middle-aged and elderly Chinese adults: a cross-sectional study. Br. J. Nutr. 115, 113-120. doi: 10.1017/S0007114515004134

Shimizu, H., Kiyohara, Y., Kato, I., Kitazono, T., Tanizaki, Y., Kubo, M., et al. (2004). Relationship between plasma glutathione levels and cardiovascular disease in a defined population: the Hisayama study. Stroke 35, 2072-2077. doi: 10.1161/01.STR.0000138022.86509.2d

Shin, D. Y., Kim, G.-Y., Hwang, H. J., Kim, W.-J., and Choi, Y. H. (2014). Diallyl trisulfide-induced apoptosis of bladder cancer cells is caspase-dependent and regulated by PI3K/Akt and JNK pathways. Environm. Toxicol. Pharmacol. 37, 74-83. doi: 10.1016/j.etap.2013.11.002

Shokolenko, I. N., Wilson, G. L., and Alexeyev, M. F. (2014). Aging: a mitochondrial DNA perspective, critical analysis and an update. World J. Exp. Med. 4:46.

Shokoohinia, Y., Rashidi, M., Hosseinzadeh, L., and Jelodarian, Z. (2015). Quercetin-3-O- $\beta$-d-glucopyranoside, a dietary flavonoid, protects PC12 cells from $\mathrm{H} 2 \mathrm{O} 2$-induced cytotoxicity through inhibition of reactive oxygen species. Food Chem. 167, 162-167. doi: 10.1016/j.foodchem.2014.06.079

Shuid, A. N., Mehat, Z., Mohamed, N., Muhammad, N., and Soelaiman, I. N. (2010). Vitamin E exhibits bone anabolic actions in normal male rats. J. Bone Mineral Metab. 28, 149-156. doi: 10.1007/s00774-009-0122-2

Shults, C. W., Oakes, D., Kieburtz, K., Beal, M. F., Haas, R., Plumb, S., et al. (2002). Effects of coenzyme Q10 in early Parkinson disease: evidence of slowing of the functional decline. Arch. Neurol. 59, 1541-1550. doi: 10.1001/archneur.59.10.1541

Siddiqui, K., Bawazeer, N., and Scaria Joy, S. (2014). Variation in macro and trace elements in progression of type 2 diabetes. Sci. World J. 2014, article ID 461591, 9 pages. doi: 10.1155/2014/461591

Sifuentes-Franco, S., Pacheco-Moisés, F. P., Rodríguez-Carrizalez, A. D., and Miranda-Díaz, A. G. (2017). The role of oxidative stress, mitochondrial function, and autophagy in diabetic polyneuropathy. J. Diabetes Res. 2017, article ID 1673081, 15 pages, doi: 10.1155/2017/1673081

Singh, S. V., Powolny, A. A., Stan, S. D., Xiao, D., Arlotti, J. A., Warin, R., et al. (2008). Garlic constituent diallyl trisulfide prevents development of poorly differentiated prostate cancer and pulmonary metastasis multiplicity in TRAMP mice. Cancer Res. 68, 9503-9511. doi: 10.1158/0008-5472.CAN-08-1677

Smith, R. A. J., and Murphy, M. P. (2011). Mitochondria-targeted antioxidants as therapies. Discov. Med. 11, 106-114.

Snow, B. J., Rolfe, F. L., Lockhart, M. M., Frampton, C. M., O'Sullivan, J. D., Fung, V., et al. (2010). A double-blind, placebo-controlled study to assess the mitochondria-targeted antioxidant MitoQ as a disease-modifying therapy in Parkinson's disease. Mov Disord. 25, 1670-1674. doi: 10.1002/mds.23148

Sobenin, I. A., Nedosugova, L. V., Filatova, L. V., Balabolkin, M. I., Gorchakova, T. V., and Alexander, N. O. (2008). Metabolic effects of time-released garlic powder tablets in type 2 diabetes mellitus: the results of double-blinded placebo-controlled study. Acta Diabetol. 45, 1-6. doi: 10.1007/s00592-007-0011-x

Sohmiya, M., Tanaka, M., Tak, N. W., Yanagisawa, M., Tanino, Y., Suzuki, Y., et al. (2004). Redox status of plasma coenzyme Q10 indicates elevated systemic oxidative stress in Parkinson's disease. J. Neurol. Sci. 223, 161-166. doi: 10.1016/j.jns.2004.05.007

Spector, R., and Johanson, C. E. (2014). The nexus of vitamin homeostasis and DNA synthesis and modification in mammalian brain. Mol. Brain 7:3. doi: 10.1186/1756-6606-7-3

Sreelakshmi, K., Prathesha, P., Shantikumar, N. V., and Vinoth-Kumar, L. (2018). Comparison and existence of nanotechnology in traditional alternative medicine: an onset to future medicine. Nanosci. Nanotechnol. 8, 13-25. doi: $10.2174 / 2210681206666160402004710$

Stampfer, M. J., Hennekens, C. H., Manson, J. E., Colditz, G. A., Rosner, B., and Willett, W. C. (1993). Vitamin E consumption and the risk of coronary disease in women. New Engl. J. Med. 328, 1444-1449. doi: 10.1056/NEJM199305203282003
Stelmach, I., Grzelewski, T., Bobrowska-Korzeniowska, M., Kopka, M., Majak, P., Jerzynska, J., et al. (2014). "The role of zinc, copper, plasma glutathione peroxidase enzyme, and vitamins in the development of allergic diseases in early childhood: The Polish mother and child cohort study", in: Allergy and asthma proceedings. (OceanSide Publications, Inc), $227-232$

Stephenson, J., Nutma, E., van der Valk, P., and Amor. (2018). Inflammation in CNS neurodegenerative diseases. Immunol.154, 204-219. doi: $10.1111 /$ imm. 12922

Stocker, R., Bowry, V. W., and Frei, B. (1991). Ubiquinol-10 protects human low density lipoprotein more efficiently against lipid peroxidation than does alpha-tocopherol. Proc. Natl. Acad. Sci. U.S.A. 88, 1646-1650.

Su, B., Su, J., Zeng, Y., Liu, F., Xia, H., Ma, Y.-H., et al. (2016). Diallyl disulfide suppresses epithelial-mesenchymal transition, invasion and proliferation by downregulation of LIMK1 in gastric cancer. Oncotarget 7:10498. doi: 10.18632/oncotarget.7252

Swinton, E., de Freitas, E., Swinton, C., Shymansky, T., Hiles, E., Zhang, J., et al. (2018). Green tea and cocoa enhance cognition in Lymnaea. Commun. Integ. Biol. 11:e1434390. doi: 10.1080/19420889.2018.1434390

Tan, B. L., and Norhaizan, M. E. (2017). Scientific evidence of rice by-products for cancer prevention: chemopreventive properties of waste products from rice milling on carcinogenesis in vitro and in vivo. BioMed Res. Int. 2017, article ID 9017902, 18 pages. doi: 10.1155/2017/9017902

Tan, B. L., Norhaizan, M. E., Huynh, K., Heshu, S. R., Yeap, S. K., Hazilawati, H., et al. (2015a). Water extract of brewers rice induces apoptosis in human colorectal cancer cells via activation of caspase- 3 and caspase- 8 and downregulates the $\mathrm{Wnt} / \beta$-catenin downstream signaling pathway in brewers' rice-treated rats with azoxymethane-induced colon carcinogenesis. BMC Complemen. Altern. Med. 15:205. doi: 10.1186/s12906-015-0730-4

Tan, B. L., Norhaizan, M. E., Huynh, K., Yeap, S. K., Hazilawati, H., and Roselina, K. (2015b). Brewers' rice modulates oxidative stress in azoxymethanemediated colon carcinogenesis in rats. World J. Gastroenterol. 21, 8826-8835. doi: $10.3748 /$ wjg.v21.i29.8826

Tan, B. L., Norhaizan, M. E., and Liew, W.-P.-P. (2018). Nutrients and oxidative stress: friend or foe? Oxid. Med. Cell. Longev. 2018, article ID 9719584, 24 pages. doi: 10.1155/2018/9719584

Tang, F., Lu, M., Zhang, S., Mei, M., Wang, T., Liu, P., et al. (2014). Vitamin E conditionally inhibits atherosclerosis in ApoE knockout mice by antioxidation and regulation of vasculature gene expressions. Lipids 49, 1215-1223. doi: 10.1007/s11745-014-3962-z

Tang, Y., Fung, E., Xu, A., and Lan, H. Y. (2017). C-reactive protein and ageing. Clin. Exp. Pharmacol. Physiol. 44, 9-14. doi: 10.1111/1440-1681.12758

Tian, W., Wang, Y., Xu, Y., Guo, X., Wang, B., Sun, L., et al. (2014). The hypoxiainducible factor renders cancer cells more sensitive to vitamin C-induced toxicity. J. Biol. Chem. 289, 3339-3351. doi: 10.1074/jbc.M113.538157

Tofler, G., Massaro, J., O’Donnell, C., Wilson, P. W. F., Vasan, R., Sutherland, P., et al. (2016). Plasminogen activator inhibitor and the risk of cardiovascular disease: The Framingham Heart Study. Thromb. Res. 140, 30-35. doi: 10.1016/j.thromres.2016.02.002

Ugarte, M., Grime, G. W., and Osborne, N. N. (2014). Distribution of trace elements in the mammalian retina and cornea by use of particle-induced $\mathrm{X}$-ray emission (PIXE): localisation of zinc does not correlate with that of metallothioneins. Metallomics 6, 274-278. doi: 10.1039/c3mt00271c

Valderas-Martinez, P., Chiva-Blanch, G., Casas, R., Arranz, S., Martínez-Huélamo, M., Urpi-Sarda, M., et al. (2016). Tomato sauce enriched with olive oil exerts greater effects on cardiovascular disease risk factors than raw tomato and tomato sauce: A randomized trial. Nutrients 8:170. doi: 10.3390/nu8030170

Vashum, K. P., McEvoy, M., Milton, A. H., Islam, M. R., Hancock, S., and Attia, J. (2014). Is serum zinc associated with pancreatic beta cell function and insulin sensitivity in pre-diabetic and normal individuals? Findings from the Hunter Community Study. PLoS ONE 9:e83944. doi: 10.1371/journal.pone.0083944

Veber, D. F., Johnson, S. R., Cheng, H. Y., Smith, B. R., Ward, K. W., and Kopple, K. D. (2002). Molecular properties that influence the oral bioavailability of drug candidates. J. Med. Chem. 45, 2615-2623. doi: 10.1021/jm020017n

Viola, J., and Soehnlein, O. (2015). "Atherosclerosis-a matter of unresolved inflammation”, in: Seminars in immunology: (Elsevier), 184-193.

Vitale, M., Masulli, M., Rivellese, A. A., Bonora, E., Cappellini, F., Nicolucci, A., et al. (2018). Dietary intake and major food sources of polyphenols in 
people with type 2 diabetes: The TOSCA.IT Study. Eur. J. Nutr. 57, 679-688. doi: 10.1007/s00394-016-1355-1

Viteri, G., Chung, Y. W., and Stadtman, E. R. (2010). Effect of progerin on the accumulation of oxidized proteins in fibroblasts from Hutchinson Gilford progeria patients. Mech. Ageing Dev. 131, 2-8. doi: 10.1016/j.mad.2009.11.006

Voronkov, M., Braithwaite, S. P., and Stock, J. B. (2011). Phosphoprotein phosphatase 2A: a novel druggable target for Alzheimer's disease. Future medicinal chemistry 3, 821-833. doi: 10.4155/fmc.11.47

Vuyyuri, S. B., Rinkinen, J., Worden, E., Shim, H., Lee, S., and Davis, K. R. (2013). Ascorbic acid and a cytostatic inhibitor of glycolysis synergistically induce apoptosis in non-small cell lung cancer cells. PLoS One 8:e67081. doi: 10.1371/journal.pone.0067081

Wabitsch, M., Funcke, J. B., von Schnurbein, J., Denzer, F., Lahr, G., Mazen, I., et al. (2015). Severe early-onset obesity due to bioinactive leptin caused by a p. N103K mutation in the leptin gene. J. Clin. Endocrinol. Metab. 100, 3227-3230. doi: 10.1210/jc.2015-2263

Wallace, D. C. (2013). A mitochondrial bioenergetic etiology of disease. J. Clin. Invest. 123, 1405-1412. doi: 10.1172/JCI61398

Wang, F., Wang, N., Gao, Y., Zhou, Z., Liu, W., Pan, C., et al. (2017). $\beta$ carotene suppresses osteoclastogenesis and bone resorption by suppressing NF-кB signaling pathway. Life Sci. 174, 15-20. doi: 10.1016/j.lfs.2017.03.002

Wang, J., Li, L., Wang, Z., Cui, Y., Tan, X., Yuan, T., et al. (2018). Supplementation of lycopene attenuates lipopolysaccharide-induced amyloidogenesis and cognitive impairments via mediating neuroinflammation and oxidative stress. J. Nutr. Biochem. 56, 16-25. doi: 10.1016/j.jnutbio.2018.01.009

Wang, X., Ye, S., and Ge, L. (2015). Analysis of the anticoagulant activity and ingredients of chives. J. Chin. Inst. Food Sci. Technol. 15, 216-222. doi: 10.16429/j.1009-7848.2015.03.029

Wang, Y., Chun, O. K., and Song, W. O. (2013). Plasma and dietary antioxidant status as cardiovascular disease risk factors: a review of human studies. Nutrients 5, 2969-3004. doi: 10.3390/nu5082969

Wang, Y., and Hekimi, S. (2016). Understanding ubiquinone. Trends Cell Biol. 26, 367-378. doi: 10.1016/j.tcb.2015.12.007

Wannamethee, S. G., Bruckdorfer, K. R., Shaper, A. G., Papacosta, O., Lennon, L., and Whincup, P. H. (2013). Plasma vitamin C, but not vitamin E, is associated with reduced risk of heart failure in older men. Circ. Heart Fail. 6, 647-654. doi: 10.1161/CIRCHEARTFAILURE.112.000281

Watts, G. F., Playford, D. A., Croft, K. D., Ward, N. C., Mori, T. A., and Burke, V. (2002). Coenzyme Q(10) improves endothelial dysfunction of the brachial artery in Type II diabetes mellitus. Diabetologia 45, 420-426. doi: 10.1007/s00125-001-0760-y

Weidinger, A., and Kozlov, A. V. (2015). Biological activities of reactive oxygen and nitrogen species: oxidative stress versus signal transduction. Biomolecules 5, 472-484. doi: 10.3390/biom5020472

Weinberg, S. E., Sena, L. A., and Chandel, N. S. (2015). Mitochondria in the regulation of innate and adaptive immunity. Immun. 42, 406-417. doi: 10.1016/j.immuni.2015.02.002

Wen, Y.-D., and Zhu, Y.-Z. (2015). "The pharmacological effects of S-propargylcysteine, a novel endogenous H 2 S-producing compound," in Chemistry, Biochemistry and Pharmacology of Hydrogen Sulfide. Springer), 325-336.

West, K. P. (2015). Epidemiology and prevention of vitamin A deficiency disorders. The Retinoids: Biol., Biochem, and Dis, 505-527. doi: 10.1002/9781118628003.ch23

Winterbourn, C. C. (2016). Revisiting the reactions of superoxide with glutathione and other thiols. Arch. Biochem. Biophys. 595, 68-71. doi: 10.1016/j.abb.2015.11.028

Wojtunik-Kulesza, K. A., Oniszczuk, A., Oniszczuk, T., and WaksmundzkaHajnos, M. (2016). The influence of common free radicals and antioxidants on development of Alzheimer's Disease. Biomed. Pharmacother. 78, 39-49. doi: 10.1016/j.biopha.2015.12.024

Wong, W. L., Su, X., Li, X., Cheung, C. M., Klein, R., Cheng, C.-Y., et al. (2014). Global prevalence of age-related macular degeneration and disease burden projection for 2020 and 2040: a systematic review and metaanalysis. Lancet Global Health 2:e106-e116. doi: 10.1016/S2214-109X(13) 70145-1

World Health Organization (2014). World Health Statistics- large gains in life expectancy. Available online at: http://www.who.int/mediacentre/news/ releases/2014/world-health-statistics-2014/en/.
World Health Organization (2018). Life expectancy. Available online at: http:// www.who.int/gho/mortality_burden_disease/life_tables/en/.

Worman, H. J. (2012). Nuclear lamins and laminopathies. J. Pathol. 226, 316-325. doi: 10.1002/path.2999

Wu, X., Cheng, J., and Wang, X. (2017). Dietary antioxidants: potential anticancer agents. Nutr. Cancer 69, 521-533. doi: 10.1080/01635581.2017.12 99872

Xia, S., Zhang, X., Zheng, S., Khanabdali, R., Kalionis, B., Wu, J., et al. (2016). An update on inflamm-aging: mechanisms, prevention, and treatment. J. Immunol. Res. 2016, article ID 8426874, 12 pages. doi: 10.1155/2016/8426874

Xiang, S., Liu, F., Lin, J., Chen, H., Huang, C., Chen, L., et al. (2017). Fucoxanthin inhibits $\beta$-amyloid assembly and attenuates $\beta$-amyloid oligomerinduced cognitive impairments. J. Agric. Food Chem. 65, 4092-4102. doi: 10.1021 /acs.jafc.7b00805

Xu, J., Song, C., Song, X., Zhang, X., and Li, X. (2017). Carotenoids and risk of fracture: a meta-analysis of observational studies. Oncotarget 8:2391. doi: 10.18632 /oncotarget.13678

Xu, W., He, P., He, S., Cui, P., Mi, Y., Yang, Y., et al. (2018). Gammatocotrienol stimulates the proliferation, differentiation, and mineralization in osteoblastic MC3T3-E1 cells. J. Chem. 2018, article ID 3805932, 9 pages. doi: 10.1155/2018/3805932

Yamamoto, M., Yamato, E., Toyoda, S., Tashiro, F., Ikegami, H., Yodoi, J., et al. (2008). Transgenic expression of antioxidant protein thioredoxin in pancreatic beta cells prevents progression of type 2 diabetes mellitus. Antioxid. Redox Signal. 10, 43-49. doi: 10.1089/ars.2007.1586

Yang, Y., Luo, N. S., Ying, R., Xie, Y., Chen, J. Y., Wang, X. Q., et al. (2017) Macrophage-derived foam cells impair endothelial barrier function by inducing endothelial-mesenchymal transition via CCL-4. Int. J. Mol. Med. 40, 558-568. doi: $10.3892 / \mathrm{ijmm} .2017 .3034$

Yaroshevich, I., Krasilnikov, P., and Rubin, A. (2015). Functional interpretation of the role of cyclic carotenoids in photosynthetic antennas via quantum chemical calculations. Comput. Theor. Chem. 1070, 27-32. doi: 10.1016/j.comptc.2015.07.016

Ye, Z.-W., Zhang, J., Ancrum, T., Manevich, Y., Townsend, D. M., and Tew, K. D. (2017). Glutathione S-transferase P-mediated protein S-glutathionylation of resident endoplasmic reticulum proteins influences sensitivity to druginduced unfolded protein response. Antioxid. Redox Signal. 26, 247-261. doi: $10.1089 /$ ars.2015.6486

Yin, X., Manczak, M., and Reddy, P. H. (2016). Mitochondria-targeted molecules MitoQ and SS31 reduce mutant huntingtin-induced mitochondrial toxicity and synaptic damage in Huntington's disease. Hum. Mol. Genet. 25, 1739-1753. doi: $10.1093 / \mathrm{hmg} / \mathrm{ddw} 045$

Yun, J., Mullarky, E., Lu, C., Bosch, K. N., Kavalier, A., Rivera, K., et al. (2015). Vitamin C selectively kills KRAS and BRAF mutant colorectal cancer cells by targeting GAPDH. Sci. 350, 1391-1396. doi: 10.1126/science. aaa5004

Zamora-Ros, R., Barupal, D. K., Rothwell, J. A., Jenab, M., Fedirko, V., Romieu, I., et al. (2017). Dietary flavonoid intake and colorectal cancer risk in the European prospective investigation into cancer and nutrition (EPIC) cohort. Int. J. Cancer 140, 1836-1844. doi: 10.1002/ijc.30582

Zbikowska, H. M., Szejk, M., Saluk, J., Pawlaczyk-Graja, I., Gancarz, R., and Olejnik, A. K. (2016). Polyphenolic-polysaccharide conjugates from plants of Rosaceae/Asteraceae family as potential radioprotectors. Int. J. Biol. Macromol. 86, 329-337. doi: 10.1016/j.ijbiomac.2016. 01.090

Zhang, F., and Jiang, L. (2015). Neuroinflammation in Alzheimer's disease. Neuropsychiatric Dis Treat. 11:243. doi: 10.2147/NDT.S75546

Zhang, L., Reyes, A., and Wang, X. (2018). The role of mitochondriatargeted antioxidant MitoQ in neurodegenerative disease. Mol. Cell. Ther. 6:1 doi: 10.26781/2052-8426-2018-01

Zhang, X., Wang, X., Wu, T., Li, B., Liu, T., Wang, R., et al. (2015). Isoliensinine induces apoptosis in triple-negative human breast cancer cells through ROS generation and p38 MAPK/JNK activation. Sci. Rep. 5:12579. doi: $10.1038 /$ srep 12579

Zhu, Z.-G., Sun, M.-X., Zhang, W.-L., Wang, W.-W., Jin, Y.-M., and Xie, C.L. (2017). The efficacy and safety of coenzyme Q10 in Parkinson's disease: a meta-analysis of randomized controlled trials. Neurol. Sci. 38, 215-224. doi: 10.1007/s10072-016-2757-9 
Zu, K., Mucci, L., Rosner, B. A., Clinton, S. K., Loda, M., Stampfer, M. J., et al. (2014). Dietary lycopene, angiogenesis, and prostate cancer: a prospective study in the prostate-specific antigen era. JNCI: J. Natl. Cancer Inst. 106, djt430. doi: $10.1093 /$ jnci/djt430

Zucca, F. A., Segura-Aguilar, J., Ferrari, E., Muñoz, P., Paris, I., Sulzer, D., et al. (2017). Interactions of iron, dopamine and neuromelanin pathways in brain aging and Parkinson's disease. Progr. Neurobiol. 155, 96-119. doi: 10.1016/j.pneurobio.2015.09.012

Zuo, L., Zhou, T., Pannell, B. K., Ziegler, A., and Best, T. M. (2015). Biological and physiological role of reactive oxygen species-the good, the bad and the ugly. Acta Physiol. 214, 329-348. doi: 10.1111/apha.12515
Conflict of Interest Statement: The authors declare that the research was conducted in the absence of any commercial or financial relationships that could be construed as a potential conflict of interest.

Copyright $\odot 2018$ Tan, Norhaizan, Liew and Sulaiman Rahman. This is an openaccess article distributed under the terms of the Creative Commons Attribution License (CC BY). The use, distribution or reproduction in other forums is permitted, provided the original author(s) and the copyright owner(s) are credited and that the original publication in this journal is cited, in accordance with accepted academic practice. No use, distribution or reproduction is permitted which does not comply with these terms. 